\title{
Characterization of Insulin Sensitivity and the Plasma Lipidome in Periparturient Dairy Cows
}

\author{
Sina Saed Samii
}

Follow this and additional works at: https://researchrepository.wvu.edu/etd

\section{Recommended Citation}

Saed Samii, Sina, "Characterization of Insulin Sensitivity and the Plasma Lipidome in Periparturient Dairy Cows" (2017). Graduate Theses, Dissertations, and Problem Reports. 7123.

https://researchrepository.wvu.edu/etd/7123

This Dissertation is protected by copyright and/or related rights. It has been brought to you by the The Research Repository @ WVU with permission from the rights-holder(s). You are free to use this Dissertation in any way that is permitted by the copyright and related rights legislation that applies to your use. For other uses you must obtain permission from the rights-holder(s) directly, unless additional rights are indicated by a Creative Commons license in the record and/ or on the work itself. This Dissertation has been accepted for inclusion in WVU Graduate Theses, Dissertations, and Problem Reports collection by an authorized administrator of The Research Repository @ WVU.

For more information, please contact researchrepository@mail.wvu.edu. 
Characterization of Insulin Sensitivity and the Plasma Lipidome in Periparturient Dairy Cows.

Sina Saed Samii, M.S.

Kansas State University, 2014

Dissertation submitted

to the Davis College

at West Virginia University

In partial fulfillment of the requirements for the degree of

Doctor of Philosophy in

Animal and Food Science

Joseph W. McFadden, Ph.D., Chair

Jianbo Yao, Ph.D.

Marlon Knights, Ph.D.

Maria K. Krause, Ph.D.

Hillar Klandorf, Ph.D.

Division of Animal and Nutritional Sciences

Morgantown, West Virginia

2017

Keywords: Insulin sensitivity, plasma lipidome, dairy cow

Copyright 2017 Sina Saed Samii 


\begin{abstract}
Characterization of Insulin Sensitivity and the Plasma Lipidome in Periparturient Dairy Cows.

Sina Saed Samii

During the transition from gestation to lactation, dairy cows experience negative energy balance due to an increased demand for energy to support milk production coupled with inadequate energy intake. Energy deficit during the peripartum is associated with the development of insulin resistance which contributes to adipose tissue lipolysis. In turn, elevated free fatty acids (FFA) in circulation increase triacylglycerol (TAG) deposition in liver. This metabolic impairment is known to cause postpartum metabolic diseases including fatty liver and ketosis. Consequently, postpartum metabolic disease can lead to reduced milk production in early lactation, impaired reproductive performance, and increased culling rates. Moreover, cows with enhanced prepartum adiposity are at greater risk for postpartum metabolic disease, relative to lean animals. Therefore, our first objective was to evaluate the effect of adiposity on insulin and glucose tolerance in lean and overweight dairy cows during the transition from gestation to lactation. We also wanted to compare these direct measurements with several indirect measurements, including the commonly utilized revised quantitative insulin sensitivity check index (RQUICKI). For our second objective we wanted to identify novel biomarkers for the progression of postpartum metabolic disease in periparturient dairy cows. To achieve this objective, we utilized a contemporary mass spectrometry-based lipidomics approach and a bioinformatics workflow. We demonstrate (1) that excess prepartum adiposity does not influence postpartum systemic insulin sensitivity, (2) surrogate indices for insulin sensitivity do not correlate with direction measurements, and (3) biomarkers for metabolic disease include several phosphatidylcholines.
\end{abstract}

fatty liver, metabolic health, periparturient dairy cow 


\section{ACKNOWLEDGEMENTS}

First and Foremost, I would like to express my sincere appreciation and gratitude to my advisor, Dr. McFadden, for the opportunity that he gave me as well as his support and mentorship during my Ph.D. program in West Virginia University.

I would also like to thank my committee members, Dr. Krause, Dr. Knights, Dr. Yao, and Dr. Klandorf for their support and guidance. I would like to thank my friends Patrick, Eduardo, Alice, Amanda, Billy, Zach, Hannah, and Amy for their enormous help during projects. I am also grateful for all the support provided by the West Virginia University farm crew.

Additionally, my especial appreciation goes to VanGilder family and Dovan Farm crew as well as the laboratory of Dr. Norman Haughey at Johns Hopkins University School of Medicine.

Finally, I would like to extend my special gratitude and appreciation to my parents. Mom and dad, because of you I could finish this long journey. 


\section{TABLE OF CONTENTS}

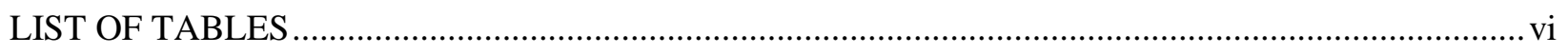

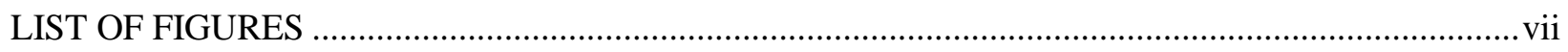

LIST OF ABBREVIATIONS ........................................................................................................

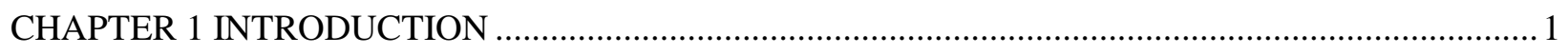

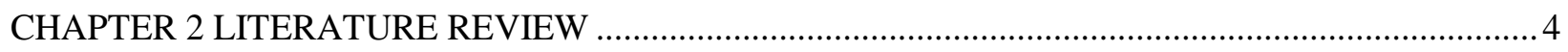

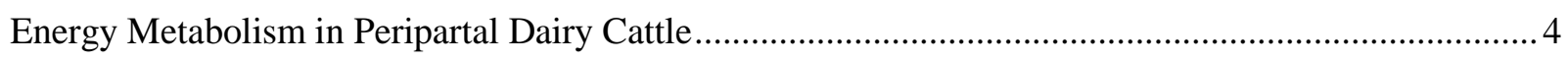

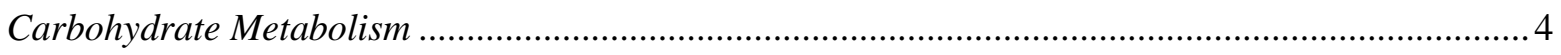

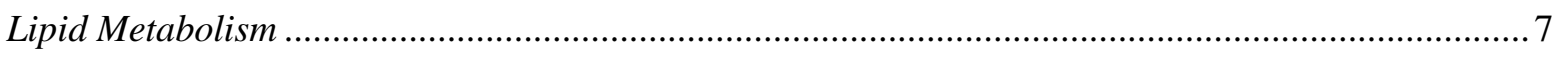

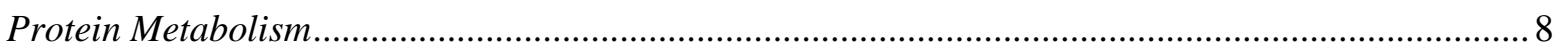

Metabolic Disease and the Role of Insulin Resistance .............................................................. 9

Insulin Signaling and Mechanisms of Insulin Resistance ............................................................ 10

Measurement of Systemic Insulin Sensitivity in Dairy Cows .......................................................... 12

Direct Measurements, Hyperinsulinemic-Euglycemic Clamp ....................................................... 12

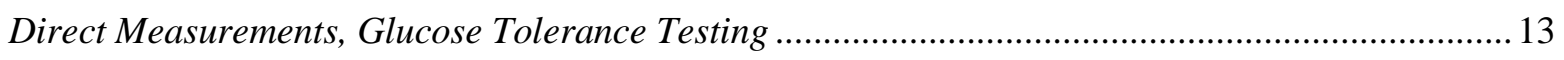

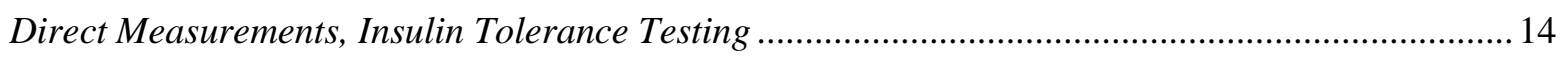

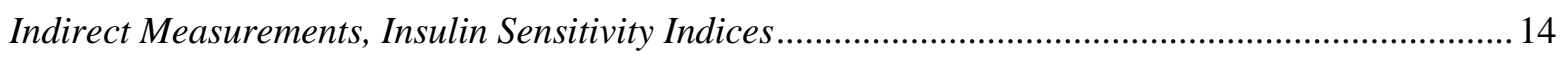

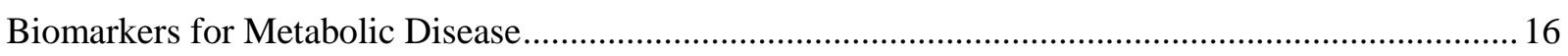

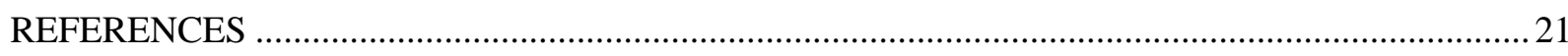

CHAPTER 3 COMPARATIVE EFFECTS OF ADIPOSITY ON DIRECT AND INDIRECT MEASUREMENTS OF INSULIN SENSITIVITY IN PERIPARTURIENT DAIRY COWS .................. 32

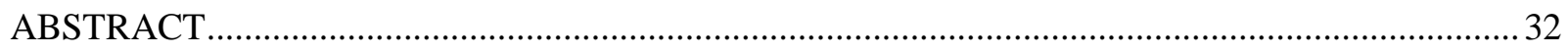

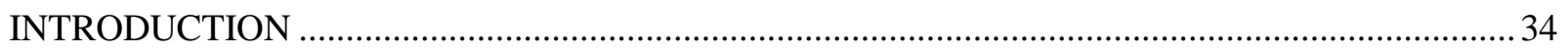

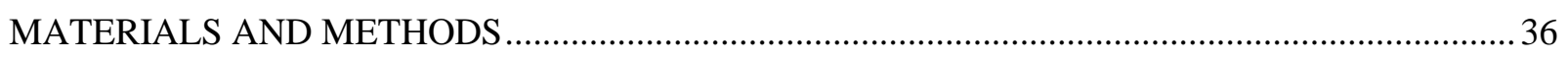

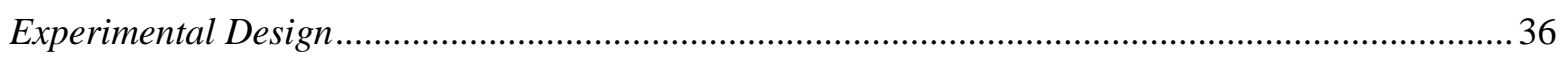

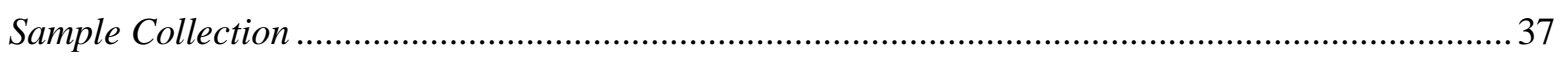

Glucose and Insulin Tolerance Testing …................................................................................. 38

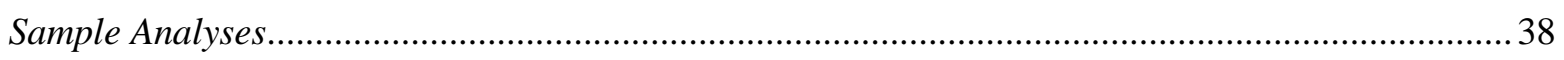

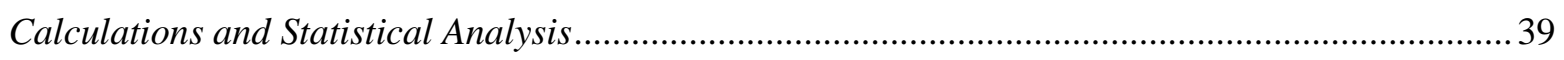

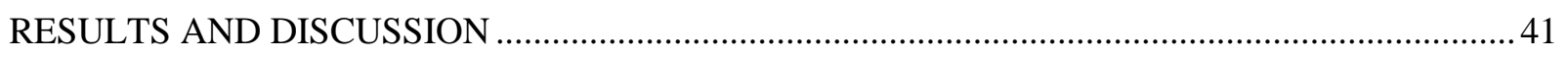

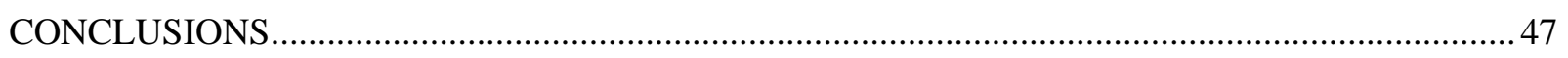

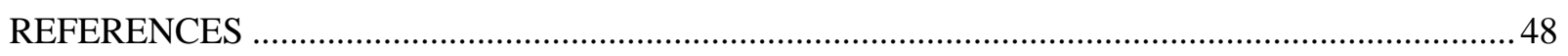


CHAPTER 4 CHARACTERIZATION OF THE PLASMA LIPIDOME IN DAIRY CATTLE TRANSITIONING FROM GESTATION TO LACTATION: IDENTIFYING NOVEL BIOMARKERS

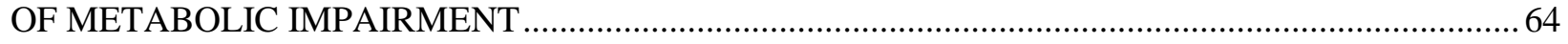

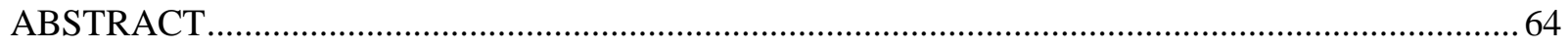

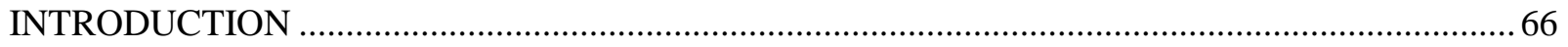

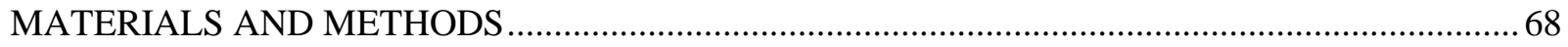

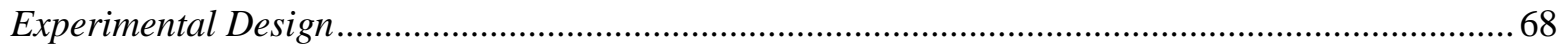

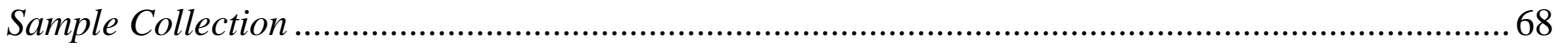

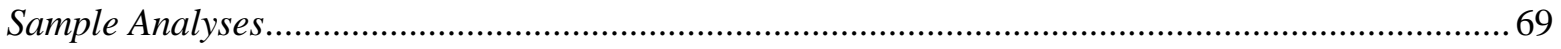

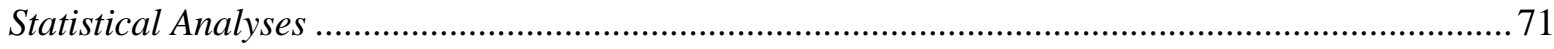

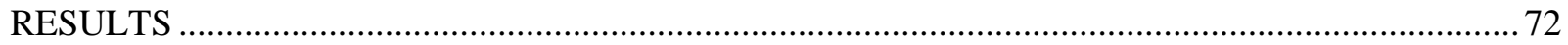

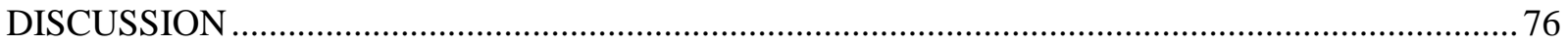

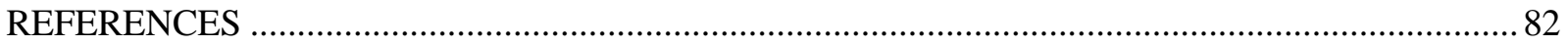

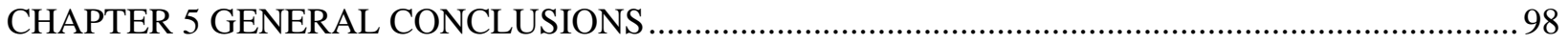




\section{LIST OF TABLES}

Table 2-1: Common surrogate indices for insulin sensitivity............................................................ 15

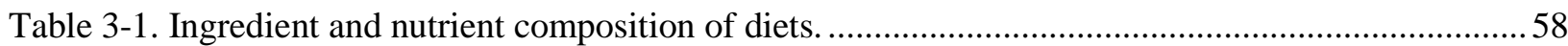

Table 3-2. Insulin tolerance test (ITT) parameters for plasma glucose in lean and overweight cows during

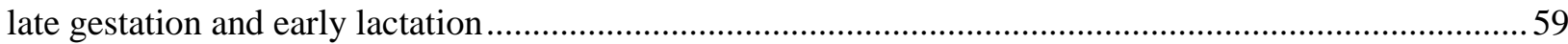

Table 3-3. Glucose tolerance test (GTT) parameters for plasma glucose in lean and overweight cows during late gestation and early lactation

Table 3-4. Glucose tolerance test (GTT) parameters for plasma FA in lean and overweight cows during

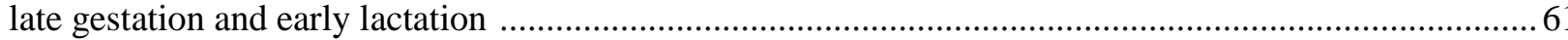

Table 3-5. Relationship between surrogate indices for insulin sensitivity............................................62

Table 3-6. Comparison of tolerance testing glucose parameters and surrogate indices of insulin sensitivity in peripartal dairy cows

Table 4-1. Ingredients and nutrient composition of diets fed to dairy cows during the transition from late gestation to early lactation. 


\section{LIST OF FIGURES}

Figure 3-1. Metabolic health in lean and overweight dairy cows transitioning from gestation to lactation.

Figure 3-2. Milk production data collected from postpartum lean and overweight dairy cows transitioning from gestation to lactation.

Figure 3-3. Plasma concentrations of glucose during an intravenous insulin tolerance test (ITT) performed in lean or overweight peripartal cows. .54

Figure 3-4. Plasma concentrations of glucose during an intravenous glucose tolerance test (GTT) performed in lean or overweight peripartal cows. .55

Figure 3-5. Changes in plasma FA concentrations during an intravenous glucose tolerance test (GTT) performed in lean and overweight peripartal cows. .56

Figure 3-6. Surrogate indices of insulin sensitivity in lean and overweight periparturient dairy cows......57

Figure 4-1. Dry matter intake (DMI) suppresses as cow approaches parturition, and body weight (BW) and body condition score (BCS) decline postpartum...

Figure 4-2. Plasma neutral lipids triacylglycerol (TAG) and monoalkyl-diacylglycerol (MADAG) decrease dramatically during the peripartum.

Figure 4-3. Random Forest analysis revealed that subjects are distinguishable across nine time points (class error $=0.15$ ). 88

Figure 4-4. Circulating total triacylglycerol (TAG) and neutral ether lipid monoalkyl-diacylglycerol (MADAG) decreased postpartum. ......

Figure 4-5. Circulating cholesterol esters (CE), diacylglycerol (DAG), and phosphatidylglycerol (PG) decrease as cow approaches parturition, circulating lysophosphatidylserine (LPS), and phosphatidylserine (PS) decrease postpartum, and lysophosphatidylglycerol (LPG) remains unchanged during the peripartum.

Figure 4-6. Plasma lipids lysophosphatidylserine (LPS) and triacylglycerol (TAG) prepartum and phosphatidylcholine (PC) and lysophosphatidylcholine (LPC) postpartum decrease drastically.

Figure 4-7. Depending on fatty acyl moiety, plasma phosphatidylcholine (PC) levels are positively or negatively correlated with circulating triacylglycerol (TAG).

Figure 4-8. Suppressed plasma phosphatidylcholine (PC) levels are associated with fatty liver disease, high free FA, and BHBA area under the curve (AUC) concentrations in periparturient Holstein dairy cows. 


\section{LIST OF ABBREVIATIONS}

ADF Acid detergent fiber

Akt Protein kinase B

ANOVA Analysis of variance

AOAC Association of analytical communities

AUC Area under the curve

BCS Body condition score

BHBA Beta-hydroxybutyric acid

BW Body weight

CE Cholesterol ester

CP Crude protein

CPT Carnitine palmitoyl transferase

CV Coefficient of variation

DAG Diacylglycerol

DIM Days in milk

DM Dry matter

DMI Dry matter intake

FA Fatty acid

FDR False discovery rate

FFA Free fatty acid

FA-CoA Fatty acid CoA

GLM Generalized linear model

GLUT4 Glucose transporter 4

GTT Glucose tolerance test

HDL High density lipoprotein

HEC Hyperinsulinemic-euglycemic clamp

HOMA-IR Homeostatic model assessment of insulin resistance 
HPLC High performance liquid chromatography

IRS Insulin receptor substrate

ITT Insulin tolerance test

LDL Low density lipoprotein

LPC Lysophosphatidylcholine

LPE Lysophosphatidylethanolamine

LPS Lysophosphatidylinositol

MADAG Monoalkyldiacylglycerols

MTP Microsomal triglyceride transfer protein

NDF Neutral detergent fiber

NEB Negative energy balance

NEFA Non-esterified fatty acid

$\mathrm{NEl} \quad$ Net energy for lactation

OVER Overweight cow

PC Phosphotidylcholine

PDK Phosphoinositide-dependent kinase

PE Phosphatidylethanolamine

PG Phosphatidylglycerol

PIP Phosphatidylinositol

PI3K Phosphatidyl inositol 3 kinase

PKC Protein kinase C

PL Phospholipid

PLS-DA Partial least squares discriminant analysis

PP2A Protein phosphatase 2A

PS Phosphatidylinositol

QUICKI Quantitative Insulin sensitivity Check Index

ROS Reactive oxygen species 
RQUICKI Revised Quantitative Insulin Sensitivity Check Index

SCS Somatic cell score

SEM Standard error of the mean

SD Standard deviation

TAG Triglycerides

TLR4 Toll-like receptor 4

TNF- $\alpha \quad$ Tumor necrosis factor alpha

TMR Total mixed ration

Tyr Tyrosine

VIP Variable importance of projection

VLDL Very low density lipoprotein 


\section{CHAPTER 1}

\section{INTRODUCTION}

Dairy cows transitioning from gestation to lactation develop metabolic adaptations to support fetal growth and milk production during the peripartum. Specifically, the peripartal cow will become progressively resistant to insulin as lactation approaches, as a means to shift nutrients away from adipose and skeletal muscle tissues and towards the mammary gland for the production of milk (Bell, 1995). This homeorhetic adaptation is accompanied by enhanced lipolysis and circulating free fatty acids (FFA). Elevated circulating FFA predispose cows to postpartum metabolic disease risk including ketosis, fatty liver, inflammation, and oxidative stress (Mulligan and Doherty, 2008). A predisposing factor that increases metabolic disease risk in peripartal cows is overfeeding of energy and body fat accretion (Dann et al., 2006). In turn, overweight dairy cows exhibit greater body weight loss during the peripartum relative to lean cows (Rico et al., 2015). Nutritional approaches are needed to improve metabolic health in peripartal cows with varying adiposity. Better understanding the underpinning mechanisms of insulin resistance during the transition period can potentially help nutritionists and farmers improve the metabolic health and performance of dairy cows.

Reduced systemic insulin and glucose tolerance in monogastrics is associated with enhanced adiposity (Ross et al., 2001; Hayashi et al., 2008). It has been reported that the greater magnitude of adiposity in overweight transition dairy cows may predispose these animals to enhanced insulin resistance and adipose tissue lipolysis, thus contributing to increased disease risk (Rico et al., 2015; Bossaert et al., 2008). Therefore, we aimed to evaluate the link between adiposity and glucose responsiveness to insulin in lean and overweight peripartal cows using direct and indirect methodologies to measure systemic insulin sensitivity. For direct measurements, the glucose tolerance test (GTT) and insulin tolerance test (ITT) can be employed (Defronzo et al., 
1979; McCann and Reimers, 1985; De Koster and Opsomer, 2013). For indirect assessment, the revised quantitative insulin sensitivity check index (RQUICKI) has been commonly utilized to evaluate insulin sensitivity in dairy cows (Kerestes et al., 2009); however, discrepancies between RQUICKI and direct approaches have been documented (Holtenius and Holtenius, 2007; De Koster et al., 2016; Mann et al., 2016). Thus, our second objective was to compare direct with indirect measurements of insulin sensitivity in peripartal dairy cows with contrasting adiposity.

Monitoring circulating FFA and $\beta$-hydroxybutyrate (BHBA) is a common dairy industry practice to diagnose metabolic disease. The main limitations of FFA and BHBA testing are the inability to detect metabolic disease before onset. Lipidomics and metabolomics are systems biology approaches that have the potential to identify novel predictive biomarkers for the development of metabolic disease (Kenéz et al., 2016). Several studies have utilized a metabolomics approach to diagnose periparturient diseases using milk, blood, and rumen fluid collected during the peripartum (Klein et al., 2012; Saleem et al., 2012; Li et al., 2014). However, the characterization of the comprehensive lipidome in peripartal dairy cows relative to changes in FFA, BHBA, and liver lipid accumulation is limited. Therefore, our third objective was to characterize changes in the plasma lipidome of peripartal dairy cows receiving a common total mixed ration (TMR) and relate these changes to the disease state of the animal. Our main hypothesis was that the plasma lipidome of the dairy cow is highly dynamic during the peripartum and changes in association with the progression of metabolic disease. Our targeted focus was on phosphatidylcholine (PC) and phosphatidylethanolamine (PE) because of their role on hepatic lipoprotein secretion and liver lipid accumulation. To test our hypothesis, we utilized liquid chromatography and time-of-flight mass spectrometry. We then applied a bioinformatics approach 
to analyze our large data set. Our goal was to identify novel biomarkers for metabolic disease which can be targeted by future nutritional interventions. 


\section{CHAPTER 2}

\section{LITERATURE REVIEW}

\section{Energy Metabolism in Peripartal Dairy Cattle}

The transition period is defined as three weeks before to three weeks after parturition, and represents a vital period that can negatively impact dairy cow health and productivity as well as producer profits (Grummer, 1995; Drackley, 1999). Regulation of energy metabolism during the peripartum involves homeorhetic adaptations facilitated by changes in endocrine status. Homeorhetic adaptations are defined as the coordinated shifts in body tissue metabolism to support gestation and lactation (Bauman and Currie, 1980). These metabolic modifications involve fluctuations in hormone supply and action. In brief, growth hormone $(\mathrm{GH})$ increases during the peripartum. Growth hormone increases adipose tissue lipolysis and reduces glucose uptake by inhibiting insulin sensitivity in adipose tissue (Balogh et al. 2008). The concentration of antilipolytic insulin is lower during early lactation, relative to late gestation, which is accompanied by increased FFA mobilization. Block and coworkers (2003) determined that leptin concentrations are low during the transition from gestation to lactation, a change that may be mediated in part by insulin and may regulate feed intake, and energy expenditure (Yamada et al., 2003). Epinephrine is another critical hormone that stimulates FFA mobilization and gluconeogenesis at parturition (Sacca et al., 1983). Collectively, the endocrine status of the peripartal cow changes dramatically during the peripartum to provide energy for fetal growth, the gravid uterus, and the neonate.

\section{Carbohydrate Metabolism}

The carbohydrate glucose is a major source of energy for all mammals to maintain their normal physiological status (Aschenbach et al., 2010). The dairy cow uses glucose for maintenance of basal tissue functions, support fetal growth, and for the mammary synthesis of milk lactose. Of 
highest demand, the mammary gland can account for 50 to $85 \%$ of whole-body glucose uptake (De Koster and Opsomer, 2013). In contrast to monogastrics, the dairy cow's dependence on glucose absorption from the small intestine is limited due to extensive carbohydrate fermentation by the rumen microbiome (Mills et al., 1999; Aschenbach et al., 2010). To meet glucose demand, the cow relies on hepatic gluconeogenesis utilizing rumen-derived propionate as the major precursor for hepatic glucose synthesis. The quantitative contribution of propionate during the transition period is 60 to 70\%, followed by lactate, glucogenic amino acids (AA), and glycerol (De Koster and Opsomer, 2013). The relative contribution of glucogenic substrates can be modified by feed composition, intake, stage of lactation, and energy balance. For instance, feeding a high concentrate diet to peripartal dairy cows can shift the rumen microbiome toward amylolytic bacteria as a means to increase lactate and propionate production (De Koster and Opsomer, 2013). With certainty, propionate and lactate play a pivotal role as glucogenic substrate during late gestation and early lactation (Drackley et al., 2001; Reynolds et al., 2003). Glucogenic AA (e.g., alanine and glutamine derived from the catabolic breakdown of skeletal muscle) contribute to gluconeogenesis during the transition period, more so than other stages of lactation (Drackley et al., 2001). Specifically, alanine accounts for $24 \%$ of nitrogen-derived AA in portal circulation and is considered the predominant glucogenic AA precursor in dairy cattle (Reynolds et al., 1991). Additionally, lipolysis-derived glycerol is converted to dihydroxyacetone phosphate and glyceraldyde 3-phosphate to support glucose synthesis during negative energy balance (NEB), the predominant physiological state of early lactation. However, glycerol is a minor contributor to hepatic glucose synthesis, relative to the other precursors described.

The key regulatory enzymes of gluconeogenesis include phosphoenolpyruvate carboxykinase and pyruvate carboxylase. During the transition from gestation to lactation, mRNA 
abundance of phosphoenolpyruvate carboxykinase and pyruvate carboxylase are responsive to the onset of calving (Greenfield et al., 2000). Specifically, hepatic phophoenolpyruvate carboxykinase mRNA is elevated by d 28 postpartum, relative to prepartum levels, and hepatic mRNA expression of pyruvate carboxylase increases postpartum (Greenfield et al., 2000; Hartwell et al., 2001). These changes in hepatic gene transcription support the maintenance of glucose homeostasis during the peripartum.

Glucose disappearance from circulation involves two distinct processes: facilitated diffusion and cotransport. The majority of glucose uptake occurs by facilitated diffusion via glucose transporters (GLUT; Zhao and Keating, 2007). GLUT1 has ubiquitous distribution in all tissues and is mainly responsible for basal glucose uptake. GLUT4 is the only insulin-regulated transporter which is responsible for glucose uptake in skeletal and cardiac muscle as well as adipose tissue, a transporter that translocates to the plasma membrane in response to insulin receptor binding (Watson et al., 2004; Watson and Pessin, 2006). During late gestation and early lactation, skeletal muscle and adipose tissue GLUT4 translocation to the plasma membrane decreases due to reduced insulin action; however, GLUT1 mRNA expression increases to enhance insulin-independent glucose uptake by the gravid uterus, fetus, and mammary gland (Zhao and Keating, 2007).

Glycogen serves as the storage form of glucose in liver and skeletal muscle tissues. Only the liver can provide glucose to blood circulation due to the conversion of glucose-6-phosphate into glucose via the actions of glucose-6-phosphatase (De Koster and Opsomer, 2013). Because liver glycogen pools are limited, the contribution of glycogenolysis to blood glucose levels is minor during the peripartal period (Veenhuizen et al., 1991; Karcagi et al., 2008). Reduced insulin levels during the peripartum are associated with reduced hepatic glycogenesis (Brockman and 
Laarveld, 1986). In a reciprocal fashion, circulating glucagon concentrations increase during early lactation as a means to enhance gluconeogenesis and glycogen breakdown (de Boer et al., 1985). Overall, the simultaneous rise in circulating glucagon levels coupled with the fall in circulating insulin concentrations during early lactation modifies hepatic glucose metabolism to maintain blood glucose supply (Rooyackers and Nair, 1997; Aschenbach et al., 2010).

\section{Lipid Metabolism}

During the transition period, adipose tissue metabolism shifts from lipogenesis to lipolysis to meet the energy requirements of the cow experiencing NEB (McNamara, 199; Patterson et al., 1994). The state of energy deficit is characterized by increased adipose tissue FFA mobilization from TAG deposits due to decreased plasma insulin concentrations, a progressive increased refractoriness of adipose tissue to insulin action (Bell and Bauman, 1997), increased activity of adipose tissue lipases such as hormone sensitive lipase and TAG lipase (Langin et al., 2005), and increased circulating levels of catecholamines, growth hormone and glucocorticoids (Contreras and Sordillo, 2011). In turn, circulating FFA are primarily used for oxidative phosphorylation by peripheral tissues, re-esterification of milk fat TAG in mammary tissue, formation of hepatic ketone bodies (i.e., BHBA), and/or re-esterification to form neutral lipids such as TAG in liver. Although adipose tissue lipolysis can provide glycerol for hepatic gluconeogenesis, an increased concentration of FFA in circulation is associated with increased hepatic TAG accumulation. If TAG accumulation is severe in liver, then fatty liver disease can develop in dairy cows (Rukkwamsuk, 1998; Drackley, 1999). Unfortunately, hepatic gluconeogenesis and glycogen storage are suppressed in cows experiencing fatty liver (Overton and Waldron, 2004). 
Changes in hepatic TAG accumulation may be due in part to compromised mitochondrial fatty acid oxidation. First, hepatic oxidation of long-chain fatty acids (LCFA) involves increased activity of multiple key enzymes including acyl-coA synthetase to activate LCFA for oxidation and carnitine palmitoytransferase I to import LCFA into mitochondria (Drackley et al., 2001; Louet et al., 2001). In the liver, the capacity of FFA oxidation can be influenced by the rate of FFA uptake. Unfortunately, the dairy cow's ability to completely oxidize palmitate to $\mathrm{CO}_{2}$ does not increase during the peripartum (Litherland et al., 2011). Meantime, incomplete oxidation and reesterification is increased during the transition from gestation to lactation. Interestingly, the transcription factors sterol regulatory element binding protein-1 (SREBP-1) and peroxisome proliferator activated receptor- $\alpha$ (PPAR $\alpha$ ) may mediate oxidative metabolism during the peripartum (Li et al., 2014; Shahzad et al., 2014). Although the hepatic expression of anabolic SREBP1 is lowest during early lactation (Loor et al., 2005), PPAR $\alpha$ activation is also reduced (Shahzad et al., 2014). Inactivation of PPAR $\alpha$ may represent the cause of impaired fatty acid oxidation which likely supports the partitioning of fatty acids to alternative metabolic fates including TAG (i.e. fatty liver), phospholipids, or sphingolipids.

\section{Protein Metabolism}

At the onset of lactation, the dairy cow in energy deficit experiences protein breakdown. This catabolic change is mediated in part by insulin. Insulin can stimulate protein synthesis and suppress protein degradation (Brockman and Laarveld, 1986); therefore, reduced circulating insulin concentrations with concomitant increases in catecholamine levels and GH concentrations can increase the flux of AA to the liver for hepatic gluconeogenesis and mammary gland for milk

protein synthesis (Kuhla et al., 2011). Of importance, GH serves as a promoter of AA uptake and 
incorporation into protein, particularly in skeletal muscle and mammary tissue (Machlin, 1976).

Obviously, this response is in contrast with the catabolism of protein reserve in the peripartal dairy cow. It has been hypothesized that the capacity for the anabolic effects of GH in skeletal muscle is small to favor the partitioning of nutrients toward the mammary gland (Bell, 1995). Unfortunately, conventional mixed rations fed to dairy cows are inadequate in methionine (Met) and lysine (Lys), the two essential rate-limiting AA for milk protein synthesis (NCR, 2001). Supplementation of early lactation diets with rumen protected Met and Lys can improve milk yield and protein synthesis (Lara, 2006; Socha, 2008).

\section{Metabolic Disease and the Role of Insulin Resistance}

It is well recognized that many of the metabolic diseases that develop during the transition period are in association with insufficient energy intake and increased energy requirements for lactation (Curtis et al., 1985). First, the dairy cow has an inherently low capacity to export TAG within very low density lipoproteins (VLDL) to blood (Kleppe et al., 1988; Pullen et al., 1990), and excessive hepatic FFA infiltration can lead to TAG accumulation and the progression of fatty liver (Bobe et al., 2004). Furthermore, excessive FFA uptake can increase ketone synthesis (e.g., BHBA) leading to subclinical or clinical ketosis and other associated metabolic disorders, such as mastitis, metritis, milk fever, and displaced abomasum (Herdt, 2000; Bobe et al., 2004). Second, the elevation in circulating FFA during NEB is associated with a dysfunctional immune system (Sordillo et al., 2009; Sordillo and Raphael, 2013). For instance, the pro-inflammatory cytokine tumor necrosis factor alpha $(\mathrm{TNF} \alpha)$ promotes lipolysis and TAG accumulation, and decreases gluconeogenesis in the liver (Kettelhut et al., 1987; Kushibiki et al., 2001; García-Ruiz et al., 2006). Third, increased FFA influx in the liver is associated with elevated reactive oxygen species 
(ROS), which form lipid peroxides (Bernabucci et al., 2005). Lipid peroxides can reduce the ability of immune cells to respond to infection (Pessayre et al., 2004; Spears and Weiss, 2008). As a consequence, the combination of excessive FFA mobilization, hepatic TAG accumulation, inflammation, and oxidative stress can compromise cow milk production, milk quality, and longevity.

\section{Insulin Signaling and Mechanisms of Insulin Resistance}

Insulin is an anabolic peptide hormone produced by beta cells of the pancreatic islets of Langerhans. Insulin is released into circulation, and signals through receptor tyrosine kinases (Lemmon and Schlessinger, 2010). First, insulin binds to the $\alpha$-subunit of the insulin receptor, and activates the $\beta$-subunit through auto-phosphorylation of tyrosine residues (Ward and Lawrence, 2009). The activated receptor recruits and activates insulin receptor substrates (IRS; Sun et al., 1993). In turn, phosphatidylinositol 3-kinase is activated, followed by the phosphorylation of phosphatidylinositol 4,5-bisphosphate. This cascade of events results in the activation of protein kinase B (Akt) which facilitates the translocation of GLUT to the plasma membrane.

When sensitive to insulin action, insulin stimulates glycogenesis, lipogenesis, glycolysis, and protein synthesis (Brockman and Laarveld, 1986; Edgerton et al., 2006; Hayirli, 2006; Sjaastad et al., 2010; Dimitriadis et al., 2011). In addition, insulin reduces lipolysis, protein degradation, and glycogenolysis. During early lactation, dairy cows develop insulin resistance as a homeorhetic adaptation to partition nutrients to the mammary gland for milk synthesis; however, accelerated insulin resistance can promote excessive lipolysis and increase disease risk. Specifically, insulin resistance can be defined as a state where normal concentrations of insulin elicit a reduced biological response (Kahn, 1978). It can be characterized into 2 distinct entities (insulin sensitivity 
and insulin responsiveness). Insulin sensitivity is defined as the insulin concentrations needed to induce a half-maximal response; whereas, insulin responsiveness is determined as the maximal effect of insulin. It is well documented that insulin sensitivity and responsiveness decreases during late gestation and early lactation in ruminants (De Koster and Opsomer, 2013). It is important to mention that the development of insulin resistance can be specific to a certain metabolic process within a given tissue (De Koster and Opsomer, 2013). For instance, reduced insulin response in skeletal muscle can dampen the anabolic process of protein synthesis as well as glucose uptake. Additionally, research has observed localized adipose tissue, but not hepatic, insulin resistance during early lactation, as a result of reduced tyrosine phosphorylation of IRS-1 (Saltiel and Kahn, 2001; Zachut et al., 2013).

In monogastrics insulin resistance is correlated with elevated adiposity (Ross et al., 2001; Hayashi et al., 2008). Dephosphorylated Akt, down-regulates downstream proteins such as glycogen synthase kinase-3 and SREBP1, therefore reduces glycogen synthesis and lipogenesis, respectively. Simultaneously, hormone-sensitive lipase is activated, resulting in increased circulating FFA. In dairy cows that experience excessive body fat loss, adipose tissue insulin resistance is associated with enhanced lipolysis (Zachut et al., 2013), thus, overweight cows that mobilize more FFA may be more prone to insulin resistance, relative to their lean counterparts. De Koster and coworkers (2015) evaluated the effect of adiposity on insulin resistance at the end of the dry period. The results demonstrated a negative correlation between steady-state glucose infusion rate and adiposity. Effects on insulin sensitivity may depend on dietary energy intake, rather than adiposity. For instance, glucose tolerance was evaluated in peripartal dairy cows offered three planes of nutrition during the dry period (controlled, intermediate, and high energy diet). Plane of nutrition did not modified glucose tolerance parameters (Mann et al., 2016). The 
uncertainty between overnutrition and systemic insulin action represents a gap of knowledge that should be explored.

\section{Measurement of Systemic Insulin Sensitivity in Dairy Cows}

Because of the importance of insulin resistance to lactation and metabolic health, it is critical to identify accurate and efficient approaches for measuring insulin sensitivity and responsiveness in dairy cows. It is also important to recognize that the majority of glucose uptake takes place independent of insulin action during established lactation. Therefore, one should be cautious when assessing direct measures of systemic insulin sensitivity during active milk synthesis.

\section{Direct Measurements, Hyperinsulinemic-Euglycemic Clamp}

The hyperinsulinemic-euglycemic clamp (HEC) procedure is considered as the gold standard to measure insulin sensitivity in humans and animals (Defronzo et al., 1979). First, exogenous insulin is administered as a priming dose followed by constant infusion of insulin $(0.1$, 0.5, 2 and $5 \mathrm{mIU} / \mathrm{kg} / \mathrm{min}$; De Koster et al., 2016) to raise blood insulin levels to a steady-state level. This is referred to as the hyperinsulinemic plateau. Simultaneously, blood samples are collected at regular intervals ( $\sim 5$ to 20 minutes) to measure blood glucose concentrations. To achieve euglycemia (i.e., maintain normal fasting blood glucose levels), the dose of glucose infused is calibrated based on repeated measurements of blood glucose concentrations. The steadystate of glucose can be explained as no change in glucose infusion required to maintain glucose concentrations at the fasting or basal value (Ferrannini and Mari, 1998; De Koster and Opsomer, 2013). The assessment of insulin sensitivity is characterized by the steady-state insulin 
concentration (SSIC) and the steady-state glucose infusion rate (SSGIR). A higher SSGIR is indicative of high insulin-stimulated glucose uptake by peripheral tissues (De Koster and Opsomer, 2013). Additionally, the insulin sensitivity index can be calculated as either SSGIR/SSIC

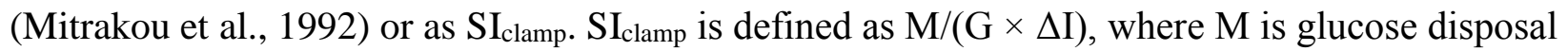
rate, $\mathrm{G}$ is steady-state blood glucose concentrations, and $\Delta \mathrm{I}$ is the difference between fasting and steady-state blood insulin concentrations (Muniyappa et al., 2008). The greater $\mathrm{SI}_{\text {clamp }}$, the higher is systemic insulin sensitivity. Although the HEC is the most accurate method to evaluate insulin sensitivity in dairy cows, the technique has major disadvantages such as being laborious, expensive, time consuming, and requires some degree of experience (De Koster and Opsomer, 2013; De Koster et al., 2016). Therefore, other direct and indirect methods have been employed to evaluate insulin sensitivity in dairy cows.

\section{Direct Measurements, Glucose Tolerance Testing}

The glucose tolerance test (GTT) is a more applied method to estimate systemic insulin sensitivity in dairy cows (De Koster and Opsomer, 2013). In detail, cows are intravenously infused with a supraphysiological dose of glucose (150 to $500 \mathrm{mg} / \mathrm{kg}$; Holtenius et al., 2003; Pires et al., 2007; Kerestes et al., 2009). Blood samples are taken at a regular interval of 10 to 20 minutes to determine insulin, FFA, and glucose concentrations in response to the challenge. Glucose concentrations measured during the GTT reflect a combination of excretion and absorption from different tissues (e.g., liver, mammary gland, intestine, gravid uterus, and skeletal muscle). The concentration of insulin reflects secretion from the pancreas and uptake of insulin by the liver. Clearance rate, area under the curve (AUC), time to reach basal and half of maximal concentrations of glucose and insulin can be calculated (Pires et al., 2007). A low rate of glucose clearance, high 
AUC for glucose, and increased time to reach basal glucose concentrations can be considered as a state of insulin resistance in dairy cows (De Koster and Opsomer, 2013).

\section{Direct Measurements, Insulin Tolerance Testing}

An insulin tolerance test (ITT) involves the administration of insulin (i.v. 0.02 to $0.1 \mathrm{U} / \mathrm{kg}$; McCann and Reimers, 1985; Oikawa and Oetzel, 2006; Pires et al., 2007). Comparable to a GTT, blood samples are collected at regular intervals following the challenge. Circulating insulin and glucose can be measured. Glucose clearance rate, blood glucose reduction (\% from basal glucose), and AUC for glucose after insulin administration can be calculated. Insulin resistance is defined as a low insulin-stimulated reduction of blood glucose levels from measurements made in the basal state, low glucose clearance, and elevated glucose AUC (De Koster and Opsomer, 2013). Previous work has demonstrated that insulin tolerance decreases in Holstein cows infused with a tallow emulsion (Pires et al., 2007). The main disadvantage of the ITT is elicited hypoglycemia and the potential neurologic danger of the test (Ferrannini et al., 1998).

Overall, multiple physiological factors for selecting a direct method to measure insulin sensitivity in dairy cows should be considered. Additionally, cost and applicability of the direct method should be considered. Because of these considerations, the dairy science research field is exploring the use of more affordable and less intensive indirect measures for insulin sensitivity (Koster and Opsomer, 2013)

\section{Indirect Measurements, Insulin Sensitivity Indices}

Indirect methods of estimating systemic insulin sensitivity have been developed in human medicine and have been utilized in dairy research due to their simplicity of use and potential 
effectiveness (Table 2-1: De Koster and Opsomer, 2013); however, these efforts have been contested (Mann et al., 2016). The indirect methods predict insulin sensitivity based on blood samples collected following an overnight fasting (Muniyappa et al., 2008). First, the homeostasis model assessment of insulin resistance (HOMA-IR) is developed (Matthews et al., 1985) to predict insulin resistance and $\beta$-cell function based on a fasting steady-state glucose and insulin values. Second, the quantitative insulin sensitivity check index (QUICKI) is a mathematical model based on the reciprocal log transformation of basal glucose and insulin concentrations (Muniyappa et al., 2008). The higher the HOMA-IR, the greater the insulin resistance of an individual. Whereas, a higher QUICKI value can be interpreted as lower insulin resistance. First developed for biomedicine (Perseghin et al., 2001; Rabasa-Lhoret et al., 2003), the revised quantitative check index (RQUICKI) has been shown to improve QUICKI correlation with the clamp-based index of insulin sensitivity (Perseghin at el., 2001). The RQUICKI was first modified to become RQUICKI $I_{\text {BHBA }}$ by adding basal plasma concentrations of BHBA (Balogh et al., 2008). Interestingly, the RQUICKI ${ }_{\mathrm{BHB}}$ has never been tested in human medicine.

Table 2-1: Common surrogate indices for insulin sensitivity.

\begin{tabular}{l|l|l}
\hline Surrogate Indices & \multicolumn{1}{|c|}{ Equation } & \multicolumn{1}{c}{ Reference } \\
\hline HOMA-IR & [glucose $(\mathrm{mmol} / \mathrm{L}) \times$ insulin $(\mu \mathrm{U} / \mathrm{mL}) / 22.5]$ & Muniyappa et al., 2008 \\
QUICKI & $1 /[\log$ insulin $(\mu \mathrm{U} / \mathrm{mL})+\log$ glucose $(\mathrm{mg} / \mathrm{dL})]$ & Katz et al., 2000 \\
RQUICKI & $1 /[\log$ glucose $(\mathrm{mg} / \mathrm{dL})+\log$ insulin $(\mu \mathrm{U} / \mathrm{mL})+\log$ FFA $(\mathrm{mmol} / \mathrm{L})]$ & Perseghin et al., 2001 \\
RQUICKI $_{\text {BHBA }}$ & $1 /[\log$ glucose $(\mathrm{mg} / \mathrm{dL})+\log$ insulin $(\mu \mathrm{U} / \mathrm{mL})+\log$ FFA $(\mathrm{mmol} / \mathrm{L})+\log$ BHBA $(\mathrm{mmol} / \mathrm{L})]$ & Balogh et al., 2008 \\
\hline
\end{tabular}

These indirect models have been used in veterinary medicine; however, limited dairy science research has evaluated their efficacy relative to direct measurements (De Koster and Opsomer, 2013). Because direct methods to measure insulin sensitivity in dairy cows are laborious and expensive; the application of an indirect method to estimate insulin sensitivity was first adopted by Holtenius and Holtenius (2007). They estimated insulin sensitivity in the first 15 weeks 
of lactation, and reported that RQUICKI may be used to determine insulin resistance in dairy cows. The RQUICKI value was not significantly changed over time. Additionally, results demonstrated a negative relationship between RQUICKI value and subcutaneous adiposity. Interestingly, indirectly they found positive relationship between RQUICKI and GTT values. The RQUICKI approach is the most commonly used index in dairy science (Holtenius and Holtenius, 2007; Balogh et al., 2008; Kerestres et al., 2009; Mann et al., 2016). However, a concern is whether these indices are comparable to direct measures. Few studies have been evaluated the association between insulin resistance indices with direct methods in periparturient dairy cows. De Koster et al (2016) validated different measures of insulin sensitivity of glucose metabolism in dairy cows during the dry period. Results indicated no association between an HEC test and RQUICKI values. Furthermore, Mann et al (2016) investigated the relationship between a GTT and surrogate indices in dry period of dairy cows offered three plane of nutrition. Correlation between indirect methods and GTT parameters were generally poor. The lack of correlation between direct and indirect methods likely reflect changes in FFA, glucose, and insulin over time; particularly in early lactation period. Moreover, the influence of the mammary gland, which uptakes glucose independent of insulin, is of concern. Additionally, these tests are often performed in the fed state (i.e. ruminants do not fast because of rumen feed retention). These uncertainties raise questions related to the usefulness of surrogate indices in dairy cows since glucose and insulin kinetics differ from human.

\section{Biomarkers for Metabolic Disease}

The prevalence of metabolic disease is high during the transition from gestation to lactation, affecting on average $40 \%$ of the dairy cow population (LeBlanc, 2010). As previously 
stated, a postpartum disease can compromise milk production, fertility, and increase treatment costs and culling rates (Gröhn et al., 1998; Gröhn et al., 1999; Duffield et al., 2009). Thus, early detection of post metabolic disease has the potential to prevent a disease from developing and thus improve milk production, fertility, and profitability (Saleem et al., 2012; Hailemariam et al., 2014; Kenéz et al., 2016). Currently, circulating FFA and BHBA are industry standard biomarkers for metabolic disease. Laboratory and cow-side tests have been developed to monitor FFA and BHBA levels, respectively. The alarm threshold levels for poor reproductive performance and milk production for prepartum FFA and BHBA are $0.27 \mathrm{mEq} / \mathrm{L}$ and $10 \mathrm{mg} / \mathrm{dL}$, respectively; and postpartum FFA of $0.60 \mathrm{mEq} / \mathrm{L}$ (Ospina et al., 2010). The limitations for testing for FFA and BHBA include (A) these metabolite thresholds represent the disease state (rather than pre-onset disease which would be preferred), (B) they ignore the interactions between other causative metabolites of metabolic disease, (C) laboratory testing is expensive, and (D) individual cow blood sampling is impractical. Therefore, alternative biomarkers for postpartum metabolic disease are needed.

Metabolomics and lipidomics are systems biology approaches that have emerged in the field of life sciences (Fischer, 2008; Nam et al., 2015). These omics approaches rely on mass spectrometry to profile the metabolome (i.e., the comprehensive set of metabolites in a biological matrix). Lipidomics and metabolomics produce large-scale data sets that when analyzed with appropriate bioinformatic tools, can expand our understanding of energy metabolism. These omics approaches have been routinely utilized to identify predictive biomarkers for insulin resistance and non-alcoholic fatty liver disease in humans (Haus et al., 2009). For instance, lipidomics approach identified lysophosphatidylcholine (LPC), particularly LPC 16:0, as the key metabolite in fatty liver-induced insulin resistance in humans (Lehmann et al., 2013). Additionally, 
phosphatidylcholine (PC) 32:3 is positively associated with nonalcoholic fatty liver insulin resistant humans (Lehmann et al., 2013). A targeted metabolomic approach has been used to identify serum PC 32:1, 36:1, 38:3, and 40:5 as biomarkers for type 2 diabetes (Floegel et al., 2013). The routine prevalence of PC as a biomarker for metabolic disease is likely due to the importance of PC for hepatic VLDL assembly and secretion (Cole et al., 2012). Because VLDL secretion is suppressed in dairy cows with fatty liver disease, and dietary choline intake is limited during the peripartum, research should evaluate whether circulating PC is representative of hepatic steatosis in dairy cattle as well.

Metabolomics and lipidomics have been limitedly employed to identify biomarkers of insulin resistance, hepatic lipidosis, mastitis, metritis and clinical and subclinical ketosis in dairy cows (Hailemariam et al., 2014; Imhasly et al., 2014; Sun et al., 2014; Imhasly et al., 2015; Rico et al., 2015). For instance, Hailemariam et al. (2014) conducted a longitudinal and cross-sectional metabolomic study to characterize the patterns and changes of plasma metabolites before and after the onset of metabolic disorders in dairy cows. They reported 3 metabolites (carnitine, propionyl carnitine, and lysophosphatidylcholine) that can predict multiple postpartum diseases including metritis, mastitis, laminitis, and retained placenta 4 weeks before initiation; moreover, 2 PC species (PC 42:2 and 42:6) reported to possibly predict disease a week before its appearance. Moreover, carnitine and LPC C16:0 have emerged as biomarkers of immune activation (Sampey et al., 2012; Kabarowski et al., 2002; Drobnik et al., 2003). Furthermore, a dairy metabolomics study was conducted to identify serum biomarkers as an alternative diagnostic approach for hepatic lipidosis (Imhasly et al., 2014). They identified 29 metabolites particularly several PC and sphingomyelins. The major metabolites to distinguish between control and diseased dairy cows were PC $30: 2,32: 2,36: 2,36: 3,36: 4,38: 3,38: 4,38: 6,40: 2,40: 3,40: 4$, and 42:2. In addition, the 
usefulness of metabolomics approach has been evaluated in dairy cows to identify healthy cows from cows affected by ketosis (Zhang et al., 2013; Sun et al., 2014). Their results demonstrated 2,3,4-trihydroxybutyric acid, $\alpha$-aminobutyric acid, methylmalonic acid, sitosterol , and $\alpha$ tocopherol as potential biomarkers for ketosis. Further, lipidomics results from our lab, established sphingolipid ceramide as a predictive biomarker of insulin resistance in peripartal dairy cows (Rico et al., 2015, Rico et al., 2016). Although omics data has emerged, data investigating the link between biomarkers and the mechanisms that mediate metabolic disease are non-existent and the inclusion of hypothesis-driven research that applies omics should be a requirement.

Biomarker discovery should focus on hepatic lipid export, considering that fatty liver disease can promote ketosis. Specifically the dairy cow's limited capacity to remove TAG from the liver is important contributor to postpartum fatty liver disease (Pullen et al., 1990). Therefore, identifying markers for VLDL assembly represents an approach to improve hepatic health. What represents a challenge is that impaired VLDL export might involve multiple factors. First, the hepatic mRNA expression and circulation of Apo $\mathrm{B}_{100}$ decreases as parturition approaches (Bernabucci et al., 2004). Second, FFA can reduce VLDL export by decreasing the abundance of microsomal transfer protein in the FFA-treated hepatocytes (Lei et al., 2014). Third, possibly the most important reason for impaired VLDL export is due to limited hepatic phospholipid sources (Van den Top et al., 1996; Kessler et al., 2014). Phosphatidylcholine is the major form of choline phospholipids and is the main component of VLDL (Zeisel, 1992). Reduced hepatic PC levels impair liver VLDL export (Verkade et al., 1993; Fast and Vance, 1995). Noticeably, reduced PC synthesis impair VLDL export in animals fed choline-deficient diets (Li and Vance, 2008). Further, phophatidylethanolamine is required for nascent VLDL assembly (Hamilton and Felding, 
1989). Thus, to facilitate lipoprotein export, PC and PE likely play a vital role and deserve further attention as potential markers for metabolic disease.

Collectively, lipidomics and metabolomics provide a global assessment of metabolite changes; however, we must carefully ensure that newly discovered biomarkers are tested for their efficacy. Once identified and tested, novel diet formulations can be created to target these newly discovered biomarkers, and new affordable prognostic and diagnostic testing procedures can be implemented to improve dairy cow health and performance. 


\section{REFERENCES}

Adewuyi, A. A., E. Gruys, and F. J. van Eerdenburg. 2005. Non esterified fatty acids (NEFA) in dairy cattle. A review. Vet Q. 27:117-126.

Agren, J. J., J. P. Kurvinen, and A. Kuksis. 2005. Isolation of very low density lipoprotein phospholipids enriched in ethanolamine phospholipids from rats injected with Triton WR 1339. J. B. B. A. 1734:34-43.

Allen, M. S., B. J. Bradford, and K. J. Harvatine. 2005. The cow as a model to study food intake regulation. Ann. Rev. Nutr. 25:523-547.

Allen, M. S., B. J. Bradford, and M. Oba. 2009. The hepatic oxidation theory of the control of feed intake and its application to ruminants. J. Anim. Sci. 87:3317-3334.

Ametaj, B. N. 2015. A systems veterinary approach in understanding transition cow diseases: Metabolomics. Proceedings of the $4^{\text {th }}$ International Symposium on Dairy Cow Nutrition and Milk Quality. Session I. Advances in Fundamental Research. May 8-10. Beijing. China. P. 78-85.

Aschenbach, J. R., N. B. Kristensen, S. S. Donkin, H. M. Hammon, and G. B. Penner. 2010. Gluconeogenesis in dairy cows: The secret of making sweet milk from sour dough. IUBMB Life 62:869-877.

Balogh, O., O. Szepes, K. Kovacs, M. Kulcsar, J. Reiczigel, J. A. Alcazar, M. Keresztes, H. Febel, J. Bartyik, S. G. Fekete, L. Fesus, and G. Huszenicza. 2008. Interrelationships of growth hormone AluI polymorphism, insulin resistance, milk production and reproductive performance in Holstein-Friesian cows. Vet. Med. 53:604-616.

Bauman, D. E., and B. W. Currie. 1980. Partitioning of nutrients during pregnancy and lactation: A review of mechanisms involving homeostasis and homeorhesis. J. Dairy Sci. 63:15141529.

Bell, A. W. 1995. Regulation of organic nutrient metabolism during transition from late pregnancy to early lactation. J. Anim. Sci. 73:2804-2819.

Bell, A. W. and D. E. Bauman. 1997. Adaptations of glucose metabolism during pregnancy and lactation. J Mammary Gland Biol Neoplasia 2:265-278.

Bell, A. W., W. S. Burthans, and T. R. Overton. 2000. Protein nutrition in late pregnancy, maternal protein reserves, and lactation performance in dairy cows. Proc. Nutr. Soc. 59:119-126.

Bernabucci, U., B. Ronchi, L. Basirico, D. Pirazzi, F. Rueca, N. Lacetera, and A. Nardone. 2004. Abundance of mRNA of apolipoprotein B100, apolipoprotein E and microsomal triglyceride transfer protein in liver from periparturient dairy cows. J. Dairy Sci. 87:28812888. 
Bobe, G., J.W. Young, and D.C. Beitz. Invited review: pathology, etiology, prevention, and treatment of fatty liver in dairy cows. 2004. J. Dairy Sci. 87:3105-24.

Boden, G., Jadali, F., White, J., Liang, Y., Mozzoli, M., Chen, X., Coleman, E., and C. Smith. . 1991. Effects of fat on insulin-stimulated carbohydrate metabolism in normal men. J. Clin. Invest. 88, 960-966.

Bossaert, P., J. L. M. R. Leroy, S. De Vliegher, and G. Opsomer. 2008. Interrelations between glucose-induced insulin response, metabolic indicators, and time of first ovulation in highyielding dairy cows. J. Dairy Sci. 91:3363-3371.

Bradford, B. J. K. Yuan, J. K. Farney, L. K. Mamedova, and A. J. Carpenter. 2015. Invited review: Inflammation during the transition to lactation: New adventures with an old flame. J. Dairy Sci. 98:6631-6650.

Bradford, B. J., K. Yuan, and C. Ylioja. 2016. Managing complexity: Dealing with systemic crosstalk in bovine physiology1. J. Dairy Sci. 99:4983-4996.

Brockman, R. P., and B. Laarveld. 1986. Hormonal-regulation of metabolism in ruminants; a review. Livest. Prod. Sci. 14:313-334.

Burhans, W. S. 2006. Effects of nutritional management on peripartum glucose and energy metabolism and postpartum health in transition dairy cows. Ph.D. Dissertation. Cornell University, Ithaca, NY.

Chen, C., Y. M. Shah, K. Morimura, K. W. Krausz, M. Miyazaki, T. A. Richardson, E. T. Morgan, J. M. Ntambi, J. R. Idle, and F. J. Gonzalez. 2008. Metabolomics reveals that hepatic stearoyl-CoA desaturase I downregulation exacerbates inflammation and acute colitis. Cell Metab. 7:35-47.

Cole, L. K., J. E. Vance, and D. E. Vance. 2012. Phosphatidylcholine biosynthesis and lipoprotein metabolism. Biochim. Biophys. Acta 1821:754-761.

Curtis, C. R., H. N. Erb, C. H. Sniffen, R. D. Smith, and D. S. Kronfeld. 1985. Path analysis of dry period nutrition, postpartum metabolic and reproductive disorders, and mastitis in Holstein cows. J. Dairy Sci. 68:2347-2360.

Defronzo, R. A., J. D. Tobin, and R. Andres. 1979. Glucose clamp technique: a method for quantifying insulin-secretion and resistance. Am. J. Phys. 237:E214-223.

De Koster, J. D., and G. Opsomer. 2013. Insulin resistance in dairy cows. Vet. Clin. Food Anim. 29:299-322.

De Koster, J., M. Hostens, K. Hermans, W. Van den Broeck, and G. Opsomer. 2016. Validation of different measures of insulin sensitivity of glucose metabolism in dairy cows using the hyperinsulinemic euglycemic clamp test as the gold standard. 57:117-126. 
De Koster, J., M. Van Eetvelde, K. Hermans, W. Van den Broeck, M. Hostens, and G. Opsomer. 2017. Short communication: Limitations of glucose tolerance tests in the assessment of peripheral tissue insulin sensitivity during pregnancy and lactation in dairy heifers. J. Dairy Sci. 100:1-7.

Dimitriadis, G., Mitrou, P., Lambadiari, V., Maratou, E., and S. A. Raptis. 2011. Insulin effects in muscle and adipose tissue. Diabetes Res. Clin. Pract. 93:S52-9

Drackley, J. K. 1999. Biology of dairy cows during the transition period: The final frontier? J. Dairy Sci. 82:2259-2273.

Drackley, J. K., T. R. Overton, and G. N. Douglas. 2001. Adaptations of glucose and long-chain fatty acid metabolism in liver of dairy cows during the periparturient period. J. Dairy Sci. 73:423-433.

Drobnik, W., G. Liebisch, F. X. Audebert, D. Fröhlich, T. Glück, P. Vogel, G. Rothe, and G. Schmitz. 2003. Plasma ceramide and lysophosphatidylcholine inversely correlate with mortality in sepsis patients. J. Lipid Res. 44:754-761.

Duffield, T. F., K. D. Lissemore, B. W. McBride, and K. E. Leslie. 2009. Impact of hyperketonemia in early lactation dairy cows on health and production. J. Dairy Sci. 92:571-580.

Duhlmeier, R., A. Hacker, A. Widdel, W. von Engelhardt, and H. P. Sallmann. 2005. Mechanisms of insulin-dependent glucose transport into porcine and bovine skeletal muscle. Am. J. Physiol. Regul. Integr. Comp. Physiol. 289:R181-R197.

Fast, D. G., D. E. Vance. 1995. Nascent VLDL phospholipid composition is altered when phosphatidylcholine biosynthesis is inhibited: evidence for a novel mechanism that regulates VLDL secretion. Biochim. Biophys. Acta. 1258:159-168.

Floegel, A., N. Stefan, Z. Yu, K. Mühlenbruch, D. Drogan, H. G. Joost, A. Fritsche, H. U. Häring, M. Hrabě de Angelis, A. Peters, M. Roden, C. Prehn, R. Wang-Sattler, T. Illig, M. B. Schulze, J. Adamski, H. Boeing, and T. Pischon. 2013. Identification of serum metabolites associated with risk of type 2 diabetes using a targeted metabolomic approach. Diabetes 62:639-648.

Fischer, H. P. 2008. Mathematical modeling of complex biological systems: From parts lists to understanding systems behavior. Alcohol Research \& Health. 31:49-59.

Edgerton, D. S., Lautz, M., Scott, M., Everett, C. A., Stettler, K. M., Neal, D. W., Chu, C. A., and A. D. Cherrington. 2006. Insulin's direct effects on the liver dominate the control of hepatic glucose production. J. Clin. Invest. 116:521-527.

Enjalbert, F., M. C. Nicot, C. Bayourthe, and R. Moncoulon. 2001. Ketone bodies in milk and blood of dairy cows: Relationship between concentrations and utilization for detection of 
subclinical ketosis. J. Dairy Sci. 84:583-589.

Ferrannini, E., and A. Mari. 1998. How to measure insulin sensitivity. J. Hypertens. 16:895-906.

Greenfield, R. B., M. J. Cecava, and S. S. Donkin. 2000. Changes in mRNA expression for gluconeogenic enzymes in liver of dairy cattle during the transition to lactation. J. Dairy Sci. 83:1228-1236.

Gröhn, Y., L-A. Lindberg, M. L. Bruss, and T. B. Farver. 1983. Fatty infiltration of liver in spontaneously ketotic dairy cows. J. Dairy Sci. 66:2320-2328.

Gröhn, Y. T., S. W. Eicker, V. Ducrocq, and J. A. Hertl. 1998. Effect of diseases on the culling of Holstein dairy cows in New York State. J. Dairy Sci. 81:966-978.

Gröhn, Y. T., J. J. McDermott, Y. H. Schukken, J. A. Hertl, and S. W. Eicker. 1999. Analysis of correlated continuous repeated observations: modelling the effect of ketosis on milk yield in dairy cows. Prev. Vet. Med. 39:137-153.

Grummer, R. R. 1995. Impact of changes in organic nutrient metabolism on feeding the transition dairy cow. J. Anim. Sci. 73:2820-2833.

Grummer, R. R., M. C. Wiltbank, P. M. Fricke, R. D. Watters, and N. Silvia-Del-Rico. 2010. Management of dry and transition cows to improve energy balance and reproduction. J. Reprod. Dev. 56:S22-S28.

Hailemariam, D., R. Mandal, F. Saleem, S. M. Dunn, D. S. Wishart, and B. N. Ametaj. 2014. Identification of predictive biomarkers of disease state in transition dairy cows. J. Dairy Sci. 97:2680-2693.

Hartwell, J. R., M. J. Cecava, and S. S. Donkin. 2001. Rumen undegradable protein, rumen-protected choline and mRNA expression for enzymes in gluconeogenesis and ureagenesis in periparturient dairy cows. J. Dairy Sci. 84:490-497.

Hayashi, T., E. J. Boyko, M. J. McNeely, D. L. Leonetti, S. E. Kahn, and W. Y. Fujimoto. 2008. Visceral adiposity, not abdominal subcutaneous fat area, is associated with an increase in future insulin resistance in Japanese americans. Diabetes 57:1269-1275.

Hayirli, A. 2006. The role of exogenous insulin in the complex of hepatic lipidosis and ketosis associated with insulin resistance phenomenon in postpartum dairy cattle. Vet Res. Commun. 30:749-774.

Haus, J. M., S. R. Kashyap, T. Kasumov, R. Zhang, K. R. Kelly, R. A. DeFronzo, and J. P. Kirwan. 2009. Plasma ceramides are elevated in obese subjects with type 2 diabetes and correlate with the severity of insulin resistance. Diabetes 58:337-343.

Herdt, T.H. 2000. Ruminant adaptation to negative energy balance. Influences on the etiology of 
ketosis and fatty liver. Vet. Clin. North Am. Food Anim. Pract. 16:215-30.

Holtenius, P., and K.Holtenius. 2007. A model to estimate insulin sensitivity in dairy cows. Acta Vet. Scand. 49:29.

Imhasly, S., H. Naegeli, S. Baumann, M. von Bergen, A. Luch, H. Jungnickel, S. Potratz, and C. Gerspach. 2014. Metabolomic biomarkers correlating with hepatic lipidosis in dairy cows. BMC Vet. Res. 10:122.

Imhasly, S., C. Bieli, H. Naegeli, L. Nyström, M. Ruetten, and C. Gerspach. 2015. Blood plasma lipidome profile of dairy cows during the transition period. BMC Vet. Res. 11:252.

Ingvartsen, K. L., and J. B. Andersen. 2000. Integration of metabolism and intake regulation: A review focusing on periparturient animals. J. dairy Sci. 83:1573-1597.

Ingvartsen, K. L., and K. Moyes. 2013. Nutrition, immune function and health of dairy cattle. Animal. 7:112-122.

Ji, P. J. S. Osorio, J. K. Drackley, and J. J. Loor. 2012. Overfeeding a moderate energy diet prepartum does not impair bovine subcutaneous adipose tissue insulin signal transduction and induces marked changes in peripartal gene network expression. J. Dairy Sci. 95:43334351.

Kabarowski, J. H., Y. Xu, and O. N. Witte. 2002. Lysophosphatidylcholine as a ligand for immunoregulation. Biochem. Pharmacol. 64:161-167.

Kahn, C. R. 1978. Insulin resistance, insulin sensitivity, and insulin unresponsiveness: a necessary distinction. Metabolism 27:1893-1902.

Karcagi, R. G., T. Gaál, L. Wágner, and F. Husvéth. 2008. Effect of various dietary fat supplementations on liver lipid and glycogen of high-yielding dairy cows in the peripartal period. Acta Vet. Hung. 56:57-70.

Kenéz, Á., S. Dänicke, U. Rolle-Kampczyk, and M. von Bergen. 2016. A metabolomics approach to characterize phenotypes of metabolic transition from late pregnancy to early lactation in dairy cows. Metabol. 12:165.

Kerestes, M., V. Faigl, M. Kulcsár, O. Balogh, J. Földi, H. Fébel, Y. Chilliard, and G. Huszenicza. 2009. Periparturient insulin secretion and whole-body insulin responsiveness in dairy cows showing various forms of ketone pattern with or without puerperal metritis. Domest. Anim. Endocrinol. 37:250-261.

Kessler, E. C., J. J. Gross, R. M. Bruckmaier, and C. Albrecht. 2014. Cholesterol metabolism, transport, and hepatic regulation in dairy cows during transition and early lactation. J. Dairy Sci. 97:5481-5490. 
Kim, I.H., and G.H., Suh. 2003. Effect of the amount of body condition loss from the dry to near calving periods on the subsequent body condition change, occurrence of postpartum diseases, metabolic parameters and reproductive performance in Holstein dairy cows. Theriogenology. 60:1445-56.

Kleppe, B. B., A. J. Aiello, R. R. Grummer, and L. E. Armentano. 1988. Triglyceride accumulation and very low density lipoprotein secretion by rat and goat hepatocytes in vitro. J. Dairy Sci. 71:1813-1822.

Komaragiri, M. V. S., and R. A. Erdman. 1997. Factors affecting body tissue mobilization in early lactation dairy cows. 1. Effect of dietary protein on mobilization of body fat and protein. J. Dairy Sci. 80:929-937.

Kuhla, B., G. Nürnberg, D. Albercht, and C. C. Metges. 2011. Involvement of skeletal muscle protein, glycogen, and fat metabolism in the adaptation on early lactation of dairy cows. J. Proteome Res. 10:4252-4262.

Lara, A., G. D. Mendoza, L. Landois, R. Barcena, M. T. Sánchez-Torres, R. Rojo, J. Ayala, and S. Vega. 2006. Milk production in Holstein cows supplemented with different levels of ruminally protected methionine. Livest. Sci. 105:105-108.

LeBlanc, S. 2010. Monitoring metabolic health of dairy cattle in the transition period. J. Reprod. Dev. 56(Suppl.):S29-S35.

Lehmann, R., A. Königsrainer, J. Machann, and A. Gastaldelli. 2013. Circulating lysophosphatidylcholines are markers of a metabolically benign nonalcoholic fatty liver. Diabetes care 36:2331-2338.

Lemmon, M. A. and J. Schlessinger. 2010. Cell signaling by receptor tyrosine kinases. Cell 141: $1117-1134$.

Li, X., Y. Li, W. Yang, C. Xiao, S. Fu, Q. Deng, H. Ding, Z. Wang, G. Liu, and X. Li. 2014. SREBP-1c overexpression induces triglycerides accumulation through increasing lipid synthesis and decreasing lipid oxidation and VLDL assembly in bovine hepatocytes. J. S. B. M. B. 143:174-182.

Li, Z., and D. E. Vance. 2008. Phosphatidylcholine and choline homeostasis. J. Lipid Res. 49:1187-1194.

Litherland, N. B., H. M. Dann, and J. K. Drackley. 2011. Prepartum nutrient intake alters palmitate metabolism by liver slices from peripartal dairy cows. J. Dairy Sci. 94:1928-1940.

Liu, L., X. Li, Y. Li, Y. Guan, Y. Song, L. Yin, H. Chen, L. Lei, J. Liu, X. Li, Z. Wang, X. Yang, and G. Liu. 2014. Effects of nonesterified fatty acids on the synthesis and assembly of very low density lipoprotein in bovine hepatocytes in vitro. J. Dairy Sci. 97:1328-1335. 
Louet, J. F., C. Le May, J. P. Pegorier, J. F. Decaux, and J. Girard. 2001. Regulation of liver carnitine palmitoyltransferase I gene expression by hormones and fatty acids. Biochem. Soc. Trans. 29:310-316.

Mann, S., F. A. Leal Yepes, M. Duplessis, J. J. Wakshlag, T. R. Overton, B. P. Cummings, and D. V. Nydam. 2016. Dry period plane of energy: Effects on glucose tolerance in transition dairy cows. J. Dairy Sci. 99:701-717.

Matthews, D. R., J. P. Hosker, A. S. Rudenski, B. A. Naylor, D. F. Treacher, and R. C. Turner. 1985. Homeostasis model assessment: insulin resistance and beta-cell function from fasting plasma glucose and insulin concentrations in man. Diabetologia 28:412-419.

McCann, J. P., and T. J. Reimers. 1985. Glucose response to exogenous insulin and kinetics of insulin metabolism in obese and lean heifers. J. Anim. Sci. 61:612-618.

McNamara, J. P. 1991. Regulation of adipose tissue metabolism in support of lactation. J. Dairy Sci. 74:706-719.

Mills, J.A.N., France, J., and J. Dijkstra. 1999. A review of starch digestion in the lactating dairy cow and proposals for a mechanistic model: (1) Dietary starch characterisation and ruminal starch digestion. J. Anim. Feed Sci. 8:291-340.

Mitrakou, A., H. Vuorinen-Markkola, G. Raptis, I. Toft, M. Mokan, P. Strumph, W. Pimenta, T. Veneman, T. Jenssen, and G. Bolli. 1992. Simultaneous assessment of insulin secretion and insulin sensitivity using a hyperglycemia clamp. J. Clin. Endocrinol. Metab. 75:379382.

Mulligan, F. J. and M. L. Doherty. 2008. Production diseases of the transition cow. Vet. J. 176:39.

Muniyappa, R., S. Lee, H. Chen, and M. J. Quon. 2008. Current approaches for assessing insulin sensitivity and resistance in vivo: advantages, limitations, and appropriate usage. Am. J. Physiol. Endocrinol. Metab. 294:E15-26.

Nam, M., M. S. choi, S. Jung, Y. Jung, J. Y. Choi, D. H. Ryu, and G. S. Hwang. 2015. Lipidomic profiling of liver tissue from obesity-prone and obesity-resistant mice fed a high fat diet. Sci. Rep. 5:16984.

National Research Council. 2001. Nutrient requirements of dairy cattle. $7^{\text {th }}$ rev. ed. National Academy Press, Washington, DC.

Ohtsuka, H., M. Koiwa, A. Hatsugaya, and S. Kawamura. 2001. Relationship between serum TNF activity and insulin resistance in dairy cows affected with naturally occuring fatty liver. J. Vet. Med. Sci. 63:1021-1025.

Oikawa, S., and Oetzel GR. 2006. Decreased insulin response in dairy cows following a four-day 
fast to induce hepatic lipidosis. J Dairy Sci. 89:2999-3005.

Ospina, P. A., D. V. Nydam, T. Stokol, and T. R. Overton. 2010. Evaluation of nonesterified fatty acids and beta-hydroxybutyrate in transition dairy cattle in the northeastern United States: Critical thresholds for prediction of clinical diseases. J. Dairy Sci. 93:546-554.

Overton, T. R., J. K. Drackley, G. N. Douglas, L. S. Emmert, and J. H. Clark. 1998. Hepatic gluconeogenesis and whole-body protein metabolism of periparturient dairy cows as affected by source of energy and intake of the prepartum diet. J. Dairy Sci. 81:295.

Overton, T. R., and M. R. Waldron. 2004. Nutritional management of transition dairy cows: Strategies to optimize metabolic health. J. Dairy Sci. 87:E105-E119.

Perseghin, G., A. Caumo, M. Caloni, G. Testolin, and L. Luzi. 2001. Incorporation of the fasting plasma FFA concentration into QUICKI improves its association with insulin sensitivity in nonobese individuals. J. Clin. Endocrinol. Metab. 86:4776-4781.

Petterson, J. A., R. Slepetis, R. A. Ehrhardt, F. R. Dunshea, and A. W. Bell. 1994. Pregnancy but not moderate undernutrition attenuates insulin suppression of fat mobilization in sheep. J. Nutr. 124:2431-2436.

Pires, J. A., A. H. Souza, and R. R. Grummer. 2007a. Induction of hyperlipidemia by intravenous infusion of tallow emulsion causes insulin resistance in Holstein cows. J. Dairy Sci. 90:2735-2744.

Pires, J. A., J. B. Pescara, and R. R. Grummer. 2007b. Reduction of plasma NEFA concentration by nicotinic acid enhances the response to insulin in feed-restricted Holstein cows. J. Dairy Sci. 90:4635-4642.

Pullen, D. L., J. S. Liesman, and R. S. Emery. 1990. A species comparison of liver slice synthesis and secretion of triacylglycerol from nonesterified fatty acids in media. J. Anim. Sci. 68:1395-1399.

Rabasa-Lhoret, R., J. P. Bastard, V. Jan, P. H. Ducluzeau, F. Andreelli, F. Guebre, J. Bruzeau, C. Louche-Pellissier, C. Maitrepierre, J. Peirat, J. Chagné, H. Vidal, and M. Laville. 2003. Modified quantitative insulin sensitivity check index is better correlated to hyperinsulinemic glucose clamp than other fasting-based index of insulin sensitivity in different insulin-resistance states. J. Clin. Endocrinol. Metab. 88:4917-4923.

Reynolds, C. K., and H. F. Tyrrell. 1991. Effects of mesenteric vein L-alanine infusion on liver metabolism in beef heifers fed on diets differing in forage: concentrate ratio. Br. J. Nutr. 66:437-450. 
Reynolds, C. K., P. C. Aikman, B. Lupoli, D. J. Humphries, and D. E. Beever. 2003. Splanchnic metabolism of dairy cows during the transition from late gestation through early lactation. J. dairy Sci. 86:1201-1217.

Rico, J. E., V. V. R. Bandaru, J. M. Dorskind, N. J. Haughey, and J. W. McFadden. 2015. Plasma ceramides are elevated in overweight Holstein dairy cows experiencing greater lipolysis and insulin resistance during the transition from late pregnancy to early lactation. J Dairy Sci. 98:7757-70.

Roche, J. R., J. M. Lee, K. A. Macdonald, and D. P. Berry. 2007. Relationships among body condition score, body weight, and milk production variables in pasture-based dairy cows. J. Dairy Sci. 90:3802-3815.

Ross, R., J. Aru, J. Freeman, R. Hudson, and I. Janssen. 2001. Abdominal adiposity and insulin resistance in obese men. Am. J. Physiol. Endocrinol. Metab. 282:E657-E663.

Rukkwamsuk, T., T. Wensing, and M. J. H. Geelen. 1998. Effect of fatty liver on hepatic gluconeogenesis in periparturient dairy cows. J. Dairy Sci. 82:500-505.

Sacca, L., C. Vigorito, M. cicala, G. Corso, and R. S. Sherwin. 1983. Role of gluconeogenesis in epinephrine-stimulated hepatic glucose production in humans. Am. J. Physiol. 245:294302.

Sakamoto, K., T. komatsu, T. Kobayashi, M. T. Rose, H. Aso, A. Hagino, and Y. Obara. 2005. Growth hormone acts on the synthesis and secretion of $\alpha$-casein in bovine mammary epithelial cells. J. Dairy Res. 72:264-270.

Saleem, F., B. N. Ametaj, S. Bouatra, R. Mandal, Q. Zebeli, S. M. Dunn, and D. S. Wishart. 2012. A metabolomics approach to uncover the effects of grain diets on rumen health in dairy cows. J. Dairy Sci. 95:6606-6623.

Saltiel, A.R., and C.R. Kahn. 2001. Insulin signaling and the regulation of glucose and lipid metabolism. Nature 414:799-806, 2001.

Scholz, M., S. Gatzek, A. Sterling, O. Fiehn, and J. Selbig. 2004. Metabolite fingerprinting: detecting biological features by independent component analysis. Bioinformatics 20:24472454.

Schooneman, M. G., F. M. Vaz, S. M. Houten, and M. R. Soeters. 2013. Acylcarnitines: reflecting or inflicting insulin resistance? Diabetes 62:1-8.

Shahzad, K., M. Bionaz, E. Trevisi, G. Bertoni, S. L. Rodriguez-Zas, and J. J. Loor. 2014. Integrative analyses of hepatic differentially expressed genes and blood biomarkers during the peripartal period between dairy cows overfed or restricted-fed energy prepartum. PLoS ONE 9:e99757. 
Socha, M. T., D. E. Putnam, B. D. Garthwaite, N. L. Whitehouse, N. A. Kierstead, C. G. Schwab, G. A. Ducharme, and J. C. Robert. 2005. Improving intestinal amino acid supply of preand postpartum dairy cows with rumen-protected methionine and lysine. J. Dairy Sci. 88:1113-1126.

Sordillo, L.M, G.A. Contreras, and S.L. Aitken. 2009. Metabolic factors affecting the inflammatory response of periparturient dairy cows. Anim Health Res Rev. 10:53-63.

Sordillo, L.M., and W. Raphael. 2013. Significance of metabolic stress, lipid mobilization, and inflammation on transition cow disorders. Vet. Clin. North Am. Food Anim. Pract. 29:26778.

Sundler, R., and B. Akesson. 1975. Biosynthesis of phosphatidylethanolamines and phosphatidylcholines from ethanolamine and choline in rat liver. Biochem. J. 146:309-315.

Sundrum, A. 2015. Metabolic disorders in the transition period indicate that the dairy cows' ability to adapt is overstressed. Animals 5:978-1020.

Sun, X.J., Crimmins D.L., Myers, M.R. Jr, Miralpeix, M., and M.F. White. 1993. Pleiotropic insulin signals are engaged by multisite phosphorylation of IRS-1. Mol. Cell. Biol. 13: $7418-7428$.

Sun, L. W., H. Zhang, Y. Wu, L. Shu, S. Xia, C. Xu, and J. S. Zheng. 2014. ${ }^{1}$ H-Nuclear magnetic resonance-based plasma metabolic profiling of dairy cows with clinical and subclinical ketosis. J. Dairy Sci. 97:1552-1562.

Vance, E. D., Z. Li, and R. L. Jacobs. 2007. Hepatic phosphatidylethanolamine $N$ methyltransferase, unexpected roles in animal biochemistry and physiology. J. Biol. Chemi. 282:33237-33241.

Van den Top, A. M., M. J. Geelen, T. Wensing, G. H. Wentink, A. T. Van t Klooster, and A. C. Beynen. 1996. Higher postpartum hepatic triacylglycerol concentrations in dairy cows with free rather than restricted access to feed during the dry period are associated with lower activities of hepatic glycerolphosphate acyltransferase. J. Nutr. 126:76-85.

Van der Drift, S. G. A., M. Houweling, J. T. Schonewille, A. G. M. Tielens, and R. Jorritsma. 2012. Protein and fat mobilization and associations with serum B-hydroxybutyrate cocentrations in dairy cows. J. Dairy Sci. 95:4911-4920.

Veenhuizen, J. J., J. K. Drackley, M. J. Richard, and J. W. Young. 1992. Metabolic changes in blood and liver during development and early treatment of experimental fatty liver and ketosis in cows. J. Dairy Sci. 74:4238-4253.

Verkade, H. J., D. G. Fast, A. E. Rusiñol, D. G. Scraba, and D. E. Vance. 1993. Impaired biosynthesis of phosphatidylcholine causes a decrease in the number of very low density 
lipoprotein particles in the golgi but not in the endoplasmic reticulum of rat liver. J. Biol. Chem. 268:24990-24996.

Ward, C. W., and M. C. Lawrence. 2009. Ligand-induced activation of the insulin receptor: a multi-step process involving structural changes in both the ligand and the receptor. Bioessays. 4:422-34.

Yamada, T., S. Kawakami, and N. Nakanishi. 2003. The relationship between plasma leptin concentrations and distribution of body fat in crossbred steers. Anim. Sci. J. 74:95-100.

Zachut, M., H. Honig, S. Striem, Y. Zick, S. Boura-Halfon, and U. Moallem. 2013. Periparturient dairy cows do not exhibit hepatic insulin resistance, yet adipose-specific insulin resistance occurs in cows prone to high weight loss. J. Dairy Sci. 96:5656-5669.

Zeisel, S. H. 1992. Choline: An important nutrient in brain development, liver function and carcinogenesis. J. Am. Coll. Nutr. 11:473-481.

Zhang, H., L. Wu, C. Xu, C. Xia, L. Sun, and S. Shu. 2013. Plasma metabolomic profiling of dairy cows affected with ketosis using gas chromatography/mass spectrometry. BMC Vet. Res. 9:1.

Zhao, F. Q., and A. F. Keating. 2007. Expression and regulation of glucose transporters in the bovine mammary gland. J. dairy Sci. 90:E76-E86. 


\title{
CHAPTER 3
}

\section{COMPARATIVE EFFECTS OF ADIPOSITY ON DIRECT AND INDIRECT MEASUREMENTS OF INSULIN SENSITIVITY IN PERIPARTURIENT DAIRY COWS.}

\begin{abstract}
Insulin resistance in periparturient dairy cows develops as a means to support lactation; however, the excessive mobilization of free fatty acids (FA) from adipose tissue can increase metabolic disease risk. Moreover, prepartum adiposity is a risk factor for the lipolytic release of FA and hepatic lipid deposition. Our primary objective was to investigate the effect of prepartum adiposity on systemic glucose and insulin tolerance in lean and overweight periparturient dairy cows fed common diets. Our secondary objective was the comparative evaluation of direct and indirect measurements of insulin sensitivity in peripartal dairy cows. Twenty-one multiparous Holstein cows were allocated into 2 groups according to their adiposity at d -28 prepartum: lean (body condition score $(\mathrm{BCS}) \leq 3.0)$ or overweight $(\mathrm{BCS} \geq 4.0)$. All cows were ad libitum fed diets formulated to meet or exceed nutrient requirements. Blood and milk samples were collected routinely. Prior to morning feeding, liver biopsies were collected on d $-27,-14$, and 4 , relative to expected calving. An intravenous insulin ( $0.1 \mathrm{IU} / \mathrm{kg}$ of body weight; ITT) or glucose $(300 \mathrm{mg} / \mathrm{kg}$ of body weight; GTT) challenge was performed following each liver biopsy. Plasma FA, insulin, glucose, and $\beta$-hydroxybutyrate (BHBA) concentrations were measured. Surrogate indices of insulin sensitivity were calculated. Data were analyzed as repeated measures using a mixed model with fixed effects of adiposity and time. Overweight cows had lower dry matter intake and lost more adiposity during the peripartum, relative to lean cows. Overweight cows had increased plasma FA and BHBA concentrations, and elevated liver lipid content. In support of impaired insulin sensitivity, GTT glucose clearance rate (30 min post-glucose infusion) was lower for all
\end{abstract}


cows postpartum. Prepartum adiposity had minimal effects on multiple ITT and GTT glucosedependent parameters; however, the ability of the cow to restore blood glucose levels following an insulin challenge was suppressed by increased adiposity. Additionally, overweight cows experienced lower glucose-stimulated reductions in FA following a glucose challenge. Collectively, glucose-dependent parameters of insulin and glucose tolerance were not correlated with surrogate indices of insulin sensitivity. We conclude that prepartum adiposity had no effect on systemic insulin sensitivity following parturition. Observed inconsistencies between surrogate indices for insulin sensitivity and direct measurements of insulin and glucose tolerance raises concerns regarding whether their application to estimate systemic insulin action in periparturient cows is suitable. 


\section{INTRODUCTION}

Dairy cattle transitioning from gestation to lactation will partition glucose away from adipose and skeletal muscle tissues, and toward the mammary gland as a means to support lactose synthesis (Bell, 1995). The adaptive change in peripheral glucose utilization during the periparturient period is caused in part by decreased insulin sensitivity (Bell and Bauman, 1997). Reduced insulin signaling in adipose tissue occurs in parallel with enhanced lipolysis of triacylglycerol during early lactation. The postpartum elevation in circulating fatty acids (FA) will promote hepatic lipid deposition and ketogenesis in the early lactation cow, peripartal risk factors for the development of fatty liver disease and ketosis.

An increase in prepartum adiposity can predispose dairy cows to a greater magnitude of FA mobilization during early lactation (Holtenius et al., 2003; Holtenius, 2007). Others have proposed that a greater extent of adipose tissue insulin resistance in overweight peripartal dairy cows may contribute to excessive lipolysis thus greater metabolic disease risk (Bossaert et al., 2008), a response that may be mediated by the sphingolipid ceramide (Rico et al., 2015). Certainly enhanced body fat accumulation can develop in dairy cattle fed in excess of energy requirements during gestation, albeit dependent upon the length of the overfeeding regimen (Marrow, 1976; Roche et al., 2013). Effort has been focused on the effects of plane of nutrition during the dry period on peripartal metabolic health and glucose disposal. For instance, feeding a high energy diet to cows prepartum does not modify systemic glucose tolerance following a challenge performed during late gestation or early lactation (Schoenberg and Overton, 2011; Schoenberg et al., 2012; Mann et al., 2016). Moreover, the ability of prepartum nutrient excess to suppress FA disappearance following a glucose challenge has been previously demonstrated during late gestation (Schoenberg and Overton, 2011; Schoenberg et al., 2012); however, this finding is in 
contrast to recent observations made during the peripartal transition (Mann et al., 2016). It is important to recognize that these studies utilized dairy cows with moderate adiposity at enrollment ( 3.0 body condition score; BCS), and prepartum elevated plane of nutrition resulted in minor gains in adiposity during gestation ( 0.25 BCS change).

Enhanced adiposity is associated with reduced systemic insulin sensitivity in fasted nonruminants (Ross et al., 2001; Hayashi et al., 2008); however, this view has been challenged by others describing obese humans that are insulin-sensitive (Klöting et al., 2010; Samocha-Bonet et al., 2012). Suppressed insulin sensitivity may explain why overweight dairy cows during the peripartal period exhibit greater FA mobilization postpartum. Pregnant cows with moderate body condition that gain adiposity through wk 1 postpartum in response to high-energy feeding have exhibited a decrease in glucose clearance rate postpartum (Holtenius et al., 2003a, b). In contrast, glucose clearance rate was not related to BCS when recorded three weeks postpartum in dairy cows with moderate FA mobilization (Jaakson et al., 2013). Recently, De Koster and coworkers (2015) evaluated nine Holstein Friesian dairy cows during late gestation with variable BCS (Wildman et al., 1982), and observed that maximal steady-state glucose infusion rate during a hyperinsulinemic-euglycemic clamp was inversely related with BCS and basal circulating FA concentrations. Undoubtedly differences in experimental designs, feeding regimens, magnitude of adiposity, metabolic status, and method of insulin sensitivity assessment during the peripartum confound our understanding of insulin action in peripartal dairy cows.

Several surrogate measures have been employed to evaluate insulin sensitivity in monogastrics and ruminants. These insulin sensitivity indices rely on the measurement of circulating FA, glucose, insulin, and $\beta$-hydroxybutyrate (BHBA) levels in the basal state (Kerestes et al, 2009; Mann et al., 2016). Initially evaluated in dairy cows by Holtenius and Holtenius (2007), 
the Revised Quantitative Insulin Sensitivity Check Index (RQUICKI) has received considerable attention (Schoenberg et al., 2011; Rico et al., 2015; Mann et al., 2016). However, Mann and colleagues (2016) recently discovered that peripartal glucose tolerance in cows fed different planes of nutrition prepartum did not correlate with multiple indices of insulin sensitivity including RQUICKI, and stated that indice values should not be compared across stages of lactation.

Our primary objective was to examine the effect of adiposity on glucose disposal in response to repeated intravenous glucose and insulin tolerance tests performed in lean and overweight periparturient dairy cows ad libitum fed common diets. Considering the recent uncertainty related to the application of surrogate indices of insulin sensitivity, our secondary objective was the comparative evaluation of direct and indirect measurements of insulin sensitivity in periparturient dairy cows with contrasting adiposity.

\section{MATERIALS AND METHODS}

\section{Experimental Design}

Experimental procedures were approved by the Institutional Animal Care and Use Committee at West Virginia University (Morgantown). The experiment was completed at Dovan Farms (700-cow Holstein dairy herd; Berlin, PA), a West Virginia University Agricultural Research and Education Partner. Twenty-one multiparous Holstein cows (parity 2 to 4 ) were enrolled 28 d before expected parturition, and immediately allocated to one of two groups according to their adiposity, as either lean $(\mathrm{BCS}=2.93 \pm 0.16)$ or overweight $(\mathrm{BCS}=4.01 \pm 0.20)$. Cows were housed on a straw bedded pack and trained to access feed from Calan gate feeders (American Calan, Inc., Norwood, NH) from enrollment through 6 DIM. Because of farm management constraints, cows were moved to adjacent free-stalls from 7 DIM through study 
completion. Diets provided ad libitum were composed of corn silage and grass haylage as the main forage components, and were formulated to meet or exceed nutrient recommendations (Table 3-1; NRC, 2001). Cows were fed once (0800 h) and twice (0800 and 1900 h) daily during pregnancy and lactation, respectively, and free access to water was provided.

\section{Sample Collection}

Samples of TMR were collected weekly throughout the experiment. Blood collection (10 $\mathrm{mL}$ ) by coccygeal venipuncture occurred prior to morning feeding on $\mathrm{d}-28,-21,-14,-7$, and -5 , relative to expected calving, and d 0, 2, 4, 7, 14, and 21 postpartum. Blood was placed on ice for $30 \mathrm{~min}$ until centrifugation at $3,400 \times \mathrm{g}$ for $10 \mathrm{~min}$. Following centrifugation, EDTA-preserved plasma was removed and snap-frozen in liquid nitrogen, and then stored at $-80{ }^{\circ} \mathrm{C}$ until further

analysis. Cows were milked twice daily at 0800 and $1800 \mathrm{~h}$. Milk yields were continually recorded and milk samples were collected at each milking on $\mathrm{d} 2,3,4,5,6,7,10,14$, and 21 postpartum. A single milk aliquot was stored with bronopol at $4{ }^{\circ} \mathrm{C}$ for component analysis. Body weights and BCS were recorded weekly.

Liver tissue biopsies were performed prior to morning feeding on $\mathrm{d}-27$ and -14 , relative to expected calving, and d 4 postpartum. Cows were anesthetized using xylazine $(0.04 \mathrm{~mL} / \mathrm{kg}$ of BW) delivered via the coccygeal vein. After the hair was clipped, the biopsy site located within the $11^{\text {th }}$ intercostal space was scrubbed with iodine and anesthetized with $5 \mathrm{~mL}$ of $2 \%$ lidocaine $\mathrm{HCl}$ (Vedco Inc., Saint Joseph, MO) delivered subcutaneously. A $0.5 \mathrm{~cm}$ incision was made through the skin and a fabricated trocar (Hughes, 1962) was utilized to collect approximately $1 \mathrm{~g}$ of liver tissue. Liver tissue was immediately snap-frozen in liquid nitrogen and stored at $-80^{\circ} \mathrm{C}$. Following each tissue collection, the biopsy site was stapled and sprayed with antiseptic, and ceftiofur 
hydrochloride antibiotic was delivered once by intramuscular injection $(0.68 \mathrm{~mL} / \mathrm{kg}$ of $\mathrm{BW}$; Excenel RTU; Zoetis, Florham Park, NJ).

\section{Glucose and Insulin Tolerance Testing}

Immediately following each liver biopsy, jugular catheters were inserted and patency was maintained by flushing with heparinized saline every $12 \mathrm{~h}$ for $2 \mathrm{~d}$. Intravenous insulin and glucose tolerance tests (ITT and GTT, respectively) were performed using previously described methods (Pires et al., 2007). Briefly, feed was removed $2 \mathrm{~h}$ prior to tolerance testing. An intravenous ITT (0.1 IU of insulin per kg BW; Humulin R; Eli Lilly and Co., Indianapolis, IN) was performed on d -26 and -13 before expected calving, and on d 5 postpartum. An intravenous GTT was performed on d -25 and -12 , relative to expected calving, and d 6 postpartum. Cows were intravenously infused with $300 \mathrm{mg}$ of glucose (dextrose, $50 \% \mathrm{wt} / \mathrm{vol}$ ) per $\mathrm{kg}$ of BW. Glucose infusion occurred within $8 \pm 2 \mathrm{~min}$, and was followed by a 10 -mL saline flush. For GTT and ITT, blood samples (10 $\mathrm{mL}$ ) were collected at $-10,0,10,20,30,40,60,90,120,150$, and 180 min relative to initiation of challenge. Blood was processed as described above. Feed was provided immediately following the completion of testing.

\section{Sample Analyses}

Weekly TMR samples were analyzed for DM content by drying at $60^{\circ} \mathrm{C}$ until a static weight was observed. Nutrient composition of TMR was analyzed using near-infrared spectroscopy (AOAC method 989.03) by Cumberland Valley Analytical Services Inc. (Cumberland, MD). Plasma samples were analyzed in duplicate for nonesterified FA, insulin, glucose, and BHBA. Plasma concentrations of FA, glucose, and BHBA were determined by enzymatic methods using 
commercial kits (HR series FA-HR (2), Autokit Glucose, and Autokit 3-HB, respectively; Wako Chemicals USA Inc., Richmond, VA). Plasma insulin concentrations were determined by ELISA (Mercodia Bovine Insulin ELISA; Mercodia AB, Uppsala, Sweden). Spectrophotometric measurements were conducted using a SpectraMax Plus 384 Microplate Reader (Molecular

Devices, Sunnyvale, CA). Intra- and interassay coefficient of variations for all colorimetric assays were $<5$ and $<10 \%$, respectively. Total liver lipid content was determined by extracting $100 \mathrm{mg}$ of liver tissue, as previously described (Hara and Radin, 1978; Piepenbrink and Overton, 2003). Individual milk samples were analyzed for fat, true protein, and lactose concentrations (Dairy One, Hagerstown, MD; AOAC, 1990; method 972.160).

\section{Calculations and Statistical Analysis}

The indices for insulin sensitivity quantitative insulin sensitivity check index (QUICKI; Katz et al., 2000), RQUICKI (Perseghin et al., 2001), RQUICKI including BHBA (RQUICKI ${ }_{B H B A}$; Balogh et al., 2008), and homeostasis model of insulin resistance (HOMA-IR; Muniyappa et al., 2008) were calculated as follows: QUICKI $=\{1 /[\log$ glucose $(\mathrm{mg} / \mathrm{dL})+\log$ insulin $(\mu \mathrm{U} / \mathrm{mL})]\}$, RQUICKI $=\{1 /[\log$ glucose $(\mathrm{mg} / \mathrm{dL})+\log$ insulin $(\mu \mathrm{U} / \mathrm{mL})+\log$ FA $(\mathrm{mmol} / \mathrm{L})]\}$ RQUICKI $_{\text {BHBA }}=\{1 /[\log$ glucose $(\mathrm{mg} / \mathrm{dL})+\log$ insulin $(\mu \mathrm{U} / \mathrm{mL})+\log \mathrm{FA}(\mathrm{mmol} / \mathrm{L})+\log \mathrm{BHBA}$ $(\mathrm{mmol} / \mathrm{L})]\}$, and HOMA-IR $=\{[$ glucose $(\mathrm{mmol} / \mathrm{L}) \times$ insulin $(\mu \mathrm{U} / \mathrm{mL})] / 22.5\}$. Glucose clearance rate $(\mathrm{CR})$, time to reach half maximal concentration $\left(\mathrm{T}_{1 / 2}\right)$, and time to reach basal concentration ( $\left.\mathrm{T}_{\text {basal }}\right)$ were calculated according to methods described by Pires et al. (2007): Glucose CR (\%/min) $=[(\ln$ glucose at $10 \mathrm{~min}-\ln$ glucose at time point $60 \mathrm{~min}) / 60] \times 100, \mathrm{~T}_{1 / 2}(\min )=[(\ln 2) / \mathrm{CR}] \times$ $100, T_{\text {basal }}(\mathrm{min})=[(\ln$ glucose at $10 \mathrm{~min}-\ln$ glucose at $60 \mathrm{~min}) / \mathrm{CR}] \times 100$. The glucose area under the curve (AUC) during a GTT was calculated using the trapezoidal method. Baseline 
glucose concentrations were calculated as the mean of measurements at -10 and 0 min, relative to start of challenge. Changes in BCS and BW of lean and overweight cows were calculated as the differences between values at $\mathrm{d}-21$ prepartum and $\mathrm{d} 21$ postpartum.

Changes in BCS and BW were analyzed under the GLM procedure of SAS (version 9.3; SAS Institute Inc., Carry, NC). Plasma, liver, and milk variables were analyzed as repeated measures over time relative to parturition under the MIXED procedure of SAS (SAS Institute Inc.). The statistical model included the random effect of cow nested within BCS, and the fixed effects of BCS, day relative to parturition, and their interaction. The most appropriate covariance structure for the repeated measures analysis was selected for each variable after evaluating 3 different covariance structures (variance components, first-order autoregressive, compound symmetry), and the structure with the smallest Akaike's information criterion coefficient was selected for analysis. The method of Kenward-Rogers was used for calculation of denominator degrees of freedom. When the BCS effect or BCS $\times$ day relative to parturition were significant, the SLICE option of SAS was used to compare treatment differences at individual time points. Non-parametric Spearman's rank-order correlations were performed in order to determine associations between surrogate indices of insulin sensitivity, direct measurements of insulin sensitivity, and plasma metabolites. In order to reduce risk of type I error for repeated measures analysis, the significance level was decreased to $P \leq 0.05$, and trends toward significance were considered at $0.05<P \leq$ 0.10. Studentized residual values $>3.0$ or $<-3.0$ were considered outliers and removed from the analysis (typically 1 per response variable). All results are expressed as least squares means and their standard errors, unless stated otherwise. 


\section{RESULTS AND DISCUSSION}

Although twenty-one prepartum cows were enrolled, 4 lean and 3 overweight cows were not included within our analyses because they were diagnosed with a metabolic disease and subsequently treated by the herd veterinarian; therefore, our data represents fourteen cows that transitioned from gestation to lactation without clinical intervention. Overweight cows displayed DMI suppression during the peripartum (Figure 3-1; $P<0.01$ ), a response that may be regulated in part by anorexigenic signals including circulating FA and BHBA (Laeger et al., 2012; Le Foll and Levin, 2016). Certainly, reductions in DMI can exacerbate negative energy balance and increase metabolic disease risk in cows with enhanced adiposity. As evidence, the transition from gestation to lactation was accompanied by accelerated loss of BW (18 vs. 9\%; $P<0.01)$ and BCS (22 vs. 13\%; $P<0.05$ ) in overweight cows (Figure 3-1). Lactation performance was comparable for lean and overweight cows; except, milk fat yield $(P<0.10)$ and content $(P<0.01)$ was greater in cows with enhanced prepartum adiposity (Figure 3-2).

Basal measurement of systemic and hepatic health were performed to confirm that prepartum adiposity is a risk factor for postpartum metabolic impairment (Figure 3-1). Plasma FA concentrations were greater in overweight animals $(P<0.05)$, and maximum lipolysis was observed at parturition with a 2.4-fold increase in circulating FA in overweight cows, relative to lean cows $(P<0.001)$. Although the development of insulin resistance in overweight humans is associated with elevated circulating FA, glucose, and insulin (Reaven et al., 1988; Thévenod, 2008), we recognize that the characteristic response to lactation and the progression of insulin resistance in cows is a decrease in circulating insulin. Unlike our previous observations (Rico et al., 2015), circulating insulin was numerically but not significantly higher in overweight cows prepartum $(P<0.05)$; whereas, plasma insulin concentrations were similar for both adiposity 
groups during early lactation. The characteristic decline in circulating insulin observed for all cows occurred in conjunction with reduced plasma glucose concentrations postpartum $(P<0.001)$, although prepartum BCS did not influence systemic glucose supply. Due in part to increased hepatic FA influx, liver lipid accumulation and plasma BHBA concentrations were elevated in cows with enhanced gestational adiposity. The poor metabolic health observed in overweight cows reinforces the importance of avoiding over-conditioning of cows during gestation.

Due to early parturition, the actual sampling day for each prepartum tolerance test was $20.5 \pm 5.8$ and $-9.4 \pm 3.5$ for each ITT, and $-21.3 \pm 5.6$ and $-9.4 \pm 3.5$ for each GTT, whereas postpartum ITT and GTT occurred as scheduled on d 5 and 6 postpartum, respectively. Several methods have been utilized to evaluate insulin sensitivity. Insulin tolerance test was first developed (Horgaard and Thayssen, 1929) to measure insulin sensitivity in vivo based on the clearance of plasma glucose concentrations after injection of insulin bolus $(0.1 \mathrm{U} / \mathrm{kg} \mathrm{BW})$. The main disadvantage for any direct measurement of insulin sensitivity (especially during lactation) is that glucose is primarily utilized by the mammary gland independent of insulin action (Bauman and Currie, 1980; Pethick, 2005). Specifically, GLUT 1 and 3 in mammary gland are insulinindependent glucose transporters (Duehlmeier et al., 2005; Zhao et al., 2006) which makes interpretation of results difficult. Although an insulin challenge lowered plasma glucose $(P<$ 0.001), we did not observe an effect of adiposity pre and postpartum (Figure 3-3). However, we did observe increased plasma glucose in lean cows 60 min post insulin challenge. Postpartum basal glucose concentration was higher for lean cows during ITT (71.3 \pm 6 vs. $65.1 \pm 6 \mathrm{mg} / \mathrm{dL}$, Table 3 2). The lowest concentration of glucose occurred 40 min after insulin challenge both pre- and postpartum. The insulin dose administered in our research was similar to (Pires et al., 2007; Kerestes et al., 2009), but lower than McCann and Reimers (1985), which is critical to consider 
when comparing results from different studies. We observed no differences between adiposity preand postpartum for reduction of glucose concentrations after insulin administration (Figure 3-3). Following insulin-stimulated glucose disappearance, return to basal glucose in overweight cows was delayed by $60 \mathrm{~min}(P<0.05)$. Glucose utilization, hepatic glucose production, intestinal glucose absorption and excretion of glucose by the kidney can determine the plasma glucose concentrations (Pires et al., 2007) and glucose clearance during ITT can be interpreted as the maximal glucose response to insulin challenge. In our study, adiposity did not impair glucose clearance prepartum; however, overweight cows had delayed glucose return to their basal concentrations, which indicates adiposity did not regulate systematic insulin resistance prepartum; but probably reflects the postpartum insulin resistance induced by adiposity. The reason for delayed glucose return to basal levels in overweight cows postpartum might be due to hepatic lipid deposition blocking gluconeogenesis. The greater insulin-stimulated blood glucose reductions after challenge indicates higher insulin sensitivity in peripheral tissues (De Koster and Opsomer, 2013), our findings indicate that glucose response to insulin was not impaired by adiposity that were in contrast with Pires et al (2007) reports indicating impaired insulin responsiveness in nonlactating, nongestating Holstein cows with hyperlipidemia. In addition, our findings were not consistent with Kerestes et al (2009) where they observed higher glucose reduction after insulin challenge in early lactation than prepartum, as well as an earlier return to basal glucose concentrations $(60 \mathrm{~min})$ in obese after administering of high insulin dose $(200 \mathrm{mU} / \mathrm{kg})$. The differences in findings can be explained by differences in experimental design, age of cows, treatments, dose of insulin administered, and adiposity. 


\section{Effect of adiposity on glucose response During GTT}

We aimed to measure insulin sensitivity by evaluating glucose response during glucose challenge. De Koster et al. (2016) validated different measures of insulin sensitivity during the dry period. They reported a positive correlation between hyperinsulinemic euglycemic clamp (HEC) and GTT parameters. The amount of glucose infused was greater than previous studies (Holtenius et al., 2003; Pires et al., 2007; Mann et al., 2016) but lower than Kerestes et al. (2009). We did not observe an effect of adiposity pre- and postpartum (Figure 3-4). Nevertheless, there were significant interactions between adiposity and GTT, with overweight cows tended to have greater glucose concentrations during the far-off at time point $40 \mathrm{~min}(P<0.1)$ after glucose infusion. The results indicate that adiposity does alter glucose metabolism during transition to lactation in dairy cows. This is in agreement with studies investigating insulin sensitivity of Holstein cows varying energy density during the dry period (Schoenberg et al., 2012; Mann et al., 2016). De Koster et al. (2013) defined insulin resistance in dairy cows as a condition where glucose clearance is low, the area under the curve for glucose is high, and time to reach basal glucose concentrations is high during GTT. Post-glucose challenge of the glucose AUC for $60 \mathrm{~min}$ and CR of glucose for the first 30 min were lower $(P<0.05)$ and tended to be lower for AUC for 30 and 180 min for postpartum cows, relative to prepartum cows (Table 3; $P=0.06$ ). Our results are in contrast with Mann et al., (2016) which reported increased glucose clearance in postpartum cows. Although adiposity had no effect on GTT; however, time to reach basal glucose concentrations was higher in overweight cows postpartum (Table 3-3; $P<0.05$ ). On the other hand, lower postpartum glucose CR in dairy cows that are fed to gain body condition has been reported (Holtenius et al., 2003). Comparability of GTT parameters of lactating cows with nonlactating, pregnant cows are intriguing; due to high turnover of glucose in early lactation (De Koster and Opsomer, 2013) as it has been demonstrated 
by lower basal glucose concentrations postpartum $(P<0.01)$. Together, our findings suggest an increased insulin resistance in early lactation regardless of adiposity.

\section{Effect of Adiposity on FA Response During GTT}

Plasma FA concentrations during GTT is depicted in Figure 3-5. Overweight cows had greater FA concentrations in the far-off period at time point $120 \mathrm{~min}(P<0.05)$ and tended to be higher at time points 20,30, 40 and $90 \mathrm{~min}(P<0.1)$ relative to time after glucose infusion. We observed higher FA concentrations in overweight cows during the entire close-up period and time points 10 through 90 min postpartum $(P<0.05)$ with a tendency to be higher at time point 120 min postpartum $(P<0.1)$ after glucose challenge. Overweight cows experienced greater glucosestimulated FA reduction pre- and postpartum (Table 3-4; $P<0.05$ ). These findings are in contrast with results suggesting no effect of difference between plane of nutrition on FA metabolism preand postpartum (Mann et al., 2016). FA concentrations reached a nadir around time point 60 min on close-up and postpartum after glucose challenge, which has delayed compare with previous studies reported at 45 min (Zachut et al., 2013; Mann et al., 2016); that might be related to the dose of glucose administered. This indicates the inhibition of lipolysis, after glucose infusion, in response to insulin regardless of adiposity and physiological stage of a cow. Although we did not observe an effect of adiposity on the percentage of FA reduction from baseline; however, we observed increased post-glucose challenge of FA AUC for 60 through $180 \mathrm{~min}$ and reduced FA CR for 60 through 180 min in postpartum, relative to prepartum $(P<0.01)$. The difference between glucose and FA metabolism during peripartum was explained by De Koster et al. (2015) which illustrated that lower insulin concentrations are needed to metabolize FA compare with its action 
on glucose metabolism. Together, our results reflect increased insulin resistance in early lactation to partition nutrients to mammary gland as means to support milk synthesis.

\section{Surrogate indices}

We first evaluated the effect of adiposity on QUICKI, RQUICKI, RQUICKI BHBA, and HOMA-IR values obtained during the peripartum (Figure 3-6). Surrogate indices have been developed and validated, particularly QUICKI, in human medicine (Muniyappa et al., 2008). Initially, RQUICKI has been utilized in dairy cows by Holtenius and Holtenius (2007) to evaluate insulin sensitivity; with few other studies comparing HEC and GTT with insulin resistance indices. Therefore, the lack of studies for evaluating surrogate indices in different adiposity during peripatrum, necessitate the investigation in dairy cows. Comparable to previous findings (Holtenius and Holtenius, 2007), enhanced adiposity was associated with a decrease in estimated insulin sensitivity before and after parturition $(P<0.001)$, a response most pronounced for late gestation $(P<0.05)$. In comparison to the effects of adiposity, changes in estimated insulin sensitivity across time were inconsistent among surrogate markers. Whereas HOMA-IR decreased and QUICKI increased with time $(P<0.01)$, reflecting an increase in estimated insulin sensitivity, the transition from gestation to lactation was not accompanied by changes in RQUICKI or RQUICKI $I_{\mathrm{BHB}}$. Considering that reduced insulin sensitivity is recognized as a homeorhetic adaptation to lactation (De Koster and Opsomer, 2013), these discrepancies between indices are concerning.

We next compared the index most often utilized in dairy science (Holtenius and Holtenius, 2007; Kerestes et al., 2009), RQUICKI with QUICKI, RQUICKI ${ }_{B H B A}$, and HOMA-IR; Table 3-

5). We detected strong positive correlations between RQUICKI and QUICKI $(\rho=0.64 ; P \leq 0.001)$, 
and RQUICKI and RQUICKI relationship between RQUICKI and HOMA-IR $(\rho=-0.63 ; P \leq 0.001)$. These correlative relationships were anticipated because higher QUICKI, RQUICKI, and RQUICKI $I_{B H B A}$, and lower HOMA-IR values are indicative of reduced insulin action in monogastrics.

We further evaluated the correlation between surrogate indices and ITT, and GTT parameters (Table 3-6). We hypothesized a strong association between IR indices and tolerance tests during the peripartum. We observed positive correlation of glucose CR at time point 10 min with RQUICKI ( $\rho=0.38 ; P<0.05)$, and RQUICKI ${ }_{\text {BHBA }}(\rho=0.32 ; P=0.05)$. We observed no other strong positive correlation between IR indices and tolerance tests. This is consistent with previous studies (De Koster et al., 2016; Mann et al., 2016) which reported poor correlation or no association between IR indices and direct measurement of insulin sensitivity. Insulin resistance in dairy cows is very different than in humans due to the drastic physiological changes initiated in the early lactation, especially for glucose, insulin, and FA metabolism. Consequently, usefulness of surrogate indices in dairy cows can be questionable. It should be emphasized that comparing results between different stages of lactation is not an accurate practice.

\section{CONCLUSIONS}

Although overweight dairy cows exhibit elevated prepartum insulin, postpartum FA, and peripartal liver lipid deposition in parallel with a greater reduction in appetite, enhanced adiposity during late gestation is not associated with modifications in glucose or insulin tolerance as assessed by GTT or ITT. Furthermore, we agree with Mann and colleagues (2016) and reaffirm that the usefulness of surrogate measures of systemic insulin sensitivity is indeed questionable, and that investigators should refrain from comparing index values across the peripartal period. 


\section{REFERENCES}

Balogh, O., O. Szepes, K. Kovacs, M. Kulcsar, J. Reiczigel, J. A. Alcazar, M. Keresztes, H. Febel, J. Bartyik, S. G. Fekete, L. Fesus, and G. Huszenicza. 2008. Interrelationship of growth hormone AluI polymorphism, insulin resistance, milk production and reproductive performance in Holstein-Friesian cows. Vet. Med. 53:604-616.

Bauman, D. E., and W. B. Currie. 1980. Partitioning of nutrients during pregnancy and lactation: A review of mechanisms involving homeostasis and homeorhesis. J. Dairy Sci. 63:15141529.

Bell, A. W., and D. E. Bauman. 1997. Adaptations of glucose metabolism during pregnancy and lactation. J. Mammary Gland Biol. Neoplasia 2:265-278.

Bell, A. W. 1995. Regulation of organic nutrient metabolism during transition from late pregnancy to early lactation. J. Anim. Sci. 73:2804-2819.

Bossaert, P., J. L. M. R. Leroy, S. De Vliegher, and G. Opsomer. 2008. Interrelations between glucose-induced insulin response, metabolic indicators, and time of first ovulation in highyielding dairy cows. J. Dairy Sci. 91:3363-3371.

Dann, H. M., N. B. Litherland, J. P. Underwood, M. Bionaz, A. D'Angelo, J. W. McFadden, and J. K. Drackley. 2006. Diets during far-off and close-up dry periods affect periparturient metabolism and lactation in multiparous cows. J. Dairy Sci. 89:3563-3577.

De Koster, J., M. Hostens, K. Hermans, W. Van den Broeck, and G. Opsomer. 2016. Validation of different measures of insulin sensitivity of glucose metabolism in dairy cows using the hyperinsulinemic euglycemic clamp test as the gold standard. Dom. Anim. Endo. 57:117126.

De Koster, J., M. Hostens, M. Van Eetvelde, K. Hermans, S. Moerman, H. Bogaert, E. Depreester, W. Van den Broeck, and G. Opsomer. 2015. Insulin response of the glucose and fatty acid metabolism in dry dairy cows across a range of body condition scores. J. Dairy Sci. 98:4580-4592.

De Koster, J. D., and G. Opsomer. 2013. Insulin resistance in dairy cows. Vet. Clin. North Am. Food Anim. Pract. 29:299-322.

Drackley, J. K., H. M. Dann, G. N. Douglas, N. A. Janovick Guretzky, N. B. Litherland, J. P. Underwood, and J. J. Loor. 2005. Physiological and pathological adaptations in dairy cows that may increase susceptibility to periparturient diseases and disorders. Ital. J. Anim. Sci. $4: 323-344$.

Duehlmeier, R., A. Hacker, A. Widdel, W. von Engelhardt, and H. Sallmann. 2005. Mechanisms of insulin-dependent glucose transport into porcine and bovine skeletal muscle. Am. J. Physiol. Regul. Integr. Comp. Physiol. 289:187-197. 
Hara, A., and N. S. Radin. 1978. Lipid extraction of tissues with a low-toxicity solvent. Anal. Biochem. 90:420-426.

Hayashi, T., E. J. Boyko, M. J. McNeely, D. L. Leonetti, S. E. Kahn, and W. Y. Fujimoto. 2008. Visceral adiposity, not abdominal subcutaneous fat area, is associated with an increase in future insulin resistance in Japanese Americans. Diabetes 57:1269-1275.

Holtenius, K., S. Agenäs, C. Delavaud, and Y. Chilliard. 2003. Effects of feeding intensity during the dry period. 2. Metabolic and hormonal responses. J. Dairy Sci. 86:883-891.

Holtenius, P., and K. Holtenius. 2007. A model to estimate insulin sensitivity in dairy cows. Acta Vet. Scand. 49:29.

Horgaard, A., and T. E. H. Thaysen. 1929. Clinical investigation into the effect of the intravenous injection of insulin. Acta. Med. Scand. 72:92-95.

Hughes, J. P. 1962. A simplified instrument for obtaining liver biopsies in cattle. Am. J. Vet. Res. 23:1111-1113.

Jaakson, H., K. Ling, J. Samarütel, A. Ilves, T. Kaart, and O. Kärt. 2013. Blood glucose and insulin response of the glucose tolerance test in relation to dairy cow body condition and milk yield. Vet. Med. Zoot. T. 62:28-35.

Katz, A., S. S. Nambi, K. Mather, A. D. Baron, D. A. Follmann, G. Sullivan, and M. J. Quon. 2000. Quantitative insulin sensitivity check index: A simple, accurate method for assessing insulin sensitivity in humans. J. Clin. Endocrinol. Metab. 85:2402-2410.

Kerestes, M., V. Faigl, M. Kulcsár, O. Balogh, J. Földi, H. Fébel, Y. Chilliard, and G. Huszenicza. 2009. Periparturient insulin secretion and whole-body insulin responsiveness in dairy cows showing various forms of ketone pattern with or without puerperal metritis. Domest. Anim. Endocrinol. 37:250-261.

Klöting, N., M. Fasshauer, A. Dietrich, P. Kovacs, M. R. Schön, M. Kern, M. Stumvoll, and M. Blüher. 2010. Insulin-sensitivity obesity. Am. J. Physiol. Endocrinol. Metab. 299:E506E515.

Le Foll, C., and B. E. Levin. 2016. Fatty acid-induced astrocyte ketone production and the control of food intake. Am. J. Physiol. Regul. Integr. Comp. Physiol.

Morrow, D. A. 1976. Fat cow syndrome. J. Dairy Sci. 59:1625-1629.

McCann, J. P., and T. J. Reimers. 1985. Glucose response to exogenous insulin and kinetics of insulin metabolism in obese and lean heifers. J. Anim. Sci. 61:612-618. 
Mann, S., F. A. Leal Yepes, M. Duplessis, J. J. Wakshlag, T. R. Overton, B. P. Cummings, and D. V. Nydam. 2016. Dry period plane of energy: Effects on glucose tolerance in transition dairy cows. J. Dairy Sci. 99:701-717.

Mann, S., F. A. Yepes, T. R. Overton, J. J. Wakshlag, A. L. Lock, C. M. Ryan, and D. V. Nydam. 2015. Dry period plane of energy: Effects on feed intake, energy balance, milk production, and composition in transition dairy cows. J. Dairy Sci. 98:3366-3382.

Muniyappa, R., S. Lee, H. Chen, and M. J. Quon. 2007. Current approaches for assessing insulin sensitivity and resistance in vivo: advantages, limitations, and appropriate usage. Am. J. Physiol. Endocrinol. Metab. 294:E15-E26.

Perseghin, G., A. Caumo, M. Caloni, G. Testolin, and L. Luzi. 2001. Incorporation of the fasting plasma FFA concentration into QUICKI improves its association with insulin sensitivity in nonobese individuals. J. Clin. Endocrinol. Metab. 86:4776-4781.

Pethick, D. W. 2005. Fat metabolism and turnover. Pages 345-371 in Quantitative Aspects of Ruminant Digestion and Metabolism. $2^{\text {nd }}$ ed. J. Dijkstra, J. M. Forbes, and J. France, ed. CABI, Cambridge, MA.

Piepenbrink, M. S., and T. R. Overton. 2003. Liver metabolism and production of cows fed increasing amounts of rumen-protected choline during the periparturient period. J. Dairy Sci. 86:1722-1733.

Pires, J. A., A. H. Souza, and R. R. Grummer. 2007. Induction of hyperlipidemia by intravenous infusion of tallow emulsion causes insulin resistance in Holstein cows. J. Dairy Sci. 90:2735-2744.

Rukkwamsuk, T., T. A. M. Kruip, and T. Wensing. 1999. Relationship between overfeeding and overconditioning in the dry period and the problems of high-producing dairy cows during the postparturient period. Vet. Q. 21:71-77.

Reaven, G. M., C. Hollenbeck, C. -Y. Jeng, M. S. Wu, and Y. -D. I. Chen. 1988. Measurement of plasma glucose, free fatty acid, lactate, and insulin for $24 \mathrm{~h}$ in patients with NIDDM. Diabetes 37:1020-1024.

Rico, J. E., V. V. Bandaru, J. M. Dorskind, N. J. Haughey, and J. W. McFadden. 2015. Plasma ceramides are elevated in overweight Holstein dairy cows experiencing greater lipolysis and insulin resistance during the transition from late pregnancy to early lactation. J. Dairy Sci. 98:1-14.

Roche, J. R., J. K. Kay, N. C. Friggens, J. J. Loor, and D. P. Berry. 2013. Assessing and managing body condition score for the prevention of metabolic disease in dairy cows. Vet. Clin. North Am. Food Anim. Pract. 29:323-336. 
Ross, R., J. Aru, J. Freeman, R. Hudson, and I. Janssen. 2001. Abdominal adiposity and insulin resistance in obese men. Am. J. Physiol. Endocrinol. Metab. 282:E657-E663.

Samocha-Bonet, D., L. V. Campbell, T. A. Mori, K. D. Croft, J. R. Greenfield, N. Turner, and L. K. Heilbronn. 2012. Overfeeding reduces insulin sensitivity and increases oxidative stress, without altering markers of mitochondrial content and function in humans. PLoS ONE. $7: 36320$.

Schoenberg, K. M., R. M. Ehrhardt, and T. R. Overton. 2012. Effects of plane of nutrition and feed deprivation on insulin responses in dairy cattle during late gestation. J. Dairy Sci. 95:670682.

Schoenberg, K. M., and T. R. Overton. 2011. Effects of plane of nutrition and 2,4thiazolidinedione on insulin responses and adipose tissue gene expression in dairy cattle during late gestation. J. Dairy Sci. 94:6021-6035.

Thévenod, F. 2008. Pathophysiology of diabetes mellitus type 2: Roles of obesity, insulin resistance and $\beta$-Cell dysfunction. Front Diabetes. Pages 1-18 in Diabetes and Cancer: Epidemiological Evidence and Molecular Links. Vol. 19. K. Masur, F. Thévenod, and K. S. Zänker, ed. Karger, Basel, Switzerland.

Wildman, E. E., G. M. Jones, P. E. Wagner, and R. L. Bowman. 1982. A dairy cow body condition scoring system and its relationship to selected production characteristics. J. Dairy Sci. 65:495-501.

Zachut, M., H. Honig, S. Striem, Y. Zick, S. Boura-Halfon, and U. Moallem. 2013. Periparturient dairy cows do not exhibit hepatic insulin resistance, yet adipose-specific insulin resistance occurs in cows prone to high weight loss. J. Dairy Sci. 96:5656-5669.

Zhao, F. Q., W. M. Moseley, H. A. Tucker, and J. J. Kennelly. 2006. Regulation of glucose transporter gene expression in mammary gland, muscle, and fat of lactating cows by administration of bovine growth hormone and bovine growth hormone-releasing factor. $\mathbf{J}$. Anim. Sci. 74:183-189. 

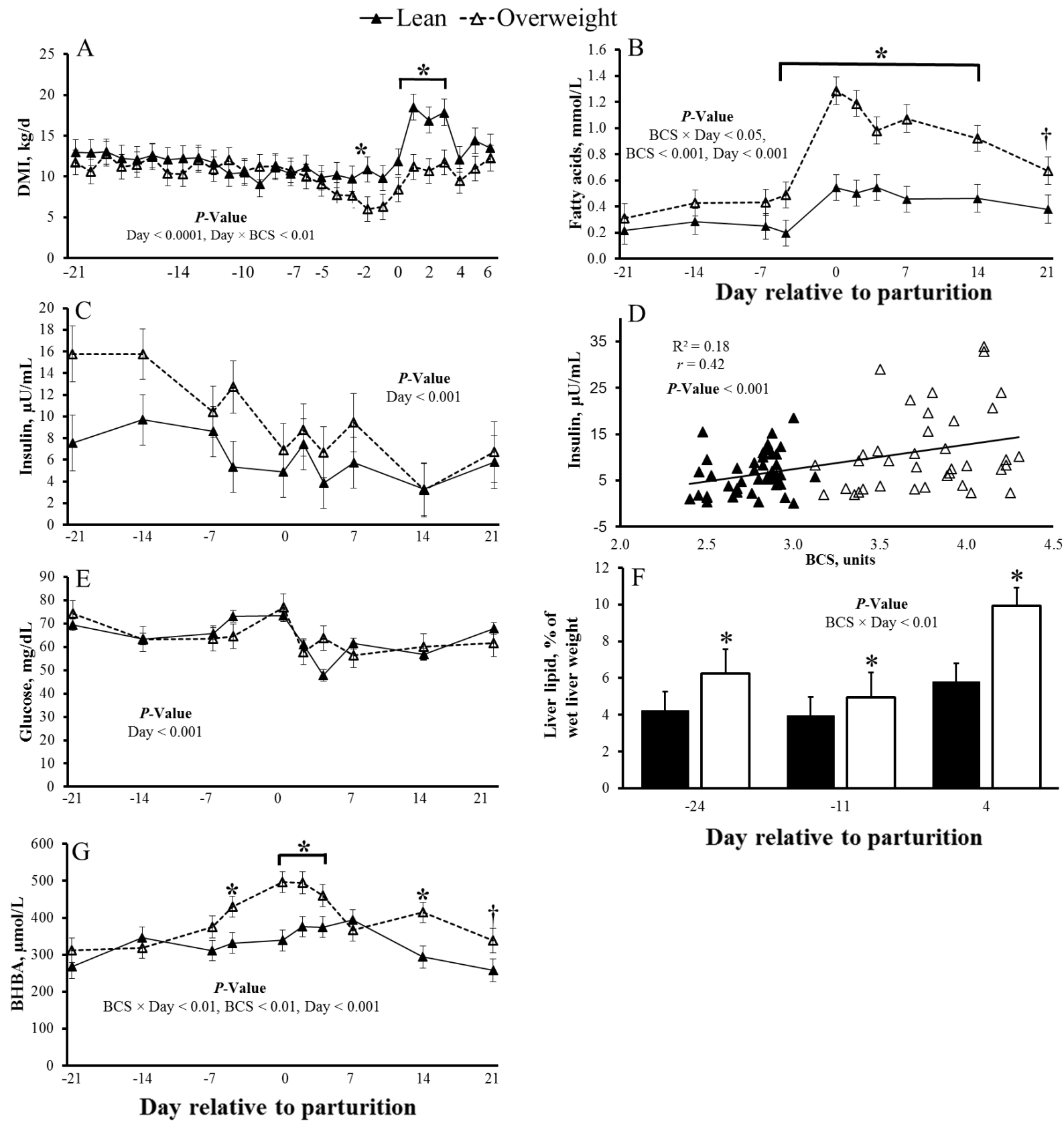

Day relative to parturition

Figure 3-1. Metabolic health in lean and overweight dairy cows transitioning from gestation to lactation. (A) Continuous DMI (kg/d). Plasma concentrations of (B) FA, (C) insulin, (D) regression analysis of plasma insulin and BCS units, and (E) plasma concentrations of glucose. (F) Percent liver lipid and $(\mathrm{G})$ plasma concentrations of BHBA. Adiposity groups differed at each time point: $*, P<0.05 ; \dagger, P<0.10$. Data are represented as least squares means and their standard errors. 

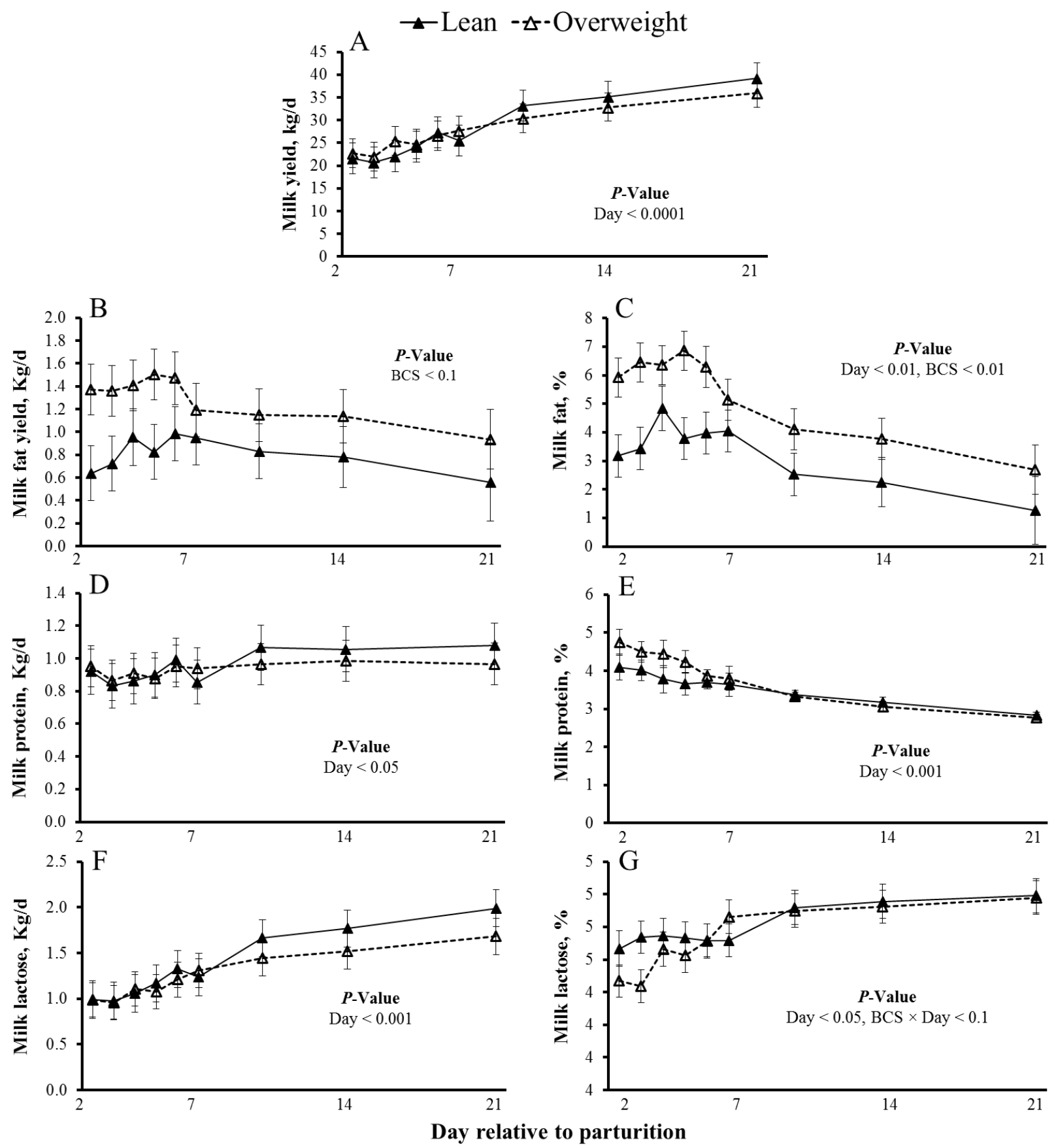

Figure 3-2. Milk production data collected from postpartum lean and overweight dairy cows transitioning from gestation to lactation. (A) The continuous evaluation of milk yield. Early lactation yields $(\mathrm{kg} / \mathrm{d})$ of milk (B) fat, (C) protein, and (D) lactose in cows assigned as lean or overweight -28 d prior to expected parturition. Differences in percent milk (E) fat, $(F)$ protein, and (G) lactose. Data are represented as least squares means and their standard errors. 
$\neg$ Lean $-\Delta$-Overweight
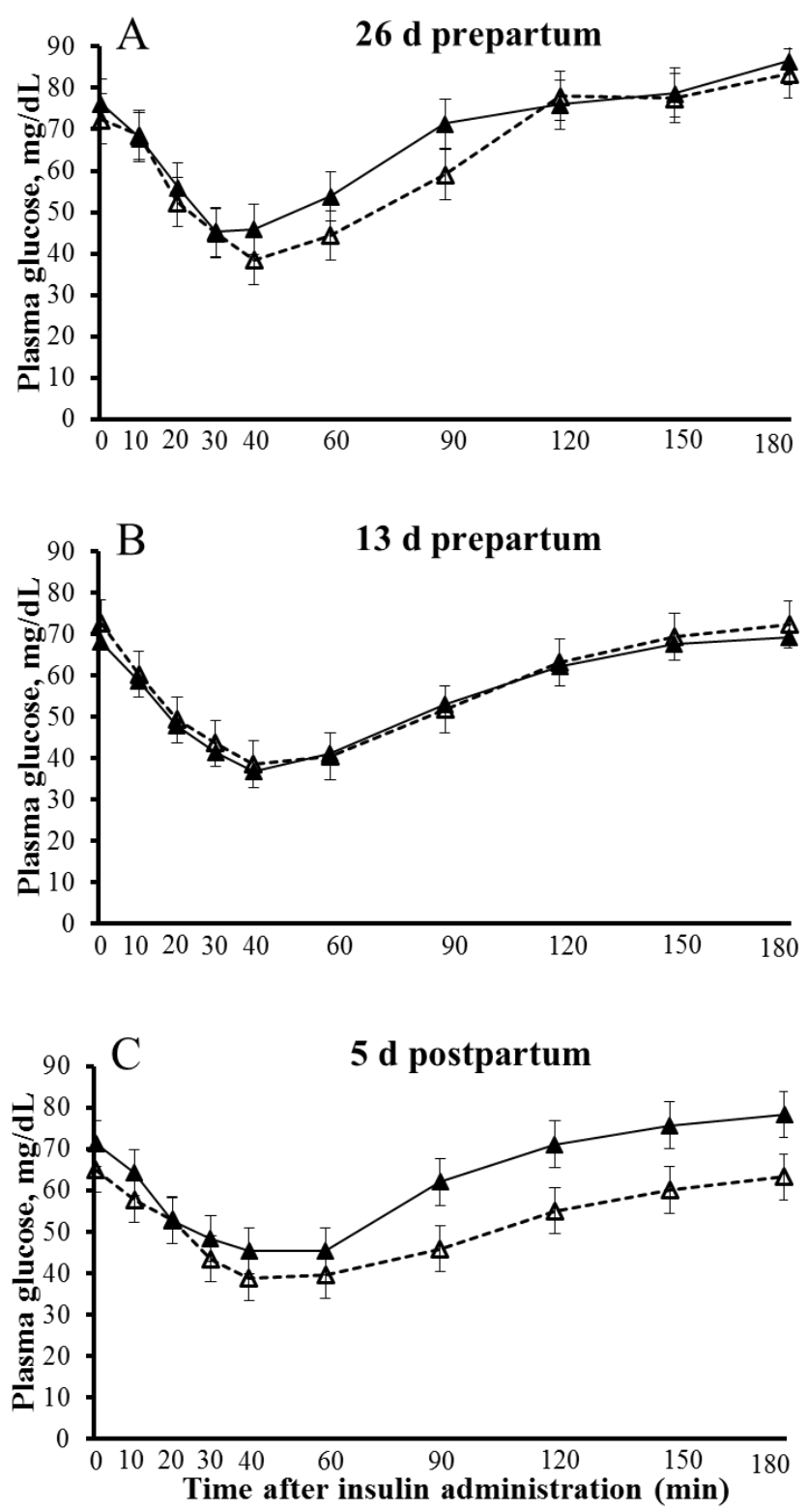

Figure 3-3. Plasma concentrations of glucose during an intravenous insulin tolerance test (ITT) performed in lean or overweight peripartal cows. Insulin tolerance testing was completed at (A) 26 and (B) $13 \mathrm{~d}$ prepartum, and (C) $5 \mathrm{~d}$ postpartum. Baseline measurements represent the average of samples collected at -10 and 0 min relative to intravenous administration of $0.01 \mathrm{IU}$ of insulin per $\mathrm{kg}$ of BW. Fixed effects in model: BCS (not significant), Day $<0.001$, and BCS $\times$ Day $<0.01$. Adiposity groups differed at each time point: $*, P<0.05 ; \dagger, P<0.10$. Data are represented as least squares means and their standard errors. 

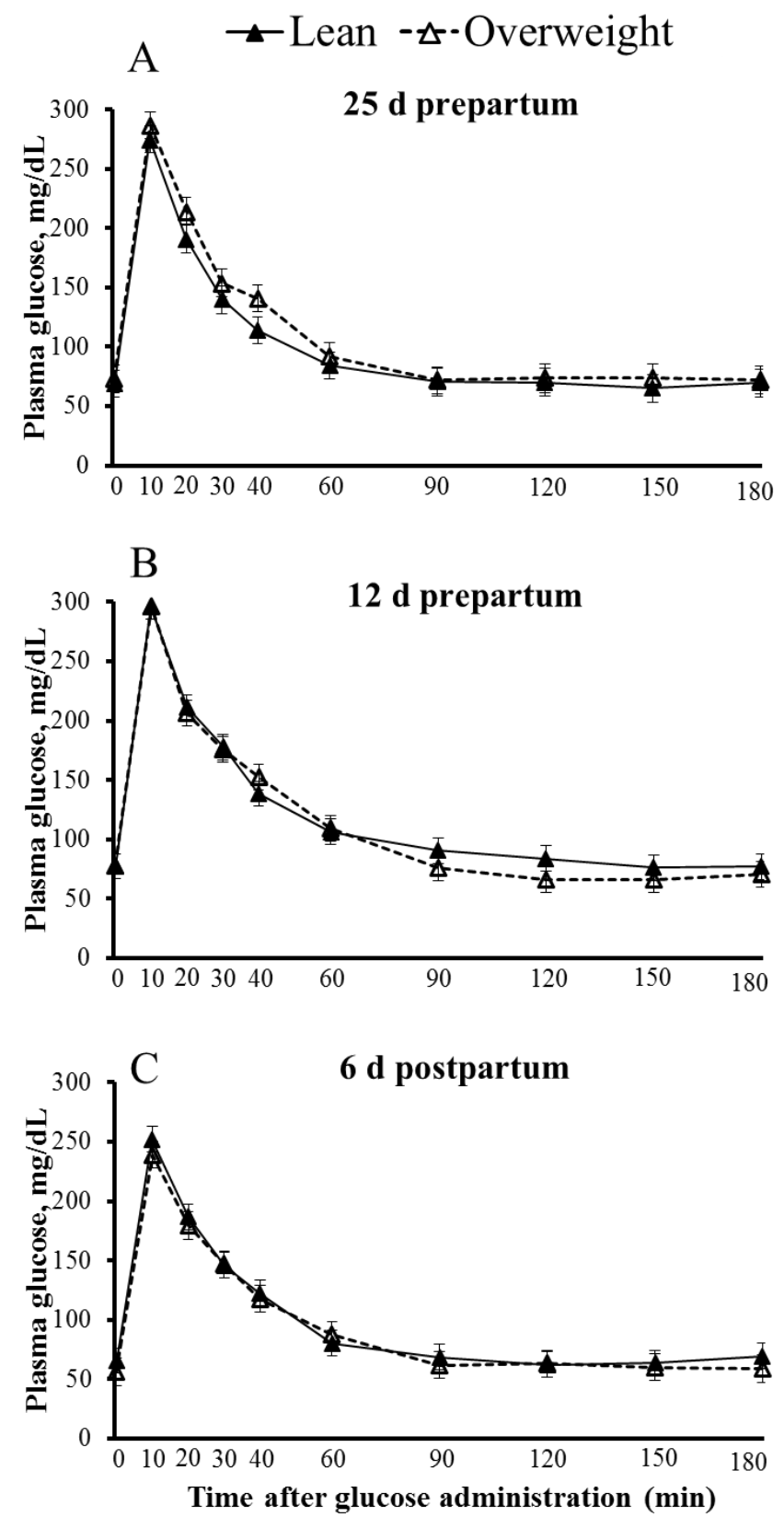

Figure 3-4. Plasma concentrations of glucose during an intravenous glucose tolerance test (GTT) performed in lean or overweight peripartal cows. Glucose tolerance testing was completed at (A) 25 and (B) $12 \mathrm{~d}$ prepartum, and (C) $6 \mathrm{~d}$ postpartum. Baseline measurements represent the average of samples collected at -10 and 0 min relative to intravenous administration of $300 \mathrm{mg}$ of dextrose per kg of BW. Fixed effects in model: BCS (not significant), Day $<0.001$, and BCS $\times$ Day $<0.05$. Adiposity groups differed at each time point: $\dagger, P<0.10$. Data are represented as least squares means and their standard errors. 
$\neg$ Lean $-\bowtie$-Overweight
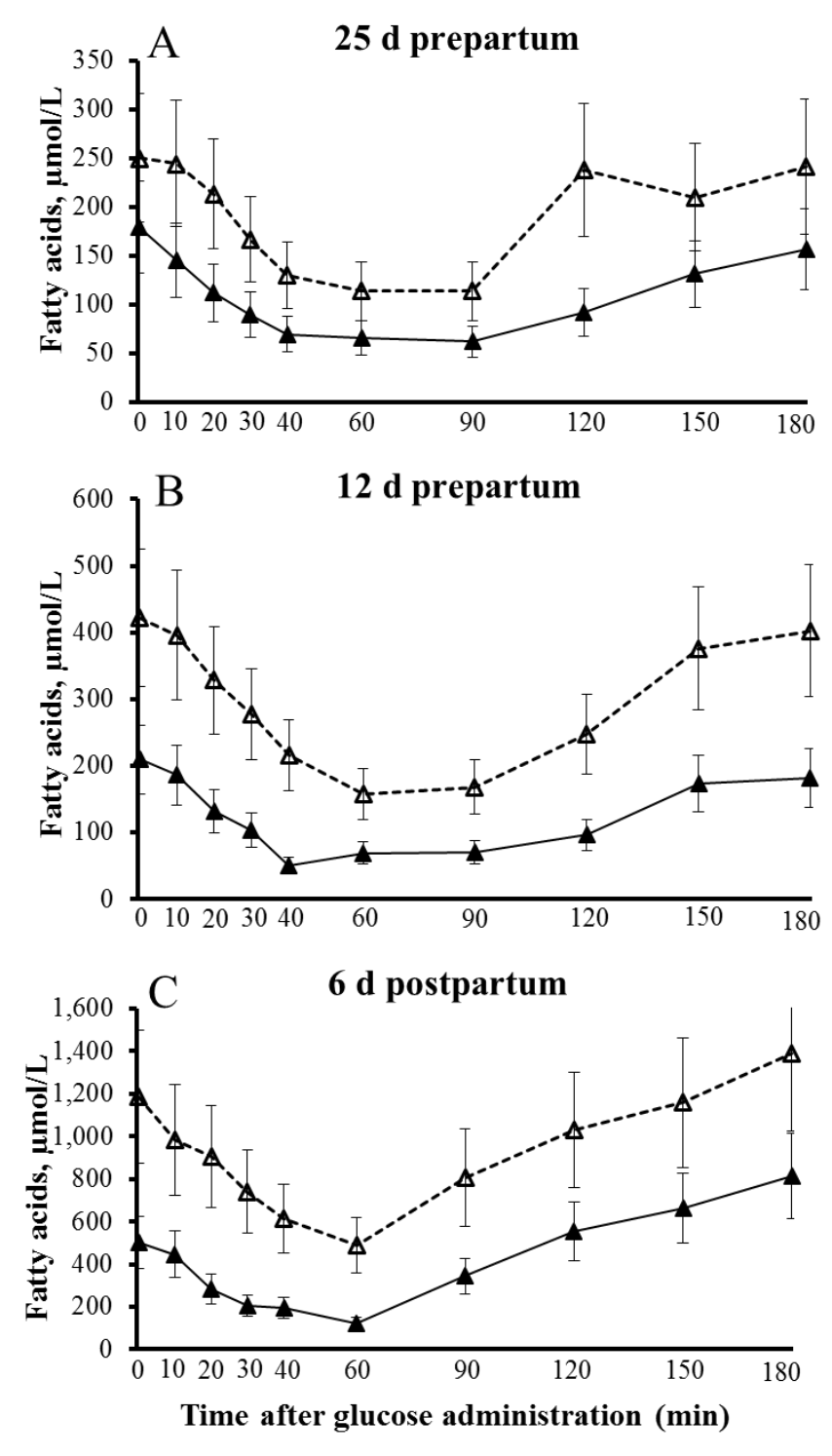

Figure 3-5. Changes in plasma FA concentrations during an intravenous glucose tolerance test (GTT) performed in lean and overweight peripartal cows. Plasma FA concentrations during GTT completed on d (A) 25 and (B) 12 prepartum, and (C) d 6 postpartum. Baseline measurements represent the average of samples collected at -10 and 0 min relative to intravenous administration of $300 \mathrm{mg}$ of dextrose per $\mathrm{kg}$ of BW. Fixed effects in model: BCS $<0.001$, Day $<0.001$, and BCS $\times$ Day $<0.001$. Adiposity groups differed at each time point: ${ }^{*}, P<0.05 ; \dagger, P<0.10$. Data are represented as least squares means and their standard errors. 

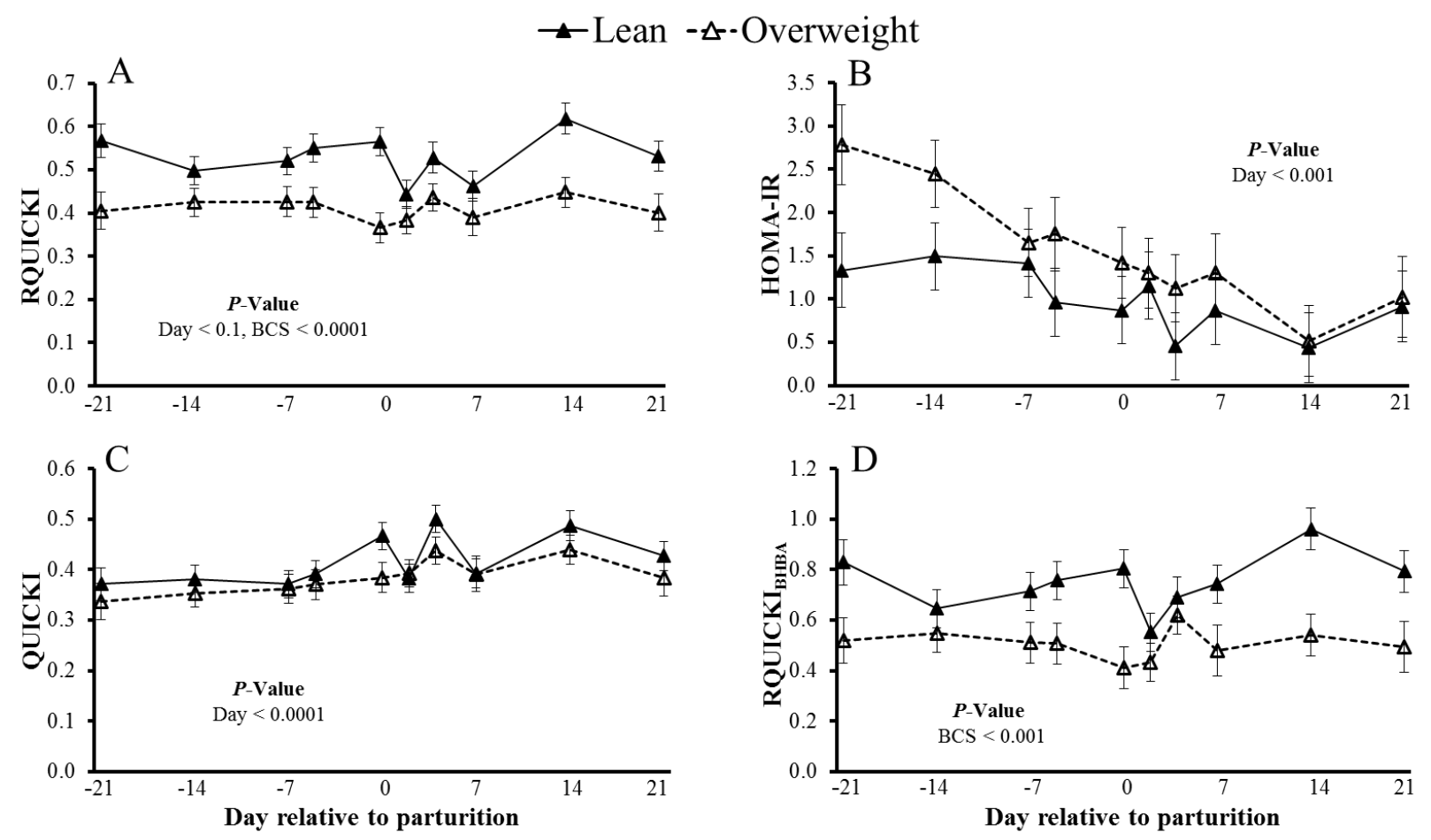

Figure 3-6. Surrogate indices of insulin sensitivity in lean and overweight periparturient dairy cows. Estimated insulin sensitivity as measured by the (A) revised quantitative insulin sensitivity check index (RQUICKI), (B) homeostasis model of insulin resistance (HOMA-IR), (C) QUICKI and (D) RQUICKI including BHBA (RQUICKIBHBA). Description of abbreviations can be found within Table 2. Data are represented as least squares means and their standard errors. 
Table 3-1. Ingredient and nutrient composition of diets.

\begin{tabular}{lcc}
\hline & \multicolumn{2}{c}{ Diets } \\
\cline { 2 - 3 } Item & Gestation & Lactation \\
\hline Ingredient (\% DM) & & \\
Corn silage & 30.7 & 42.4 \\
Grass haylage & 28.4 & 7.0 \\
Grass hay & 13.2 & 2.1 \\
Dry ground corn & - & 14.4 \\
Prepartum mix ${ }^{1}$ & 13.9 & - \\
Lactation mix A & - & 14.0 \\
Soybean meal & 9.0 & 4.7 \\
Cottonseed with lint & - & 4.5 \\
Sugar cane syrup & - & 3.6 \\
Lactation mix B & - & 4.5 \\
Close-up supplement & 4 \\
Rumensin mix & 4.8 & 2.7 \\
Nutrient composition & - & 0.1 \\
DM, \% & 55.5 & \\
NDF & 48.3 & 51.6 \\
Forage NDF & 43.7 & 37.6 \\
Forage NDF, \% of NDF & 90.5 & 25.1 \\
ADF & 32.0 & 66.7 \\
CP & 12.2 & 25.2 \\
Starch & 14.1 & 16.5 \\
Crude fat & 3.16 & 21.2 \\
Ash & 7.5 & 4.33 \\
NEl, Mcal/kg DM & 1.44 & 7.3 \\
\hline
\end{tabular}

${ }^{1}$ Mix contained 27\% commercial dry cow mix with Animate (Phibro Animal Health Corp., Teaneck, NJ), $17.3 \%$ ground corn, $17.3 \%$ crimped oats, $13 \%$ corn distillers, $12.9 \%$ soybean meal, $4.3 \%$ calcium carbonate, $4.3 \%$ calcium sulfate, 2.6\% Omnigen AF (Phibro Animal Health Corp.), 1.1 Monocalcium phosphate, and <1\% of each of the following: Sel-plex 600 (Alltech Biotechnology, Nicholasville, KY) and vitamin E.

${ }^{2}$ Mix contained $33.6 \%$ citrus pulp, $19 \%$ soybean meal, $15.6 \%$ canola meal, $14 \%$ soybean hulls, $4.5 \%$ calcium carbonate, $4.5 \%$ sodium bicarbonate, $2.8 \%$ urea, $2.7 \%$ fat, $2.4 \%$ sodium chloride, and $<1 \%$ from each of the following: Monocalcium phosphate, biotin, and Rumensin 90 (Elanco Animal Health, Greenfield, IN).

${ }^{3}$ Mix contained $43.6 \%$ Fermenten (Church and Dwight Co., Princeton, NJ), 21.8\% calcium carbonate, $10.8 \%$ soybean hulls, $7.8 \%$ Mintrex blend (Novus International Inc., St. Charles, MO), 5.2\% blood meal, 3.5\% magnesium oxide, 2.6\% Celmanax (Vi-COR, Mason City, IA), 2.6\% Omnigen (Phibro Animal Health Corp.), and $<1 \%$ of each of the following: vitamin E, selenium selenite, and selenium yeast 600 . ${ }^{4}$ Mix contained $74.5 \%$ ground oats, $15.3 \%$ commercial amino acid, $8 \%$ Reashure (Balchem Encapsulates, Slate Hill, NY), and $<1 \%$ of each of the following: vitamin E and Niashure (Balchem Corporation, New Hampton, NY).

${ }^{5}$ Rumensin for dairy included at $4,890 \mathrm{mg} / \mathrm{kg}$. 
Table 3-2. Insulin tolerance test (ITT) parameters for plasma glucose in lean and overweight cows during late gestation and early lactation. ${ }^{1}$

\begin{tabular}{|c|c|c|c|c|c|c|}
\hline \multirow[b]{2}{*}{ Item } & \multicolumn{2}{|c|}{ BCS } & \multirow[b]{2}{*}{ SEM } & \multicolumn{3}{|c|}{$P$-value } \\
\hline & Lean & Overweight & & BCS & Period & BCS $\times$ Period \\
\hline Basal glucose concentration (mg/dL) & & & & 0.71 & 0.48 & 0.53 \\
\hline-26 & 76.5 & 72.4 & 4.11 & & & \\
\hline-13 & 68.1 & 72.5 & 3.79 & & & \\
\hline+5 & 71.2 & 65.1 & 3.79 & & & \\
\hline $\begin{array}{l}\text { Minimum glucose concentration } \\
(\mathrm{mg} / \mathrm{dL})\end{array}$ & & & & 0.36 & 0.55 & 0.70 \\
\hline-26 & 44.7 & 36.9 & 3.36 & & & \\
\hline-13 & 35.9 & 35.8 & 3.08 & & & \\
\hline+5 & 39.7 & 36.7 & 3.08 & & & \\
\hline $\begin{array}{l}\text { Maximum glucose concentration } \\
(\mathrm{mg} / \mathrm{dL})\end{array}$ & & & & 0.53 & 0.12 & 0.35 \\
\hline-26 & 87.3 & 86.8 & 4.82 & & & \\
\hline-13 & 73.3 & 75.7 & 4.45 & & & \\
\hline+5 & 84.1 & 70.5 & 4.45 & & & \\
\hline Glucose $\mathrm{CR}^{2}(\% / 10 \mathrm{~min})$ & & & & 0.97 & 0.23 & 0.78 \\
\hline-26 & 1.03 & 0.51 & 0.49 & & & \\
\hline-13 & 1.73 & 2.07 & 0.45 & & & \\
\hline+5 & 1.01 & 1.25 & 0.43 & & & \\
\hline Glucose CR (\%/20 min) & & & & 0.88 & 0.52 & 0.74 \\
\hline-26 & 1.46 & 1.75 & 0.32 & & & \\
\hline-13 & 1.77 & 1.97 & 0.30 & & & \\
\hline+5 & 1.55 & 1.23 & 0.29 & & & \\
\hline Glucose CR (\%/30 min) & & & & 0.91 & 0.55 & 0.79 \\
\hline-26 & 1.83 & 1.62 & 0.22 & & & \\
\hline-13 & 1.65 & 1.77 & 0.20 & & & \\
\hline+5 & 1.35 & 1.53 & 0.20 & & & \\
\hline Glucose CR (\%/40 min) & & & & 0.21 & 0.39 & 0.71 \\
\hline-26 & 1.17 & 1.57 & 0.15 & & & \\
\hline-13 & 1.51 & 1.62 & 0.14 & & & \\
\hline+5 & 1.25 & 1.36 & 0.13 & & & \\
\hline $\mathrm{ISRG}^{3}(\mathrm{mg} / \mathrm{dL})$ & & & & 0.62 & 0.41 & 0.51 \\
\hline-26 & 32.0 & 35.1 & 2.72 & & & \\
\hline-13 & 32.2 & 36.7 & 2.52 & & & \\
\hline+5 & 31.6 & 28.4 & 2.52 & & & \\
\hline Glucose $\mathrm{AUC}^{4}$ (mg $\left.40 \mathrm{~min} / \mathrm{dL}\right)$ & & & & 0.54 & 0.28 & 0.66 \\
\hline-26 & 2163 & 1930 & 136 & & & \\
\hline-13 & 1730 & 1797 & 125 & & & \\
\hline+5 & 1952 & 1800 & 125 & & & \\
\hline Glucose AUC (mg 40 to $180 \mathrm{~min} / \mathrm{dL}$ ) & & & & 0.20 & 0.09 & 0.40 \\
\hline-26 & 9559 & 8740 & 557 & & & \\
\hline-13 & 7580 & 7652 & 512 & & & \\
\hline+5 & 8675 & 6832 & 512 & & & \\
\hline
\end{tabular}


Table 3-3. Glucose tolerance test (GTT) parameters for plasma glucose in lean and overweight cows during late gestation and early lactation. ${ }^{1}$

\begin{tabular}{|c|c|c|c|c|c|c|}
\hline \multirow[b]{2}{*}{ Item } & \multicolumn{2}{|c|}{ BCS } & \multirow[b]{2}{*}{ SEM } & \multicolumn{3}{|c|}{$P$-value } \\
\hline & Lean & Overweight & & $\mathrm{BCS}$ & Period & BCS $\times$ Period \\
\hline Basal glucose concentration $(\mathrm{mg} / \mathrm{dL})$ & & & & 0.70 & 0.01 & 0.57 \\
\hline-25 & 70.5 & 71.4 & 4.55 & & & \\
\hline-12 & 77.2 & 77.2 & 4.26 & & & \\
\hline+6 & 65.5 & 56.7 & 4.41 & & & \\
\hline Minimum glucose concentration (mg/dL) & & & & 0.79 & 0.15 & 0.86 \\
\hline-25 & 64.4 & 63.2 & 4.31 & & & \\
\hline-12 & 68.1 & 63.7 & 3.97 & & & \\
\hline+6 & 54.9 & 56.3 & 4.14 & & & \\
\hline Maximum glucose concentration (mg/dL) & & & & 0.96 & 0.07 & 0.89 \\
\hline-25 & 276 & 285 & 16.2 & & & \\
\hline-12 & 296 & 295 & 14.9 & & & \\
\hline+6 & 251 & 240 & 15.6 & & & \\
\hline Glucose $\mathrm{CR}^{2}(\% / 30 \mathrm{~min})$ & & & & 0.35 & 0.02 & 0.82 \\
\hline-25 & 3.30 & 3.10 & 0.18 & & & \\
\hline-12 & 2.55 & 2.52 & 0.16 & & & \\
\hline+6 & 2.74 & 2.41 & 0.17 & & & \\
\hline Glucose CR (\%/60 min) & & & & 0.24 & 0.19 & 0.53 \\
\hline-25 & 2.33 & 2.32 & 0.12 & & & \\
\hline-12 & 2.07 & 1.95 & 0.11 & & & \\
\hline+6 & 2.34 & 1.96 & 0.12 & & & \\
\hline $\mathrm{T}_{1 / 2}^{3}(\min )$ & & & & 0.34 & 0.21 & 0.58 \\
\hline-25 & 31.1 & 30.2 & 2.15 & & & \\
\hline-12 & 34.6 & 37.3 & 1.99 & & & \\
\hline+6 & 31.1 & 36.4 & 2.07 & & & \\
\hline $\mathrm{T}_{\text {basal }}{ }^{4}(\min )$ & & & & 0.89 & 0.93 & 0.02 \\
\hline-25 & 110 & 110 & 3.92 & & & \\
\hline-12 & 117 & 103 & 3.47 & & & \\
\hline+6 & 101 & 116 & 3.61 & & & \\
\hline Glucose $\mathrm{AUC}^{5}(\mathrm{mg} 180 \mathrm{~min} / \mathrm{dL})$ & & & & 0.97 & 0.06 & 0.64 \\
\hline-25 & 17090 & 18110 & 948 & & & \\
\hline-12 & 19938 & 18791 & 878 & & & \\
\hline+6 & 16150 & 16168 & 915 & & & \\
\hline
\end{tabular}

${ }^{1}$ Data represent GTT performed at d 25 and 12 prepartum, and d 6 postpartum.

${ }^{2} \mathrm{CR}=$ clearance rate.

${ }^{3} \mathrm{~T}_{1 / 2}=$ time to reach half maximal glucose concentration.

${ }^{4} \mathrm{~T}_{\text {basal }}=$ time to reach basal glucose concentration.

${ }^{5} \mathrm{AUC}=$ area under the curve 
Table 3-4. Glucose tolerance test (GTT) parameters for plasma FA in lean and overweight cows during late gestation and early lactation. ${ }^{1}$

\begin{tabular}{|c|c|c|c|c|c|c|}
\hline \multirow[b]{2}{*}{ Item } & \multicolumn{2}{|c|}{ BCS } & \multirow[b]{2}{*}{ SEM } & \multicolumn{3}{|c|}{$P$-value } \\
\hline & Lean & Overweight & & BCS & Period & BCS $\times$ Period \\
\hline Basal FA concentration $(\mathrm{mmol} / \mathrm{L})$ & & & & 0.001 & 0.001 & 0.54 \\
\hline-25 & 179 & 244 & 1.19 & & & \\
\hline-12 & 209 & 421 & 1.17 & & & \\
\hline+6 & 501 & 1153 & 1.18 & & & \\
\hline Minimum FA concentration (mmol/L) & & & & 0.001 & 0.01 & 0.53 \\
\hline-25 & 55.4 & 98.2 & 1.32 & & & \\
\hline-12 & 39.6 & 143 & 1.30 & & & \\
\hline+6 & 116 & 466 & 1.31 & & & \\
\hline Maximum FA concentration $(\mathrm{mmol} / \mathrm{L})$ & & & & 0.01 & 0.001 & 0.88 \\
\hline-25 & 164 & 280 & 1.15 & & & \\
\hline-12 & 232 & 467 & 1.13 & & & \\
\hline+6 & 814 & 1435 & 1.14 & & & \\
\hline $\mathrm{FA} \mathrm{CR}^{2}(\% / 20 \mathrm{~min})$ & & & & 0.07 & 0.60 & 0.35 \\
\hline-25 & 2.21 & 0.66 & 0.33 & & & \\
\hline-12 & 2.29 & 1.25 & 0.32 & & & \\
\hline+6 & 1.80 & 1.30 & 0.33 & & & \\
\hline FA CR $(\% / 40 \mathrm{~min})$ & & & & 0.08 & 0.99 & 0.99 \\
\hline-25 & 2.39 & 1.63 & 0.24 & & & \\
\hline-12 & 2.37 & 1.67 & 0.24 & & & \\
\hline+6 & 2.37 & 1.67 & 0.24 & & & \\
\hline $\mathrm{T}_{1 / 2}^{3}(\mathrm{~min})$ & & & & 0.62 & 0.26 & 0.41 \\
\hline-25 & 47.1 & 50.0 & 4.89 & & & \\
\hline-12 & 41.3 & 44.5 & 4.32 & & & \\
\hline+6 & 36.0 & 52.8 & 4.67 & & & \\
\hline GSRF $(\% \text { from basal })^{4}$ & & & & 0.07 & 0.33 & 0.78 \\
\hline-25 & 67.09 & 58.05 & 5.40 & & & \\
\hline-12 & 72.90 & 65.47 & 5.01 & & & \\
\hline+6 & 71.16 & 57.51 & 5.40 & & & \\
\hline FA AUC ${ }^{5}(\mathrm{mmol} 60 \mathrm{~min} / \mathrm{L})$ & & & & 0.001 & 0.001 & 0.02 \\
\hline-25 & 5651.88 & 10417 & 2439.77 & & & \\
\hline-12 & 6420.43 & 15432 & 2194.77 & & & \\
\hline+6 & 16729 & 41733 & 2406.49 & & & \\
\hline FA AUC (mmol $90 \mathrm{~min} / \mathrm{L})$ & & & & 0.001 & 0.001 & 0.03 \\
\hline-25 & 7578.86 & 13988 & 3538.22 & & & \\
\hline-12 & 8470.43 & 20037 & 3201.49 & & & \\
\hline+6 & 24681 & 58406 & 3500.15 & & & \\
\hline FA AUC (mmol $180 \mathrm{~min} / \mathrm{L})$ & & & & 0.001 & 0.001 & 0.02 \\
\hline-25 & 18422 & 31266 & 8653.79 & & & \\
\hline-12 & 21718 & 47505 & 8011.85 & & & \\
\hline+6 & 77427 & 158890 & 8653.79 & & & \\
\hline
\end{tabular}

${ }^{1}$ Data represent GTT performed at $\mathrm{d} 25$ and 12 prepartum, and d 6 postpartum.

${ }^{2} \mathrm{CR}=$ clearance rate.

${ }^{3} \mathrm{~T}_{1 / 2}=$ time to reach half maximal glucose concentration.

${ }^{4} \mathrm{GSRF}=$ glucose-stimulated reductions in FA.

${ }^{5} \mathrm{AUC}=$ area under the curve 
Table 3-5. Relationship between surrogate indices for insulin sensitivity ${ }^{1}$.

\begin{tabular}{lcccccccc}
\hline & \multicolumn{2}{c}{ RQUICKI } & \multicolumn{2}{c}{ HOMA-IR } & \multicolumn{2}{c}{ QUICKI } & \multicolumn{2}{c}{ RQUICKI Item $^{2}$} \\
\cline { 2 - 9 } & $\rho$ & $P$-value & $\rho$ & $P$-value & $\rho$ & $P$-value & $\rho$ & $P$-value \\
\hline RQUICKI & 1 & & -0.63 & 0.001 & 0.64 & 0.001 & 0.95 & 0.001 \\
HOMA-IR & -0.63 & 0.001 & 1 & & -0.99 & 0.001 & -0.49 & 0.01 \\
QUICKI & 0.64 & 0.001 & -0.99 & 0.001 & 1 & & 0.51 & 0.001 \\
RQUICKI $_{\text {BHBA }}$ & 0.95 & 0.001 & -0.49 & 0.01 & 0.51 & 0.001 & 1 &
\end{tabular}

${ }^{1}$ Data represent basal plasma samples collected in lean and overweight cows prior to intravenous glucose tolerance tests at $\mathrm{d} 21$ and 14 prepartum, and $\mathrm{d} 4$ postpartum.

${ }^{2} \mathrm{QUICKI}=$ quantitative insulin sensitivity check, $\{1 /[\log$ glucose $(\mathrm{mg} / \mathrm{dL})+\log$ insulin $(\mu \mathrm{U} / \mathrm{mL})]\}, \mathrm{RQUICKI}=$ revised QUICKI, $\{1 /[\log$ glucose $(\mathrm{mg} / \mathrm{dL})+\log$ insulin $(\mu \mathrm{U} / \mathrm{mL})+\log \mathrm{FA}(\mathrm{mmol} / \mathrm{L})]\}, \mathrm{RQUICKI}_{\mathrm{BHBA}}=$ RQUICKI including BHBA, $\{1 /[\log$ glucose $(\mathrm{mg} / \mathrm{dL})+\log$ insulin $(\mu \mathrm{U} / \mathrm{mL})+\log \mathrm{FA}(\mathrm{mmol} / \mathrm{L})+\log$ BHBA $(\mathrm{mmol} / \mathrm{L})]\}$, and HOMA-IR $=$ homeostasis model of insulin resistance, $\{[$ glucose $(\mathrm{mmol} / \mathrm{L}) \times \mathrm{insulin}(\mu \mathrm{U} / \mathrm{mL})] /$ $22.5\}$. 
Table 3-6. Comparison of tolerance testing glucose parameters and surrogate indices of insulin sensitivity in peripartal dairy cows. ${ }^{1}$

\begin{tabular}{|c|c|c|c|c|c|c|c|c|}
\hline \multirow[b]{2}{*}{ Item } & \multicolumn{2}{|c|}{ RQUICKI } & \multicolumn{2}{|c|}{ HOMA-IR } & \multicolumn{2}{|c|}{ QUICKI } & \multicolumn{2}{|c|}{ RQUICKI $_{\mathrm{BHBA}}$} \\
\hline & $\rho$ & $P$-value & $\rho$ & $P$-value & $\rho$ & $P$-value & $\rho$ & $P$-value \\
\hline \multicolumn{9}{|l|}{ Insulin tolerance $^{2}$} \\
\hline Glucose CR $(\% / 10 \mathrm{~min})^{3}$ & 0.38 & 0.02 & -0.26 & 0.11 & 0.25 & 0.12 & 0.32 & 0.05 \\
\hline Glucose CR (\%/20 min) & 0.14 & 0.40 & 0.03 & 0.87 & -0.03 & 0.86 & 0.08 & 0.61 \\
\hline Glucose CR (\%/30 min) & 0.24 & 0.14 & -0.06 & 0.70 & 0.03 & 0.83 & 0.16 & 0.32 \\
\hline Glucose CR (\%/40 min) & -0.01 & 0.96 & 0.16 & 0.34 & -0.15 & 0.36 & -0.02 & 0.91 \\
\hline ISRG $^{4}$ & -0.01 & 0.99 & 0.06 & 0.71 & -0.07 & 0.66 & 0.06 & 0.72 \\
\hline Glucose AUC (mg $40 \mathrm{~min} / \mathrm{dL})$ & -0.07 & 0.66 & 0.05 & 0.75 & -0.05 & 0.74 & 0.05 & 0.75 \\
\hline \multicolumn{9}{|l|}{ Glucose tolerance 5} \\
\hline Glucose CR (\%/30 min) & 0.20 & 0.22 & 0.10 & 0.54 & -0.12 & 0.44 & 0.15 & 0.34 \\
\hline Glucose CR (\%/60 min) & 0.16 & 0.32 & 0.03 & 0.82 & -0.06 & 0.69 & 0.15 & 0.35 \\
\hline $\mathrm{T}_{1 / 2}(\min )^{6}$ & -0.16 & 0.33 & -0.04 & 0.80 & 0.07 & 0.67 & -0.14 & 0.37 \\
\hline $\mathrm{T}_{\text {basal }}(\min )^{7}$ & 0.17 & 0.30 & -0.12 & 0.47 & 0.11 & 0.50 & 0.17 & 0.29 \\
\hline Glucose AUC $(\mathrm{mg} 180 \mathrm{~min} / \mathrm{dL})^{8}$ & -0.01 & 0.94 & 0.18 & 0.26 & -0.18 & 0.28 & -0.01 & 0.96 \\
\hline FA CR (\%/10 min $)$ & 0.24 & 0.16 & -0.32 & 0.05 & 0.32 & 0.05 & 0.34 & 0.05 \\
\hline FA CR (\%/20 min $)$ & 0.31 & 0.06 & -0.25 & 0.13 & 0.25 & 0.13 & 0.32 & 0.05 \\
\hline FA CR (\%/30 min $)$ & 0.11 & 0.50 & -0.12 & 0.46 & 0.12 & 0.46 & 0.14 & 0.38 \\
\hline FA CR (\%/40 min) & 0.12 & 0.47 & -0.08 & 0.62 & 0.08 & 0.63 & 0.19 & 0.26 \\
\hline FA AUC (mg $20 \mathrm{~min} / \mathrm{dL})$ & -0.05 & 0.74 & -0.38 & 0.02 & 0.38 & 0.02 & -0.11 & 0.49 \\
\hline FA AUC (mg $30 \mathrm{~min} / \mathrm{dL})$ & -0.06 & 0.73 & -0.37 & 0.02 & 0.37 & 0.02 & -0.12 & 0.46 \\
\hline FA AUC (mg $40 \mathrm{~min} / \mathrm{dL})$ & -0.07 & 0.65 & -0.34 & 0.04 & 0.34 & 0.04 & -0.14 & 0.41 \\
\hline
\end{tabular}

${ }^{1}$ Description of abbreviation can be found within table 1 .

${ }^{2} \mathrm{CR}=$ clearance rate.

${ }^{3}$ Data reflect samples collected at $\mathrm{d} 26$ and 13 prepartum, and d 5 postpartum.

${ }^{4}$ ISRG $=$ insulin-stimulated reductions in glucose.

${ }^{5}$ Data reflect samples collected at $\mathrm{d} 25$ and 12 prepartum, and d 6 postpartum.

${ }^{6} \mathrm{~T}_{1 / 2}=$ time to reach half maximal glucose concentration.

${ }^{7} \mathrm{~T}_{\text {basal }}=$ time to reach basal glucose concentration.

${ }^{8} \mathrm{AUC}=$ area under the curve. 


\title{
CHAPTER 4
}

\section{CHARACTERIZATION OF THE PLASMA LIPIDOME IN DAIRY CATTLE TRANSITIONING FROM GESTATION TO LACTATION: IDENTIFYING NOVEL BIOMARKERS OF METABOLIC IMPAIRMENT.}

\begin{abstract}
The discovery of novel biomarkers for metabolic disease can refine nutritional interventions aimed at improving dairy cow health and performance. Therefore, our objective was to characterize the plasma lipidome and identify metabolites associated with common markers of metabolic disease in peripartal dairy cattle. Twenty-seven multiparous Holstein cows were enrolled -28 d prepartum and fed diets formulated to meet or exceed requirements. Blood and liver samples were routinely collected from enrollment through d 14 postpartum. To characterize the plasma lipidome spanning nine time points, untargeted lipidomics was performed using quadrupole time-of-flight mass spectrometry. Univariate and multivariate analyses of normalized, auto-scaled lipidomic data were performed. Based on postpartum metabolic health data, cows were categorized into low or high free fatty acid area under the curve (FFA AUC $_{\text {; }}$ d 1 - 14 postpartum; $4,915 \pm 1,369$ vs. $12,501 \pm 2,761[\mu \mathrm{mol} / \mathrm{L} \times 14 \mathrm{~d}] ; \mathrm{n}=18), \beta$-hydroxybutyrate area under the curve (BHBA $_{\mathrm{AUC}} ; \mathrm{d} 1-14$ postpartum; 4,583 \pm 459 vs. $7901 \pm 1,206[\mu \mathrm{mol} / \mathrm{L} \times 14 \mathrm{~d}] ; \mathrm{n}=18$ ), or mean postpartum liver lipid content (d 5 and 14 postpartum; $5 \pm 1$ vs. $12 \pm 2 \%$ of wet weight; $n=18$ ). Significant variables associated with a specific category were identified based on leverage/squared prediction error plots. Lipidomics revealed 301 plasma lipids including 8 cholesterol esters, 163 phospholipids, and 130 acylglycerols. Independent of category, all cows displayed dramatic decreases in plasma triacylglycerols and monoalkyl-diacylglycerols $(P<0.01)$, and the majority of phospholipids reached a nadir at parturition $(P<0.01)$. Analyses revealed that phosphatidylcholine (PC) 32:3, 35:5, $37: 5$ were specific for high FFA ${ }_{\mathrm{AUC}}$, PC 31:3, 32:3, 35:5, and
\end{abstract}


37:5 were specific for high $\mathrm{BHBA}_{\mathrm{AUC}}$, and PC 31:2, 31:3, and 32:3 were specific for high liver lipid. Notably, PC 32:3 was specific for cows with elevated FFA, BHBA, and liver lipid content, a metabolite that was lower in abundance relative to healthy cows $(P<0.01)$. Other lipids specific for two or more categories included phosphatidylglycerol 38:4 and lysophosphatidylcholine 15:0. Our lipidomics approach confirms dynamic remodeling of the bovine lipidome during the peripartum. Future focus should be on nutritional interventions that increase plasma PC 32:3 in cows during the peripartal period. 


\section{INTRODUCTION}

The prevalence of metabolic disease is high during the transition from gestation to lactation, affecting on average $40 \%$ of the dairy cow population (LeBlanc, 2010). Metabolic diseases develop because of the onset of negative energy balance caused by insufficient energy intake and increased energy demand for lactation (Curtis et al., 1985). Postpartum metabolic diseases in dairy cows include fatty liver, ketosis, mastitis, metritis, milk fever, and displaced abomasum. The development of a metabolic disease can compromise milk production and reproductive performance as well as cost associated with health management (Gröhn et al., 1998; Gröhn et al., 1999; Duffield et al., 2009). Therefore, early detection or prevention of metabolic disease has the potential to minimize disease onset and thus improve milk production, fertility, and profitability (Saleem et al., 2012; Hailemariam et al., 2014; Kenéz et al., 2016). The advent of lipidomics has the potential to improve our understanding of bovine lipid metabolism and reveal novel biomarkers for metabolic disease which will refine nutritional interventions aimed at improving dairy cattle health and performance.

At the present time, circulating free fatty acid (FA) and $\beta$-hydroxybutyrate (BHBA) are industry standard biomarkers for metabolic impairment during the periparturient period. Laboratory and cow-side tests have been developed to monitor circulating free FA and BHBA levels, respectively. The alarm threshold levels for poor reproductive performance and milk production for prepartum free FA and BHBA are $270 \mu \mathrm{mol} / \mathrm{L}$ and $550 \mu \mathrm{mol} / \mathrm{L}$, respectively; and postpartum free FA of $600 \mu \mathrm{mol} / \mathrm{L}$ (Ospina et al., 2010). The limitations for free FA and BHBA testing are that (A) these metabolite thresholds represent the disease state (rather than pre-onset disease which would be preferred), (B) free FA and BHBA monitoring ignores the interactions between other causative metabolites of metabolic disease, (C) laboratory testing is expensive and 
requires additional labor, and (D) individual cow blood sampling is impractical. Therefore, alternative biomarkers for postpartum metabolic disease are needed.

Lipidomics is a system biology approach that emerged in the field of life sciences to investigate metabolite alterations in biological samples (Nicholson et al., 1999; Fischer, 2008; Nam et al., 2015). The application of lipidomics to identify novel biomarkers of metabolic disease in non-ruminants has been extensively employed (Barber et al., 2012; Donovan et al., 2013; Nam et al., 2015). However, only a limited number of studies have employed this analytical technology to better understand dairy cow health and performance (Hailemariam et al., 2014; Imhasly et al., 2014; Sun et al., 2014; Imhasly et al., 2015; Rico et al., 2015). Initial work has identified several phosphatidylcholines (PC) as biological indicators of postpartum metabolic disease (Hailemariam et al., 2014). For instance, PC 30:2, 32:2, 36:2, 36:3, 36:4, 38:3, 38:4, 38:6, 40:2, 40:3, 40:4, and 42:2 can be used to distinguish between healthy cows or those with a varying clinical disease (Imhasly et al., 2014). Phosphatidylcholine is a promising candidate because of the role it plays in hepatic very low density lipoproteins (VLDL)-triacylglycerol synthesis and export (Agren et al., 2005). However, a more comprehensive analysis of the bovine lipidome with multiple common markers of metabolic disease has the potential to refine our current understanding. Applying high throughput mass spectrometry-based technologies and bioinformatics can be employed cooperatively to achieve this goal. Therefore, our objective was to employ this approach to characterize the bovine plasma lipidome in Holstein dairy cows transitioning from gestation to lactation, and relate these findings to circulating free FA, BHBA and liver lipid accumulation. 


\section{MATERIALS AND METHODS}

\section{Experimental Design}

Experimental procedures were approved by the Institutional Animal Care and Use Committee at West Virginia University (Morgantown). The experiment was completed at Dovan Farms, a West Virginia University Agricultural Research and Education Partner located in Berlin, PA. Nonlactating, pregnant, multiparous Holstein cows ( $\mathrm{n}=27$; parity 2 and 3$)$ were enrolled 32 d prior to expected parturition, and offered a total mixed ration (TMR) to meet or exceed nutrient requirements (Table 4-1). Cows were fed once (0800 h) and twice (0800 and $1900 \mathrm{~h})$ daily during pregnancy and lactation, respectively, and were provided free access to water. Cows were milked twice daily at 0800 and $1800 \mathrm{~h}$ from d 1 to $\mathrm{d} 14$ postpartum, then milked three times a day thereafter (0500, 1400, and $2100 \mathrm{~h})$.

\section{Sample Collection}

Blood collection $(10 \mathrm{~mL})$ by coccygeal venipuncture occurred prior to morning feeding on d $-28,-21,-14$, daily from -7 to $7,10,12,14,21$, and 28 , relative to expected calving. Plasma samples were placed on ice for $30 \mathrm{~min}$, whereas serum samples were allowed to clot for $30 \mathrm{~min}$ at room temperature until centrifugation at $3,400 \times \mathrm{g}$ for $10 \mathrm{~min}$. Following centrifugation, plasma and serum samples were removed and snap-frozen in liquid nitrogen, and then stored at $-80^{\circ} \mathrm{C}$ until further analysis. Samples of TMR were collected weekly throughout the experiment, and dry matter content was determined by heating at $60^{\circ} \mathrm{C}$ until a static weight was observed. Body weight (BW) and body condition score (BCS) were recorded weekly.

Liver tissue biopsies were performed prior to morning feeding on $\mathrm{d}-28,5$, and $14 \mathrm{~d}$, relative to expected calving. Cows were anesthetized using xylazine $(0.04 \mathrm{~mL} / \mathrm{kg}$ of BW) delivered via the 
coccygeal vein. After the hair was clipped, the biopsy site located within the $11^{\text {th }}$ intercostal space was scrubbed with iodine and anesthetized with $5 \mathrm{~mL}$ of $2 \%$ lidocaine HCL (Vedco Inc., Saint Joseph, MO) delivered subcutaneously. A $0.5 \mathrm{~cm}$ incision was made through the skin and fabricated trocar (Hughes, 1962) was inserted to collect approximately $1 \mathrm{~g}$ of liver tissue. Liver samples were immediately snap-frozen in liquid nitrogen and stored at $-80^{\circ} \mathrm{C}$. Following biopsy, the collection site was stapled and sprayed with antiseptic, and ceftiofur hydrochloride antibiotic was administered once by intramuscular site $(0.68 \mathrm{~mL} / \mathrm{kg}$ of BW; Excenel RTU; Zoetis, Florham Park, NJ).

\section{Sample Analyses}

Nutrient composition of TMR was analyzed using near-infrared spectroscopy (AOAC method 989.03) by Cumberland Valley Analytical Services Inc. Plasma samples were analyzed in duplicate for free FA, glucose, and BHBA by commercial kits using enzymatic methods (HR series FA-HR (2), Autokit Glucose, Autokit 3-HB, respectively; Wako chemicals USA Inc., Richmond, VA). Plasma concentrations of insulin were determined by ELISA (Mercodia Bovine Insulin ELISA; Mercodia AB, Uppsala, Sweden). Spectrophotometric measurements were conducted using a SpectraMax Plus 384 Microplate Reader (Molecular Devices, Sunnyvale, CA). Total liver lipid content was determined using method described by Hara and Radin (1978), and Piepenbrink and Overton (2003).

For lipidomics, plasma samples were extracted using a modified Bligh and Dyer procedure to obtain a crude lipid fraction. In brief, $60 \mu \mathrm{l}$ of plasma was gently mixed in a glass vial with 940

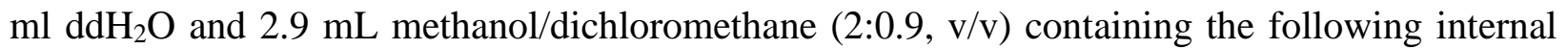
standards: N-lauroyl-D-erythro-sphingosine (Cer d18:1/12:0, 6 ng/mL), 1,3(d5)-dihexadecanoyl- 
glycerol (d5-DAG d16:0/16:0, $12.5 \mathrm{ng} / \mathrm{mL}$ ), D-galactosyl- $\beta$-1,1' N-lauroyl-D-erythro-sphingosine (GlcCer d18:1/12:0, $3.3 \mathrm{ng} / \mathrm{mL}$ ), D-lactosyl- $\beta$-1,1' N-lauroyl-D-erythro-sphingosine (LacCer 18:1/12:0, $\quad 10.6 \quad \mathrm{ng} / \mathrm{mL}), \quad$ 1,3(d5)-dihexadecanoyl-2-octadecanoyl-glycerol (D-5 TAG 16:0/18:0/16:0, $0.5 \mathrm{ng} / \mathrm{mL}$ ), cholesteryl-d7 palmitate (cholesteryl-d7 ester 16:0, $30 \mathrm{ng} / \mathrm{mL}$ ), 1,2dilauroyl-sn-glycero-3-phosphate (sodium salt) (PA d12:0/12:0, 1025 ng/mL), 1,2-dilauroyl-snglycero-3-phosphocholine $\quad$ (PC 12:0/12:0, $0.2 \quad \mathrm{ng} / \mathrm{mL}$ ), 1,2-dilauroyl-sn-glycero-3phosphoethanolamine (PE d12:0/12:0, $1.6 \mathrm{ng} / \mathrm{mL}$ ), 1,2-dilauroyl-sn-glycero-3-phospho-[1'-racglycerol] (PG d12:0/12:0, 200 ng/mL), 1,2-dilauroyl-sn-glycero-3-phospho-L-serine (PS d12:0/12:0), N-lauroyl-D-erythro-sphingosylphosphorylcholine (SM d18:1/12:0, 0.3 ng/mL), all internal standards were purchased from Avanti Polar Lipids, Inc. (Alabaster, AL). To obtain a biphasic mixture, an additional $1 \mathrm{~mL}$ of $\mathrm{ddH}_{2} \mathrm{O}$ and $0.9 \mathrm{~mL}$ dichloromethane was added and vortexed. The resultant mixture was incubated on ice for $30 \mathrm{~min}$ and centrifuged (10 min, $3000 \mathrm{~g}$, $\left.4^{\circ} \mathrm{C}\right)$ to separate the organic and aqueous phases. The organic phase was removed and stored at $20^{\circ} \mathrm{C}$. Just prior to analysis $1 \mathrm{~mL}$ of the organic layer was dried using a nitrogen evaporator (Organomation Associates, Inc., Berlin, MA, USA) and re-suspended in $250 \mu 1$ of running solvent (dichloromethane:methanol (1:1) containing $5 \mathrm{mM}$ ammonium acetate), and $5 \mathrm{mg} / \mathrm{mL}$ of ceramide C17:0 used to track instrument performance. All solvents used were HPLC grade.

Lipid analysis was conducted by MS/MS ${ }^{\mathrm{ALL}}$ on a TripleTOF ${ }^{\mathrm{TM}} 5600$ (AB SCIEX, Redwood City, CA) mass spectrometer. Samples (50 $\mu \mathrm{L}$ injection volume) were infused by HPLC at a constant flow rate of $5 \mu \mathrm{L} / \mathrm{min}$ using a LC-20AD pump, and SIL-20AC XR autosampler (Shimazu, Canby, OR). Source parameters were as follows: ion source gases 15 psi (GSI) and 20 psi (GS2), curtain gas $30 \mathrm{psi}$, temperature $150^{\circ} \mathrm{C}$, positive ion spray voltage $+5500 \mathrm{~V}$, declustering potential at $80 \mathrm{~V}$ and collision energy at $10 \mathrm{~V}$. Each sample was run in duplicate in positive ion 
mode. An initial TOF MS scan provided an overview of the total lipid content at an accumulation time of $5 \mathrm{~s}$. Precursor ions were selected by sequential 1 Da mass steps from 200 to $1200 \mathrm{~m} / \mathrm{z}$, and the analytes in each 1Da step were introduced into the collision chamber and fragments identified by TOF with a scan range of $100-1500 \mathrm{~m} / \mathrm{z}$ and accumulation time of $450 \mathrm{~ms}$. TOF MS and MS/MS ${ }^{\mathrm{ALL}}$ data obtained was post-aligned to internal standards using Analyst 1.7 TF.

Lipid identifications were validated using a pooled sample that was extracted and sequentially analyzed 8 times. Criteria for inclusion of lipid analytes for analysis was that MS/MS fragment peaks were present in 7 of the 8 pooled runs, and coefficient of variation $(\mathrm{CV})$ for peak identifications were less than $20 \%$. Peak identifications meeting these criteria were then used to develop a targeted method in LipidView. The targeted method was used to identify these prevalidated lipid species in experimental samples using a custom made MatLab script and MultiQuant software (version 3.0, AB SCIEX, Concord, ON, Canada). All peak intensities were corrected by their corresponding internal standard, and each sample duplicate was averaged. If duplicates varied more than $30 \%$, the sample was re-run. For statistical analyses, intensity values of 0 were replaced with a minimum intensity value that was calculated by dividing the average intensity value of for that particular lipid by 0.001 .

\section{Statistical Analyses}

Changes in BW and BCS were analyzed under the GLM procedure of SAS (version 9.3; SAS Institute Inc., Carry, NC). Plasma variables and liver lipid percent were analyzed as repeated measures over time relative to parturition under the MIXED procedure of SAS (SAS Institute Inc.). The statistical model included the random effect of cow, and the fixed effect of time (day relative to parturition). The most appropriate covariance structure for the repeated measures analysis was 
selected for each variable after evaluating 3 different covariance structures (variance components, first-order autoregressive, compound symmetry), and the structure with the smallest Akaike's information criterion coefficient was selected for analysis. The method of Kenward-Rogers was used for calculation of denominator degrees of freedom. In order to reduce risk of type I error for repeated measures analysis, the significance level was decreased to $P \leq 0.05$, and trends toward significance were considered at $0.05<P \leq 0.10$. Studentized residual values $>3.0$ or $<-3.0$ were considered outliers and removed from the analysis (typically 1 per response variable). All related results are expressed as least squares means and their standard errors, unless stated otherwise.

Lipidomic data were analyzed using MetaboAnalyst (Xia et al., 2016). Log transformation and autoscaling were employed for normalization of all lipidomic data, followed by visual inspection of normal distribution. To perform longitudinal analysis, we analyzed time-dependent metabolite changes over an 8-wk period. Multivariate analysis of normalized, auto-scaled lipidomic data included random forest $(\mathrm{RF})$ classification, partial least squares discriminant analysis (PLS-DA), ANOVA, and Pearson's correlation coefficient procedures. Based on postpartum metabolic health data, cows were separately categorized into low or high free FA area under the curve (FFA $\left.\mathrm{AUC}_{\mathrm{AC}}\right)$, BHBA area under the curve $\left(\mathrm{BHBA}_{\mathrm{AUC}}\right)$, or mean postpartum liver lipid content. Significant variables associated with a specific category were identified based on leverage/squared prediction error plots.

\section{RESULTS}

\section{Metabolic Health Status}

The transition from gestation to lactation was accompanied by suppressed DMI (Figure 41A; $P<0.01$ ), as well as BW and BCS loss (Figure 1B and C; $P<0.01$ ). Characteristic 
observations indicative of metabolic stress were detected. Specifically, plasma free FA and BHBA levels, and liver lipid content were elevated postpartum (Figure 4-1D, E, and F; $P<0.01$ ), while plasma insulin and glucose levels were expectedly lower following parturition (Figure 4-1G, and $\mathrm{H} ; P<0.01)$.

\section{Plasma Lipidome Remodeling during the Peripartum}

HPLC/TOF MS data were loaded for PLS-DA analyses to investigate the global lipidome of plasma samples from multiparous Holstein dairy cows during the transition period. The lipidomic approach revealed 301 plasma lipids including 163 phospholipids (phosphatidylcholine (PC), phosphatidylethanolamine (PE), phosphatidylserine (PS), phosphatidylglycerol (PG), lysophosphatidylcholine (LPC), lysophosphatidylethanolamine (LPE), lysophosphatidylserine (LPS)), 130 fatty acylglycerols (triacylglycerol (TAG), diacylglycerol (DAG), and monoalkyldiacylglycerol (MADAG)) and 8 cholesteryl esters (CE). A two-dimensional PLS-DA model was applied to identify a subset of variables that distinguishes between time points (d -28 to d 14 , relative to parturition) and a variable importance of projection (VIP) score of $>1$ based on Component 1 (explained $40 \%$ of variables) of the PLS-DA model was used to determine the relative contribution of lipid species to discriminate between time points (Figure 4-2). PLS-DA (Figure 4-2A) score plots illustrate a significant separation across all time points. Variance for Component 1 was explained by dynamic changes in TAG, MADAG, PS, and LPS (Figure 4-2B). Additionally, a dominant lipid pattern showing a reduction of TAG 60:1, 62:0, 56:1, 60:0, 56:0, 62:1, 58:0, 58:1, 58:2, and 56:4; MADAG 58:1, 60:1, 60:2, 62:1, 56:4, 60:0, 54:5, 52:1, 48:0, 52:0,

58:0, and 50:0; PS 28:0; and LPS 30:6 postpartum. These changes reflected total plasma TAG and MADAG, LPS, PS levels which consistently declined during the transition from gestation to 
lactation (Figure 4-4 and 4-5; $P<0.01$ ); while total PC and PE levels increased postpartum. The majority of phospholipids such as LPC, PC, LPE, and PE reached a nadir at parturition $(P<0.01)$. Component 2 (explained 19\% of the variance; Figure 4-2C) was explained by reduction in TAG, MADAG, PS, and LPS; meanwhile increase in LPE 18:2, PC 34:2, LPC 18:2, and DAG 38:3 during the peripartum period. Specifically, component 2 included reductions in TAG 60:1, 62:0, 56:1, 56:0, 60:0, 62:1, 58:0, and 58:1; MADAG 60:1, 60:2, 52:2, 56:4, 62:2, 60:0, 54:5, 50:1, 48:0, and 52:0; PS 28:0; and LPS 30:6.

Random forest analysis was developed by Breiman (2001) and has since been used as a supervised statistical tool in clinical metabolomics and gene selection studies (Díaz-Uriarte et al., 2006; Chen et al., 2013). It is an excellent classification method that provide measures for metabolite selection by identifying key metabolites that discriminate between time points during the transition period. The main advantage of this model is to retrieve very small sets of metabolites that possess a high predictive accuracy, thus can be an ideal method for metabolite characterization and classification. Random forest (Figure 4-3A) is used to predict classes of metabolites based on days and is based on bootstrap sampling (e.g. take random samples from original data set with replacement), thus some data are left out of the bootstrap sample, which are called out-of-bag (OOB). The OOB data is then used as a test sample to predict the classification error rate. Therefore, the mean decrease in accuracy (Figure 4-3B) is calculated based on prediction of the OOB data set. Figure 3B shows important metabolites that differentiate between time points. As cows approached parturition, TAG 38:2 and 58:1, LPS 30:6, and MADAG 58:1, 46:0, 54:1, and 60:7 declined and remained low until day 14, whereas DAG 38:3, LPE 18:2, LPC 16:0 and 18:2, PG 36:2, and PC 36:2 and 34:2 increased after parturition. 
Prepartum data was isolated, and two-dimensional PLS-DA model was used to identify a subset of variables that distinguishes between prepartum time points (Figure 4-6A). Plasma lipids LPS, TAG, LPC, and MADAG decreased as parturition approached. Prepartum variance for Component 1 is explained by changes in LPS, TAG, LPC, and MADAG. A heat map shows reduction in LPS 30:6, TAG 38:2, 54:0, 56:1, 54:1, 56:2, 56:3, 56:0, and 56:6, LPC 18:0, 15:0, 20:4, and 20:3, and MADAG 54:1, 52:0, 62:1, 60:2, 60:0, 54:7, 52:1, 56:3, and 54:0 prepartum (Figure 4-6C).

Postpartum data was isolated, and two-dimensional PLS-DA model was used to identify metabolites that distinguishes between postpartum time points (Figure 4-6B). Plasma PC, LPC, PG, LPE, PE, and DAG increased postpartum. Postpartum variance for Component 1 is explained by changes in PC, LPC, PG, LPE, PE, and DAG. A heat map shows increases in PC 34:2, 36:2, $36: 3,35: 2,33: 2,35: 3,36: 4,33: 3,36: 1$, and 34:3, LPC 18:2, 16:0, 18:0, 18:1, 28:3, 30:3, 28:2, 16:1, and 30:4, PG 38:5, LPE 18:2, PE 34:2, 36:2, and 26:4, and DAG 38:3 postpartum (Figure 46D).

\section{Correlations of PC and TAG Species}

Because of the characterized relationship between hepatic PC synthesis and VLDL-TAG export (Li and Vance, 2008), we explored the relationship between circulating PC and TAG using Pearson's correlation coefficient analysis (Figure 4-7). A heat map ( $r$-values) demonstrates that 69 PC (C24-C42) were correlated with 49 TAG (C38-C64). Our results illustrate that the plasma levels of PC species were positively or negatively correlated with the plasma levels of TAG, depending on fatty acyl chain length of PC species. 


\section{Identification of Biomarkers Associated with Metabolic Stress}

Based on postpartum metabolic health status, cows were categorized into low or high free FFA $_{A U C}(\mathrm{~d} 1-14 \mathrm{pp} ; 4,915 \pm 1,369$ vs. $12,501 \pm 2,761[\mu \mathrm{mol} / \mathrm{L} \times 14 \mathrm{~d}]), \mathrm{BHBA}_{\mathrm{AUC}}(\mathrm{d} 1-14 \mathrm{pp}$ 4,583 \pm 459 vs. 7,901 $\pm 1,206[\mu \mathrm{mol} / \mathrm{L} \times 14 \mathrm{~d}])$, or mean liver lipid deposition (d 5 and 14 pp; $5 \pm$ 1 vs. $12 \pm 2 \%$ of wet weight, respectively). Significant variables associated with a specific category were identified based on leverage/squared prediction error plots (Figure 4-8). Our analyses revealed that PC 36:6, 32:3, 34:4, 32:2, 31:3, 34:6, 33:5, 31:2, 37:6, 38:2, 40:5, 38:3, 35:6, 37:0, and PE 34:4 and 34:3 were specific for high liver lipid content, PC 32:3, 35:2, 38:1, 35:5, 33:1, 37:2, 37:0, 35:0, 33:0, 37:5, 33:2, 36:4, 39:2, PE 39:0 and 45:4, LPC 30:2 and 30:1, TAG 46:2, and PG 38:4 were specific for high FFAAUc, whereas PG 36:4, 39:0, 38:4, 38:6, PC 37:5, 32:3, 35:5, 32:0, 31:3, 32:4, 30:2, DAG 40:4, 36:0, 30:2, LPC 22:5, 15:0, 18:0, and PE 37:6 and 34:3 were specific for high $\mathrm{BHBA}_{\mathrm{AUC}}$ (Figure 4-8). Notably, PC 32:3 was specific for high $\mathrm{FFA}_{\mathrm{AUC}}, \mathrm{BHBA}_{\mathrm{AUC}}$, and liver lipid cows.

\section{DISCUSSION}

The transition from gestation to lactation is defined as three weeks before to three weeks after parturition, which imposes a metabolic risk in dairy cow (Grummer, 1995; Drackley, 1999). It is well documented that the development of metabolic diseases are associated with suppressed feed intake and increased energy requirements for lactation (Curtis et al., 1985). In particular, dysfunctional lipid metabolism is associated with diverse metabolic disorders in Holstein dairy cows (Drackley, 1999). Thus, better understanding of bovine lipid metabolism is crucial to improve animal health and productivity. In our study, we utilized lipidomics approach to profile the plasma lipidome of multiparous dairy cow transitioning from gestation to lactation to shed light 
on our understanding of metabolic disease and work towards identifying novel targets for future nutritional intervention aimed at improving dairy cow health and performance.

In our study, the dramatic loss of BW and BCS were accompanied by suppressed DMI and elevated free FA and BHBA, responses that have been previously observed in periparturient dairy cows (Roche et al., 2009), reflecting a metabolic adaptation associated with the onset of lactation in dairy cows (Reid et al., 1986). Adaptations in nutrient metabolism ensure energy supply to the fetus and neonate (Bauman and Currie, 1980). However, maternal adaptations accelerate lipolysis and predispose dairy cow to enhanced risk for developing a postpartum metabolic disorders. Insulin resistance is a common physiological response during the transition from late gestation to early lactation, which promotes adipose tissue lipolysis and enhances metabolic disease (Rico, et al., 2015; Rico et al, 2016). Previously, our lab utilized a targeted lipidomic approach to reveal sphingolipid ceramide as a plasma and skeletal muscle biomarker of insulin resistance (Rico et al., 2016). In the present study, we utilized an untargeted lipidomics approach to (1) identify other potential biomarkers of metabolic disease and (2) improve our understanding of phospholipid and acylglycerol metabolism in relation to metabolic health.

PLS-DA score plots demonstrated clear separation of plasma metabolites between time points. As cows approach parturition, neutral lipids such as TAG and MADAG declined and remained low postpartum. Levels of TAG, MADAG, LPC, and PC differed significantly pre- and postpartum, indicating dynamic changes of lipids during peripartum. Additionally, RF was used as an alternative classification model. Similarly, results demonstrate reduction of TAG and MADAG, meanwhile increase of PC and LPC species postpartum. To consolidate our understanding, we applied PLS-DA pre- and postpartum, separately. VIP scores result for Component 1 was comparable to our previous results, which indicates reduced plasma levels of 
TAG and higher content of PC and LPC. Comparable to our study, PC 34:2 and 36:2 were recognized as the most contributing metabolites to distinguish between pre- and postpartum in dairy cow (Kenéz et al., 2016). In a non-ruminant study, lipidomic analysis revealed significant elevation of ether-linked PC and PE in plasma of an obese individual (Donovan et al., 2013). These specific results suggest that low levels of plasma PC and LPC are associated with improved cow health. However, a challenging question is whether all PC species are associated with metabolic disease or rather a subclasses of them.

In biological systems, PC comprises majority of plasma VLDL components following PE and LPC (Agren et al., 2005). Phosphatidylcholine is the main form of choline phospholipids and reduced hepatic PC levels impair VLDL export (Zeisel, 1992; Verkade et al., 1993; Fast and Vance, 1995), thus, elevate the accumulation of TAG in the liver (Bobe et al., 2004). Ruminants in particular, have an inherently low capacity to remove TAG from the liver in the form of VLDL (Kleppe et al., 1988; Pullen et al., 1990), and excessive hepatic free FA uptake can lead to TAG accumulation, and increase the incidence of fatty liver disease and ketosis, which further can lead to serious metabolic disorders, such as mastitis, metritis, and milk fever (Herdt, 2000; Bobe et al., 2004). Phosphatidylethanolamine may be as well required for VLDL assembly, particularly nascent VLDL contain more PE than plasma VLDL (Hamilton and Felding, 1989). Unfortunately, the requirement of PC and PE for VLDL assembly has not been defined for dairy cows. However, phospholipids have been recognized as potentially important metabolites for VLDL assembly and secretion (Van de Top et al., 1996; Kessler et al., 2014). Therefore, to facilitate VLDL export, PC and PE are likely needed. Noticeably, despite higher levels of PC and PE later in early lactation, plasma TAG remained low. Possible explanation might be that origin of PC extract from plasma is uncertain, and expected changes in circulating PC likely depend on acyl chain moiety. 
One should consider the diverse structure of TAG, degree of saturation, and their contribution on VLDL assembly and secretion. Therefore, we investigated the pattern of TAG saturation during the peripartum period. Levels of saturated and monounsaturated TAG were negatively correlated with the progress of the peripartum period. As cows progress through lactation mono- and polyunsaturated TAG (e.g. TAG 60:1, 58:2) and saturated TAG (e.g. TAG 60:0) are reduced. This reflects the hepatic accumulation of TAG, thus progression of fatty liver disease. Of note, the present study indicates that the PC acyl moiety in the plasma is associated with levels of plasma TAG. The acyl chain length correlation between PC and TAG species can be either positive or negative. In a previous studies, the PC levels were shown to be elevated in periparturient dairy cows, which indicates the abnormal lipid metabolism (Hailemariam et al., 2014; Kenéz et al., 2016). In particular, our results are comparable to Imhasly et al. (2015) which reported reduced TAG species with different chain length and levels of saturation, meanwhile increased PC species postpartum. Thus, one can postulate that PC acyl moiety may influence TAG export. Further, to clearly elucidate the association of PC species with TAG species, liver exploration is warranted.

Our lipidomic investigation revealed a novel lipid class not yet considered in dairy science, MADAG. Monoalkyl-diacylglycerol are neutral lipids that aggregate within hepatic lipid droplets with TAG (Bartz et al., 2007). Our results suggest that the hepatic transport of MADAG and TAG may share a similar pathway. Further, a similar pattern of TAG remodeling was observed for saturated and unsaturated MADAG. Unfortunately, the relative contribution of MADAG as a modulators of energy metabolism and VLDL secretion in ruminants and monogastrics are unknown. Thus, future studies should characterize the role of MADAG in VLDL assembly and their association with metabolic disease. 
Excessive hepatic free FA during the peripartum period can be re-esterified to form other neutral lipids (i.e., DAG, and CE) or glycerophospholipids (i.e., LPC, PS, LPG, and PG). Several studies have shown the relative contributions of DAG and LPC in obesity and diabetic nonruminants (Erion and Shulman, 2010; Barber et al., 2012). For instance, LPC 16:0 was identified as the key metabolite in fatty liver-induced insulin resistance in humans (Lehmann et al., 2013). Additionally, it has been speculated that DAG is a potential biomarker of insulin resistance in humans (Erion and Shulman, 2010). Specifically, DAG 18:1, 18:2, and 20:4 were shown to be positively associated with acute muscle insulin resistance in humans (Szendroedi et al., 2013). In our study, levels of total DAG increased after parturition that developed in parallel with elevated insulin resistance in early lactation dairy cow. However, more investigation is needed in dairy cows to unravel the role of DAG species on insulin sensitivity during the periparturient period.

Additionally, we analyzed the association of PC species with common biomarkers of metabolic impairment during the peripartum period. The circulating free FA and BHBA are diagnostic biomarkers of the active disease state and poor performance (Ospina et al., 2010; Ospina et al., 2010). However, they are not an ideal predictive biomarkers (reflect disease state) for metabolic disease during the transition period. Thus, evaluating PC species as potential predictive biomarkers of metabolic disease are warranted. The relative concentrations of several PC species were suppressed with increased postpartum liver lipid content (component of fatty liver disease), high free FA and BHBA. Therefore, one may assume that not all PC species contribute in similar manner to VLDL assembly. In particular, PC 32:3 was reduced in all aforementioned categories, which indicates the possible importance of this metabolite in VLDL assembly, thus improving cow health. 
In conclusion, the plasma samples of multiparous Holstein dairy cow model were characterized using HPLC/QTOF MS-based lipid profiling to enhance understanding of lipid metabolism during transition from gestation to lactation. Our lipidomic approach identified the importance of PC 32:3 as a potential biomarker of metabolic disease. Future studies should determine the prognostic and diagnostic efficacy of PC 32:3 to monitor disease progression. Moreover, the development of nutrition interventions that increase PC 32:3 may be beneficial. Finally, the structural and functional role of MADAG should be considered in content of hepatic VLDL export. 


\section{REFERENCES}

Barber, M. N., S. Risis, C. Yang, P. J. Meikle, M. Staples, M. A. Febbraio, and C. R. Bruce. 2012. Plasma lysophosphatidylcholine levels are reduced in obesity and type 2 diabetes. PLoS ONE. 7:e41456.

Bauman, D. E., and W. B. Currie. 1980. Partitioning of nutrients during pregnancy and lactation: a review of mechanisms involving homeostasis and homeorhesis. J. Dairy Sci. 63:15141529.

Bobe, G., J.W. Young, and D.C. Beitz. Invited review: pathology, etiology, prevention, and treatment of fatty liver in dairy cows. 2004. J. Dairy Sci. 87:3105-24.

Breiman, L. Random forests. 2001. Machine Learning. 45:5-32.

Chen, T., Y. Cao, Y. Zhang, J. Liu, Y. Bao, C. wang, W. Jia, and A. Zhao. 2013. Random forest in clinical metabolomics for phenotypic discrimination and biomarker selection. EvidenceBased complementary and alternative Medicine. 2013:298183.

Curtis, C. R., H. N. Erb, C. H. Sniffen, R. D. Smith, and D. S. Kronfeld. 1985. Path analysis of dry period nutrition, postpartum metabolic and reproductive disorders, and mastitis in Holstein cows. J. Dairy Sci. 68:2347-2360.

Díaz-Uriarte, R., and S. Alvarez de Andrés. 2006. Gene selection and classification of microarray data using random forest. BMC Bioinfo. 7:3.

Donovan, E. L., S. M. Pettine, M. S. Hickey, K. L. Hamilton, and B. F. Miller. 2013. Lipidomic analysis of human plasma reveals ether-linked lipids that are elevated in morbidly obese humans compared to lean. D. M. S. J. 5:24.

Erion, D. M., and G. I. Shulman. 2010. Diacylglycerol-mediated insulin resistance. Nature. 16:400-402.

Fischer, H. P. 2008. Mathematical modeling of complex biological systems: From parts lists to understanding systems behavior. Alcohol Research \& Health. 31:49-59.

Gröhn, Y. T., S. W. Eicker, V. Ducrocq, and J. A. Hertl. 1998. Effect of diseases on the culling of Holstein dairy cows in New York State. J. Dairy Sci. 81:966-978.

Gröhn, Y. T., J. J. McDermott, Y. H. Schukken, J. A. Hertl, and S. W. Eicker. 1999. Analysis of correlated continuous repeated observations: modelling the effect of ketosis on milk yield in dairy cows. Prev. Vet. Med. 39:137-153.

Hamilton, R. L., and P. E. Fielding. 1989. Nascent very low density lipoproteins from rat hepatocytic Golgi fractions are enriched in phosphatidylethanolamine. Bio. Bio. Res. 
Comm. 160:162-167.

Haus, J. M., S. R. Kashyap, T. Kasumov, R. Zhang, K. R. Kelly, R. A. DeFronzo, and J. P. Kirwan. 2009. Plasma ceramides are elevated in obese subjects with type 2 diabetes and correlate with the severity of insulin resistance. Diabetes 58:337-343.

Herdt, T.H. 2000. Ruminant adaptation to negative energy balance. Influences on the etiology of ketosis and fatty liver. Vet. Clin. North Am. Food Anim. Pract. 16:215-30.

Imhasly, S., C. Bieli, H. Naegeli, L. Nyström, M. Ruetten, and C. Gerspach. 2015. Blood plasma lipidome profile of dairy cows during the transition period. BMC Vet. Res. 11:252.

Kenéz, Á., S. Dänicke, U. Rolle-Kampczyk, and M. von Bergen. 2016. A metabolomics approach to characterize phenotypes of metabolic transition from late pregnancy to early lactation in dairy cows. Metabol. 12:165.

Kessler, E. C., J. J. Gross, R. M. Bruckmaier, and C. Albrecht. 2014. Cholesterol metabolism, transport, and hepatic regulation in dairy cows during transition and early lactation. J. Dairy Sci. 97:5481-5490.

Kleppe, B. B., A. J. Aiello, R. R. Grummer, and L. E. Armentano. 1988. Triglyceride accumulation and very low density lipoprotein secretion by rat and goat hepatocytes in vitro. J. Dairy Sci. 71:1813-1822.

LeBlanc, S. 2010. Monitoring metabolic health of dairy cattle in the transition period. J. Reprod. Dev. 56:S29-S35.

Lehmann, R., A. Königsrainer, J. Machann, and A. Gastaldelli. 2013. Circulating lysophosphatidylcholines are markers of a metabolically benign nonalcoholic fatty liver. Diabetes care 36:2331-2338.

Li, Z., and D. E. Vance. 2008. Phosphatidylcholine and choline homeostasis. J. Lipid Res. 49:1187-1194.

Nam, M., M. S. choi, S. Jung, Y. Jung, J. Y. Choi, D. H. Ryu, and G. S. Hwang. 2015. Lipidomic profiling of liver tissue from obesity-prone and obesity-resistant mice fed a high fat diet. Sci. Rep. 5:16984.

Nicholson, J. K., J. C. Lindon, and E. Holmes. 1999. Metabolomics: Understanding the metabolic responses of living systems to pathophysiological stimuli via multivariate statistical analysis of biological NMR spectroscopic date. Xenbiotica 29:1181-1189.

Ospina, P. A., D. V. Nydam, T. Stokol, and T. R. Overton. 2010. Evaluation of nonesterified fatty acids and $\beta$-hydroxybutyrate in transition dairy cattle in the northeastern United States: Critical thresholds for prediction of clinical diseases. J. Dairy Sci. 93:546-554. 
Ospina, P. A., D. V. Nydam, T. Stokol, and T. R. Overton. 2010. Associations of elevated nonesterified fatty acids and $\beta$-hydroxybutyrate concentrations with early lactation reproductive performance and milk production in transition dairy cattle in the northeastern United States. J. Dairy Sci. 93:1596-1603.

Pullen, D. L., J. S. Liesman, and R. S. Emery. 1990. A species comparison of liver slice synthesis and secretion of triacylglycerol from nonesterified fatty acids in media. J. Anim. Sci. 68:1395-1399.

Reid, I. M., C. J. Roberts, R. J. Treacher, and L. A. Williams. 1986. Effect of body condition at calving on tissue mobilization, development of fatty liver and blood chemistry of dairy cows. Animal Production. 43:7-15.

Rico, J. E., V. V. R. Bandaru, J. M. Dorskind, N. J. Haughey, and J. W. McFadden. 2015. Plasma ceramides are elevated in overweight Holstein dairy cows experiencing greater lipolysis and insulin resistance during the transition from late pregnancy to early lactation. J Dairy Sci. 98:7757-70.

Roche, J. R., N. C. Friggens, J. K. Kay, M. W. Fisher, K. J. Stafford, and D. P. Berry. 2009. Invited review: Body condition score and its association with dairy cow productivity, health, and welfare. J. Dairy Sci. 92:5769-5801.

Sun, L. W., H. Zhang, Y. Wu, L. Shu, S. Xia, C. Xu, and J. S. Zheng. 2014. ${ }^{1}$ H-Nuclear magnetic resonance-based plasma metabolic profiling of dairy cows with clinical and subclinical ketosis. J. Dairy Sci. 97:1552-1562.

Szendroedi, J., T. Yoshimura, E. Phielix, C. Koliaki, M. Marcucci, D. Zhang, T. Jelenik, J. Müller, C. Herder, P. Nowotny, and G. I. Shulman. 2014. Role of diacylglycerol activation of PKC $\theta$ in lipid-induced muscle insulin resistance in humans. PNAS. 111:9597-9602.

Van den Top, A. M., M. J. Geelen, T. Wensing, G. H. Wentink, A. T. Van t Klooster, and A. C. Beynen. 1996. Higher postpartum hepatic triacylglycerol concentrations in dairy cows with free rather than restricted access to feed during the dry period are associated with lower activities of hepatic glycerolphosphate acyltransferase. J. Nutr. 126:76-85. 

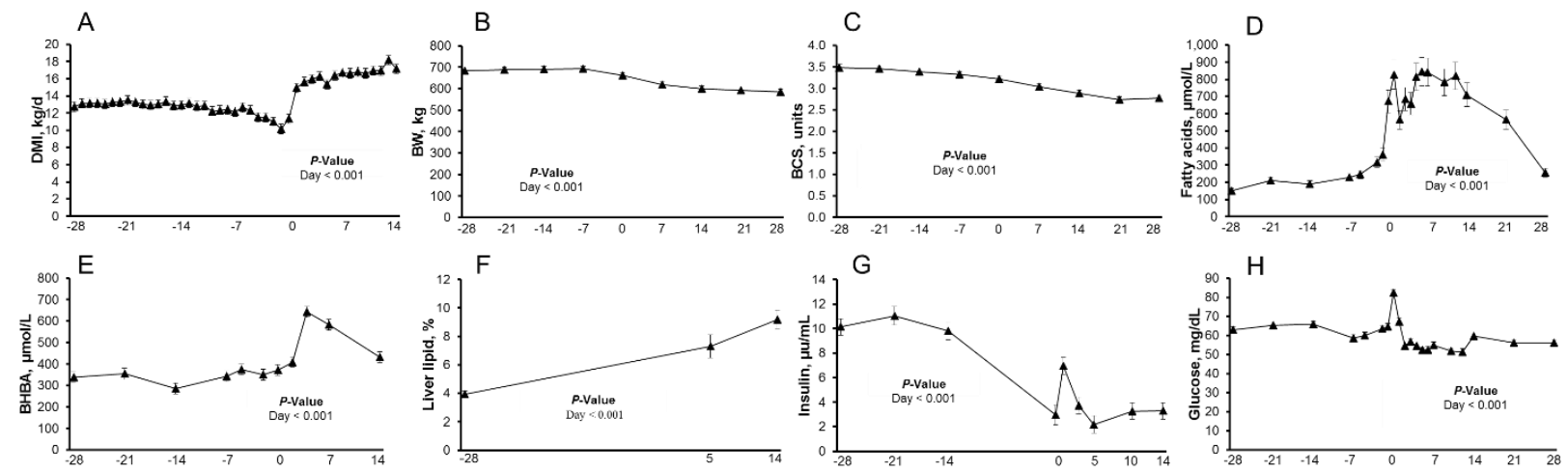

Figure 4-1. Dry matter intake (DMI) suppresses as cow approaches parturition, and body weight (BW) and body condition score (BCS) decline postpartum. Circulating free fatty acid (FA) and $\beta$ hydroxybutyrate (BHBA), and liver lipid content are elevated postpartum. Insulin and glucose concentrations decrease postpartum. (A) DMI, (B) BW, (C) BCS, (D) FA, (E) BHBA, (F) hepatic lipid deposition, $(\mathrm{G})$ insulin, and $(\mathrm{H})$ glucose. Data are represented as least squares means and their standard errors. 

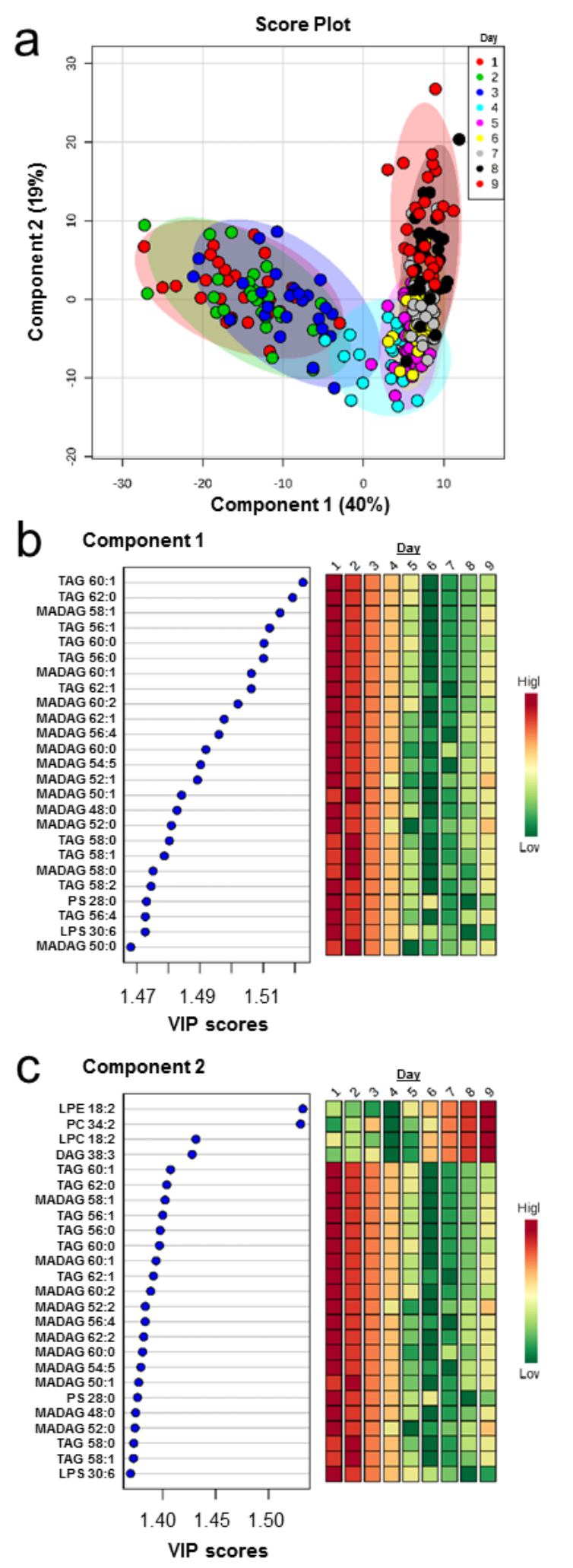
Figure 4-2. Plasma neutral lipids triacylglycerol (TAG) and monoalkyl-diacylglycerol (MADAG) decrease dramatically during the peripartum. (A) Two-dimensional partial least squares discriminant (PLS-DA) score plot, (B) VIP scores analysis based on Component 1 of the PLS-DA, and (C) VIP scores analysis based on Component 2 of the PLS-DA used to rank the relative contribution of metabolites to the variance between time points. Variance for Component 1 is explained by changes in TAG, MADAG, phosphatidylserine (PS), and lysophosphatidylserine (LPS). Normalized, auto-scaled data is representative of plasma collected from multiparous Holstein dairy cows $(n=27)$ prior to morning feeding at nine time points spanning the peripartum (d-28 to d14). PLS-DA score plots demonstrate good fitness and high predictability of model with $\mathrm{R}^{2}$ and $\mathrm{Q}^{2}$ values $\geq 0.73$ and 0.85 , respectively. Data were obtained using quadrupole time-of-flight mass spectrometry. 

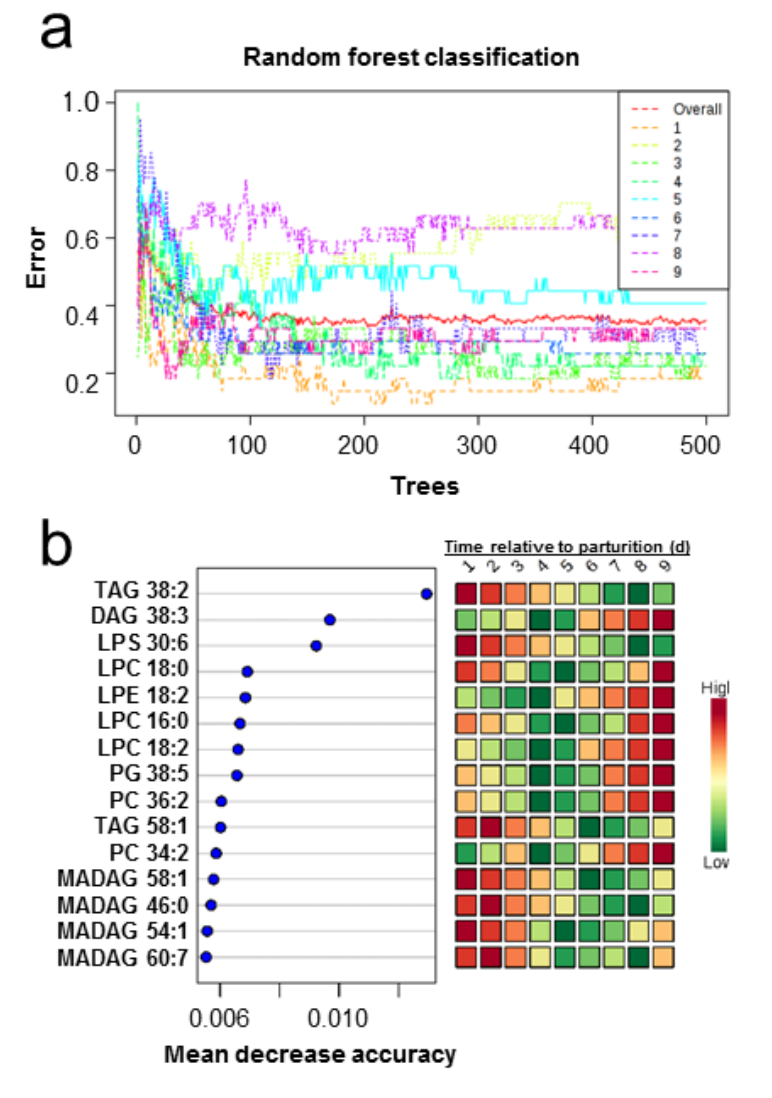

Figure 4-3. Random Forest analysis revealed that subjects are distinguishable across nine time points (class error $=0.15$ ). Permutation importance reveals significant metabolites identified by Random Forest method. The metabolites are ranked by the mean decrease in classification accuracy when they permuted. Each lines represent the error rates for each day. (A) Random Forest, (B) permutation importance. Data were obtained using quadrupole time-of-flight mass spectrometry. 

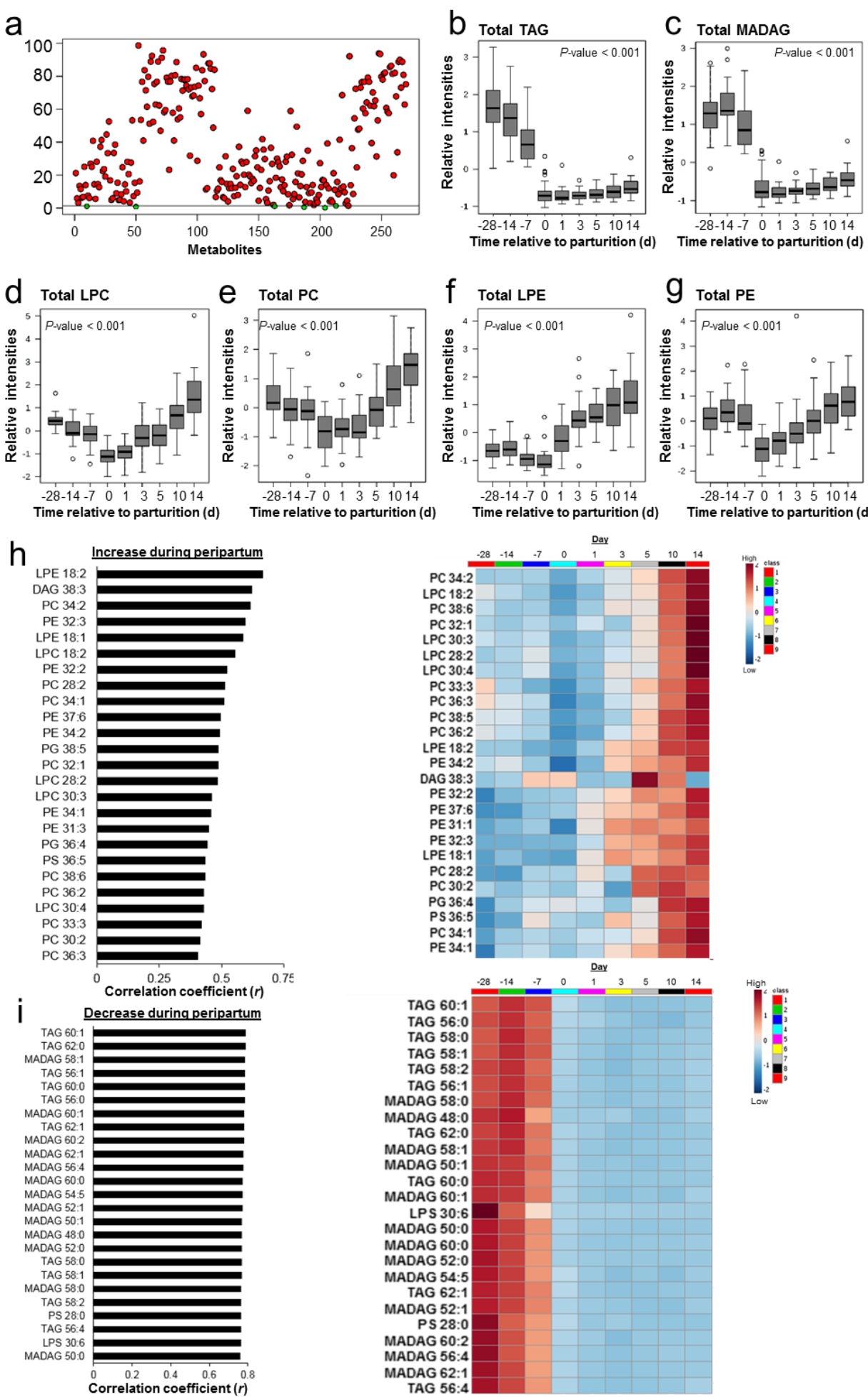

MADAG 58:0

MADAG 48:0

TAG 62:0

MADAG 50:1

TAG 60:0

MADAG 60:1

LPS 30:6

MADAG 60:0

MADAG 52:0

MADAG 54:5

TAG 62:1

TAG 62:1

PS 28:0

MADAG 60:

MADAG 56:4

MADAG 62:1

TAG 56: 
Figure 4-4. Circulating total triacylglycerol (TAG) and neutral ether lipid monoalkyldiacylglycerol (MADAG) decreased postpartum. Circulating phospholipid concentrations are lowest at parturition in periparturient Holstein dairy cows. Normalized, auto-scaled data reflect the sum of (B) 49 TAG (C38-C64), (C) 64 MADAG (C40-C62), (D) 29 lysophosphatidylcholine (LPC; C14-C30), (E) 69 phosphatidylcholine (PC; C24-C42), (F) 5 lysophosphatidylethanolamine (LPE; C18-C26), and (G) 38 phosphatidylethanolamine (PE; C26-C45) species measured in plasma collected from multiparous Holstein dairy cows $(n=27)$ at nine time points spanning the peripartum (d -28 to d 14). Data were obtained using quadrupole time-of-flight mass spectrometry. 

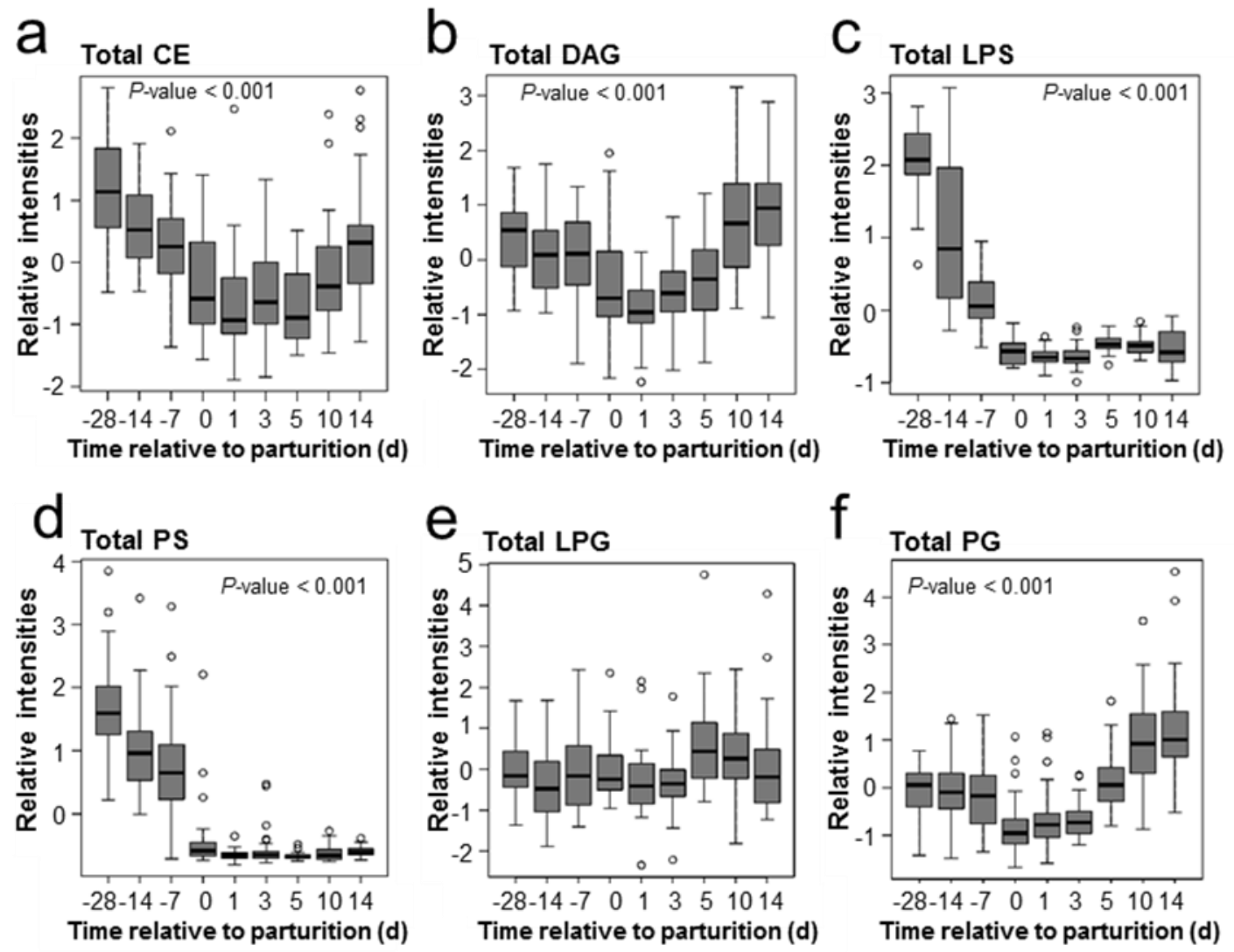

Figure 4-5. Circulating cholesterol esters (CE), diacylglycerol (DAG), and phosphatidylglycerol (PG) decrease as cow approaches parturition, circulating lysophosphatidylserine (LPS), and phosphatidylserine (PS) decrease postpartum, and lysophosphatidylglycerol (LPG) remains unchanged during the peripartum. Data were obtained using quadrupole time-of-flight mass spectrometry. 
a

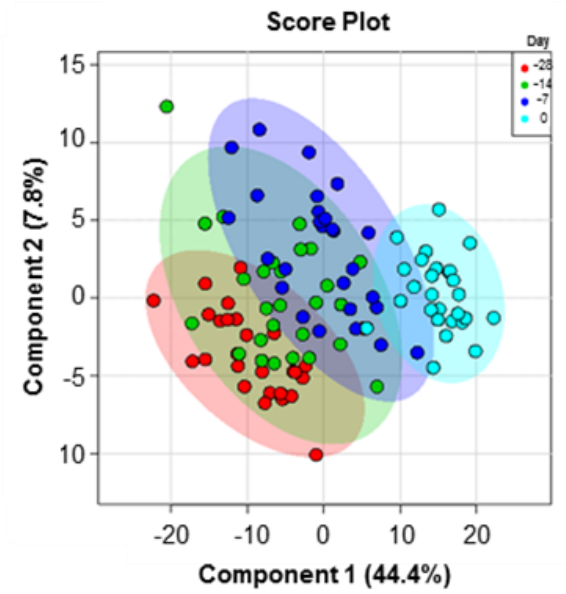

C

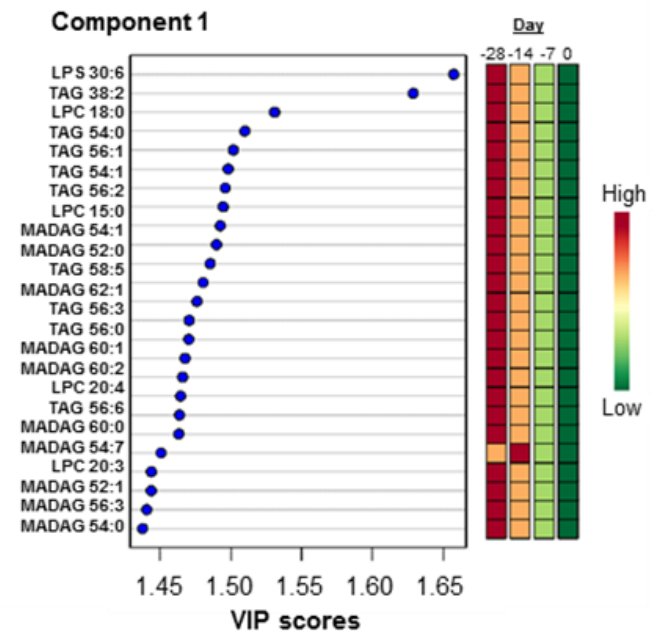

e

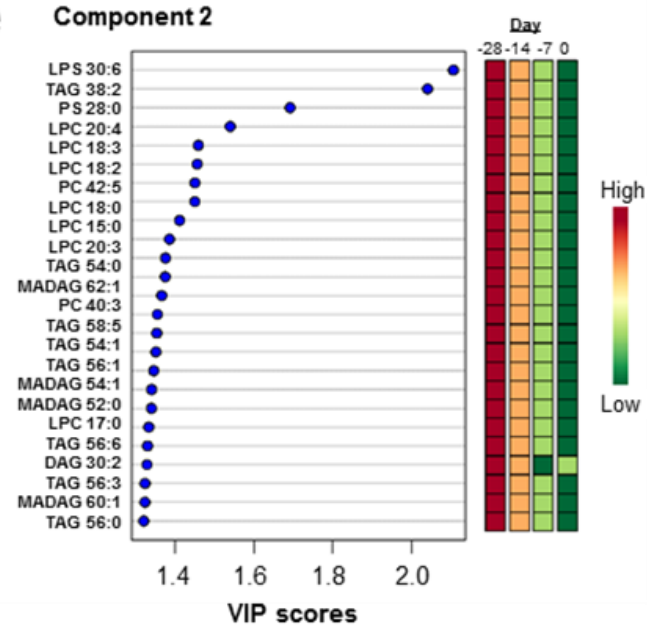

b

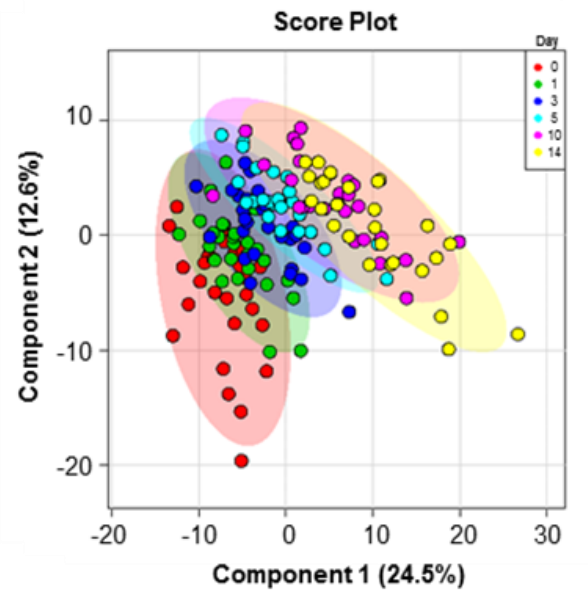

d

\section{Component 1}

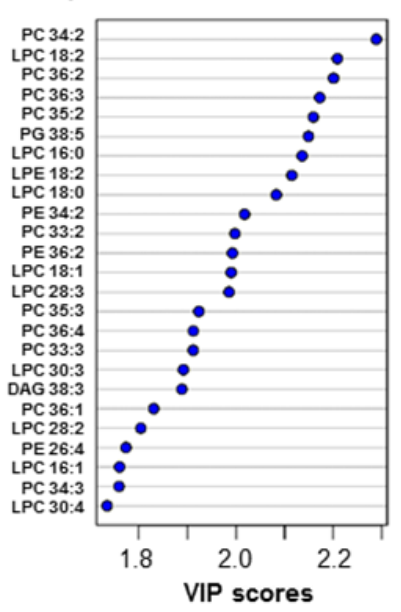

Day

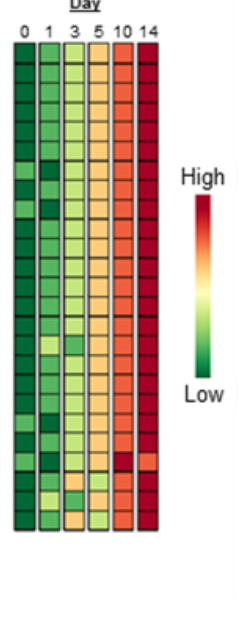

Component 2
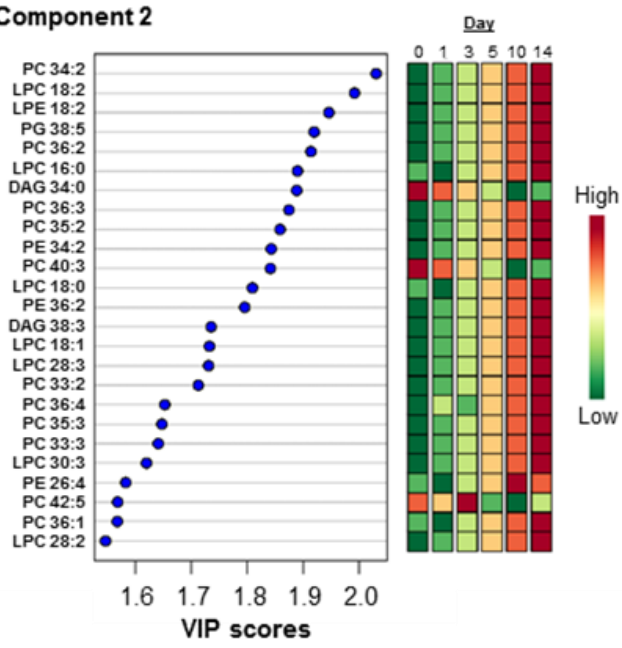
Figure 4-6. Plasma lipids lysophosphatidylserine (LPS) and triacylglycerol (TAG) prepartum and phosphatidylcholine (PC) and lysophosphatidylcholine (LPC) postpartum decrease drastically. (A) Two-dimensional partial least squares discriminant (PLS-DA) score plot prepartum, (B) Twodimensional PLS-DA score plot postpartum, (C) VIP scores analysis based on Component 1 of the PLS-DA prepartum, (D) VIP scores analysis based on Component 1 of the PLS-DA postpartum, (E) VIP scores analysis based on Component 2 of the PLS-DA prepartum, and (F) VIP scores analysis based on Component 2 of the PLS-DA postpartum used to rank the relative contribution of metabolites to the variance between time points. Prepartum variance for Component 1 is explained by changes in LPS, TAG, LPC, and monoalkyl-diacylglycerol (MADAG). Postpartum variance for Component 1 is explained by changes in PC, LPC, phosphatidylglycerol (PG), lysophosphatidylethanolamine (LPE), phosphatidylethanolamine (PE), and diacylglycerol (DAG). Normalized, auto-scaled data is representative of plasma collected from multiparous Holstein dairy cows $(n=27)$ prior to morning feeding at four time points spanning the prepartum and five time points spanning the postpartum. Data were obtained using quadrupole time-of-flight mass spectrometry. 


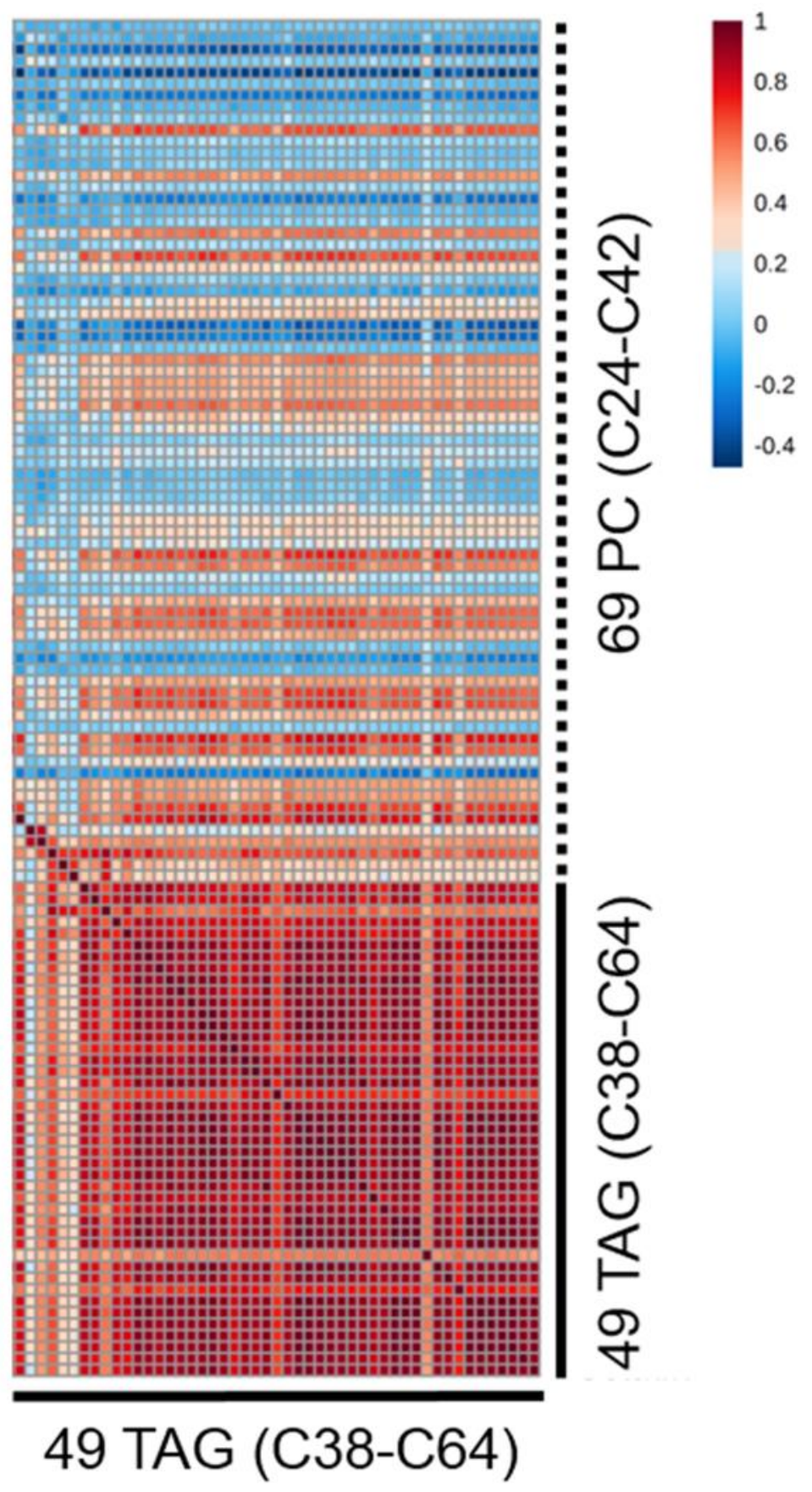

Figure 4-7. Depending on fatty acyl moiety, plasma phosphatidylcholine (PC) levels are positively or negatively correlated with circulating triacylglycerol (TAG). Pearson's correlation coefficient analysis represents normalized, auto-scaled data collected from plasma of periparturient Holstein dairy cows $(n=27)$ at nine time points spanning the peripartum ( $d-28$ to $d 14)$. Heat map is representative of $r$-values. Data were obtained using quadrupole time-of-flight mass spectrometry. 


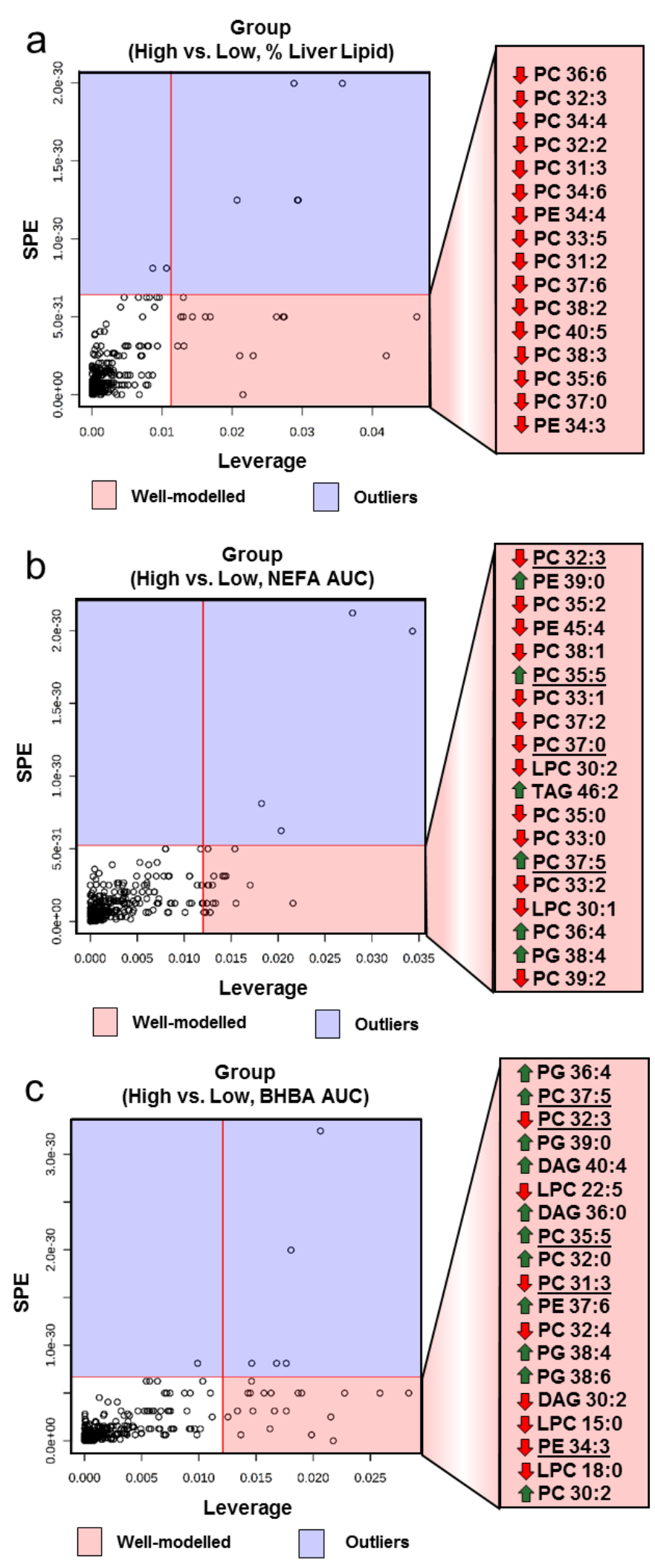


Figure 4-8. Suppressed plasma phosphatidylcholine (PC) levels are associated with fatty liver disease, high free FA, and BHBA area under the curve (AUC) concentrations in periparturient Holstein dairy cows. Leverage/squared prediction error (SPE) plot of 301 complex lipid and their relationship with (A) hepatic lipid accumulation, (B) elevated FFA AUC concentrations, and (C) elevated BHBA $A$ UC concentrations. Normalized, auto-scaled data represent data collected from periparturient Holstein dairy cows categorized into low $(n=9)$ or high $(n=9)$ mean $(d 5$ and 14 postpartum) liver lipid content ( $5 \pm 1$ vs. $12 \pm 2 \%$ of wet weight, respectively), low $(\mathrm{n}=9)$ or high $(\mathrm{n}=9) \mathrm{FFA}_{\mathrm{AUC}}(\mathrm{d} 1-14$ postpartum; 4,915 $\pm 1,369$ vs. 12,501 $\pm 2,761[\mu \mathrm{mol} / \mathrm{L} \times 14 \mathrm{~d}])$, and low $(\mathrm{n}=9)$ or high $(\mathrm{n}=9) \mathrm{BHBA}_{\mathrm{AUC}}(\mathrm{d} 1-14$ postpartum; 4,583 $\pm 459 \mathrm{vs.} 7,901 \pm 1,206[\mu \mathrm{mol} / \mathrm{L} \times 14$ d]). Metabolites in red area have high loadings and follow the expression pattern of the submodel (i.e. data demonstrate that out of 301 metabolites, the suppression of specific PC levels are most associated with fatty liver disease). Data were obtained using quadrupole time-of-flight mass spectrometry. $\mathrm{PE}=$ Phosphatidylethanolamine 
Table 4-1. Ingredients and nutrient composition of diets fed to dairy cows during the transition from late gestation to early lactation.

\begin{tabular}{lcc}
\hline & \multicolumn{2}{c}{ Diets } \\
\cline { 2 - 3 } Ingredients, \% of DM & Prepartum & Postpartum \\
\hline Corn Silage & 35.89 & 43.06 \\
Grass Haylage & 27.26 & 6.41 \\
Grass Hay & 14.7 & 3.13 \\
Concentrate Mix A & - & 16.14 \\
Ground Corn & - & 15.74 \\
Concentrate Mix B & 14.33 & - \\
Soybean Meal & 7.82 & 6.14 \\
Cottonseed & - & 4.47 \\
Concentrate Mix B & - & 4.31 \\
Palmit Fat & - & 0.5 \\
Rumensin & - & 0.1 \\
\hline Nutrient, \% of DM & & \\
\hline Dry matter (\% as-fed) & 45.73 & 49.08 \\
Crude Protein & 15.38 & 16.57 \\
Neutral detergent fiber & 47.74 & 35.42 \\
Acid detergent fiber & 29.65 & 21.65 \\
Non fiber carbohydrate & 27.45 & 39 \\
Ash & 8.82 & 7.24 \\
\hline
\end{tabular}

${ }^{1}$ Mix contained $28.0 \%$ citrus pulp, $30.3 \%$ soybean meal $47.5 \%$, $18.7 \%$ distillers, $9.3 \%$ soy hulls, $3.3 \%$ calcium carbonate, $3.7 \%$ sodium bicarbonate, $2.3 \%$ urea, $2.3 \%$ fat, $2.1 \%$ salt, $0.3 \%$ biotin 640.

${ }^{2}$ Mix contained $24.9 \%$ soybean meal $47.5 \%, 23.2 \%$ ground corn, $16.6 \%$ corn distillers, $12,4 \%$ animate, $10.4 \%$ calcium carbonate, $9.1 \%$ selenium yeast, $2.5 \%$ calcium sulfate, and $<1 \%$ of each of the following: biophos, selenium yeast, and Vitamin E.

${ }^{3}$ Mix contained $43.6 \%$ fermenten, $21.8 \%$ calcium carbonate, $13.5 \%$ soybean hulls, $7.8 \% 1965$ mill mix 4 mintrex, 5.2\% blood meal, 3.5\% magnesium oxide, $2.6 \%$ celmanax, and $<1 \%$ of each of the following: Vitamin E, selenium $0.06 \%$, and 9273 selenium yeast 600 . 


\section{CHAPTER 5}

\section{GENERAL CONCLUSIONS}

In the first experiment presented, our primary objective was to evaluate the effect of prepartum adiposity on systemic glucose and insulin tolerance test in lean and overweight dairy cattle during the transition period. Our second objective was to investigate the relationship between direct and indirect measurements of insulin sensitivity in the periparturient period. Our results demonstrate minimal effect of prepartum adiposity on glucose and insulin tolerance test parameters, except lower glucose-stimulated reductions of FA following a glucose challenge in overweight dairy cows. Additionally, we observed a poor correlation between surrogate indices and direct measurements of insulin sensitivity which questions the usefulness of indirect measurements of insulin sensitivity during the periparturient period in dairy cattle.

In the second experiment, we characterized the plasma lipidome and identified potential biomarkers associated with common biomarkers of metabolic disorder in the transition dairy cattle using mass spectrometry-based lipidomics and bioinformatics. Our results revealed 301 plasma lipids including phospholipids, acylglycerols, and cholesterol esters. Further, we identified that PC 32:3 was specific for cows with elevated FFA, BHBA, and liver lipid deposit. Collectively, our lipidomics approach demonstrates the dynamic remodeling of the plasma lipidome during the transition period. Future research should be focus on validation of these metabolites and possible nutritional intervention to modify them toward improve animal health and performance.

In summary, prepartum adiposity does not modify postpartum systemic insulin sensitivity, and surrogate indices for insulin sensitivity are not associated with direct measurements of insulin sensitivity. Moreover, we identified potential biomarkers of metabolic disease during the transition period including PC 32:3. 